\title{
8 Auf dem Pfad der Kirchengeschichte: Cesare Baronio und die Liturgiewerkstätten der Kurie
}

In Roma si va parlando a bocca piena contro di me da chi sapete: ringratio Iddio che da ogni banda sorgano i miei defensori, talché per questa occasine mi s'accumulano laudi più del mio meiro. D'ogni cosa gloria a Dio. ${ }^{822}$

In seinen Überarbeitungen des Breviarium und des Missale Romanum führte Guglielmo Sirleto die Bedeutung einer patristisch begründeten Ekklesiologie, die im Boncompagni-Pontifikat Gregors XIII. dem Kurienzeremoniell allmählich eingeschrieben wurde, vor. Der Wandel des Verständnisses, wie die kurienzeremoniellen Bestimmungen zum rituellen Vollzug der Liturgie nach dem anno santo auf der Grundlage der lateinischen und griechischen Patristik zu formulieren waren, verlieh dem Kurienzeremoniell seine römischen Charakterzüge. Der Papstbiograph Ciappi zeichnete im letzten Teil seines Compendio nach, wie Gregor XIII. trotz seiner zwei Monate nach dem Feiertag Gregors d. Gr. stattgefundenen Wahl zum Papst den Kirchenvater als seinen Namensheiligen nachahmte. ${ }^{823}$ Diese Nachahmung eines vorbildhaften Kirchenvaters bildete von Anfang an die essenzielle Grundlage für eine erfolgreiche Aufnahme der patristischen Liturgie in das Kurienzeremoniell. Damit ging ein Wandel der Liturgie, deren rituelle Bestimmungen ebenfalls an ein patristisches Verständnis angelehnt werden sollten, einher. Spezifisch wurde damit ein kirchenhistoriographisches Relief der Kirchenväter geschaffen, dass sich erstmals in der Ausgestaltung der beiden Sale dei Foconi im Palazzo Apostolico zum bildprogrammatischen Vorbild entwickelte. An diese Bildimmanenz der Patristik knüpften auch die kurienzeremoniellen Bestimmungen an, welche für die in der Petersbasilika stattfindenden Feierlichkeiten gedacht waren. Der Oratorianer Cesare Baronio fand über seine eigenen Auseinandersetzungen mit den lateinischen und griechischen Kirchenvätern seinen Weg in die Kurie. Baronios Eintritt in die kurialen Werkstätten der römischen Liturgik sollte es ihm gewährleisten, eigenständig eine Kirchengeschichte auf der Grundlage der Historia Evangelica zu verfassen.

822 BVR, Q 56, f. 15r, Cesare an den Vater Camillo Baronio, Rom, 2. Mai 1577.

823 Zur imitatio des Kirchenvaters durch den Boncompagni-Papst vgl. Ciappi, Compendio, S. 3, 50-64, 105-106; Maffei, Degli Annali di Gregorio XIII, I, S. 9, 105-106, 108, 157; Martin, Roma Sancta, S. 107-108 und Musottis memoria in BAV, Bonc.D.5, f. 180r, 201r. Das Kurienzeremoniell sah entsprechend für den 13. Mai stets ein Fest pro Anniversario Coronationis vor, für deren Messzelebration die der Cathedra Petri als Vorlage diente. Vgl. hierzu die Einträge im Zeremonialtagebuch Mucanzios ab der Papstwahl bis zum Jahr 1579 in BAV, Chig.L.II.30, f. 118r-v, 214v-215r, 329r, 425r, 538v-539r, 612v-613r.

Ә Open Access. (C) 2022 Filip Malesevic, publiziert von De Gruyter. (c) BY-NC-ND Dieses Werk ist lizenziert unter einer Creative Commons Namensnennung - Nicht-kommerziell - Keine Bearbeitung 4.0 International Lizenz. https://doi.org/10.1515/9783110741117-009 


\subsection{Quod universa tenet Ecclesia}

Mit den beiden am 21. Juli und am 19. Oktober 1576 stattgefundenen Bittprozessionen in Rom hatte das Boncompagni-Pontifikat Gregors XIII. stärker deren patristischen Grundlagen betont. Anlässlich dieser zwei Prozessionen erliess die Kurie eine Reihe von Verordnungen, um eine Ausbreitung der Pest zwischen 1575 und $1579 \mathrm{zu}$ verhindern. Im Gegensatz zu Mailand und Venedig wurde Rom von der Pest verschont. Maffei hielt in seinen Annali die päpstliche Bittprozession, die von der Petersbasilika nach Santa Maria del Popolo verlief, folgendermassen fest:

E perchè la peste l'anno passato [...] scoperta in diversi luoghi, e dilatatasi in Germania, Francia, e Spagna, ed anche ne' Peasi d'Italia incrudeliva aspramente nella Città, e negli Stati di Venezia, e di Milano con eccessiva strage degli abitanti, e con terrore continuo delle parti vicine. Gregorio oltre le solite guardie, e proibizioni ne' luoghi sospetti ed alle continue orazioni, digiuni, elemosine, e sagrifizj se nè andò egli medesimo processionalmente a piè scalsi con tutto il Clero, e con tutta la Corte dal Vaticano fino alla Chiesa di Santa Maria del Popolo, ringraziando il Signore per le terre fino allora preservate da sì aspro falgello, e supplicando per quelle, che tuttavia foggiacevano alle battiture. ${ }^{824}$

Diese Bittprozessionen waren als bewusste Nachahmung des Pestwunders Gregors d. Gr. gedacht, die den Boncompagni-Papst in eine direkte Bezugslinie mit seinem Namensheiligen brachte. Gregor XIII. trat vor der sich in Santa Maria del Popolo versammelten Stadtgesellschaft als Verkörperung des Kirchenvaters, der die Bevölkerung Roms vor der Pest verschont hatte, auf. Diese Ausnahmestellung Roms, die dem Kirchenvater Gregor d. Gr. zu verdanken war, würdigte der BoncompagniPapst mit der Ausmalung der beiden Sale dei Foconi im Palazzo Apostolico. Das Gewölbeprogramm präsentiert ausgewählte Szenen aus dem Leben des Kirchenvaters,

824 Maffei, Degli Annali di Gregorio XIII, I, S. 256-257. Vgl. diesbez. neben Santori, Autobiografia, S. 361-365 auch die einzelnen avvisi in BAV, Urb. lat. 1045, f. 119r, 130v, 165r; BAV, Urb. lat. 1046, f. 106r; BAV, Urb. lat. 1047, f. 323r-v, 329r, 380v, 383r, 387r, 390v. Der Arzt und Philosoph, Michele Mercati, widmete seine 1576 gedruckte Instruttione sopra la peste dem Kardinal von San Sisto und Papstneffen Filippo Boncompagni. Zur Rezeption des Pestwunders Gregors d. Gr. vgl. dann die entsprechenden Stellen in Mercati, Instruttione, S. 14: "Scrivono che nell'istesso tempo, nel si facevano publiche orationi, e processioni, presente il Pontefice, cascarono morti ottanta huomini, e perseverando il santo Pont. di far le solite processioni, mentre veniva à S. Pietro nel Vaticano, apparve un'Angelo in aria, sopra la mole di Adriano, in questa figura, che si vedeva rimetter la spada nel fodero, per segno, che era cessata l'ira di Dio, \& esaudite l'orationi. Doppo tal miracolo, fu edificata sopra la detta mole una chiesa chiamata sant'Angelo, e per ciò si domanda ancor hoggi castello sant'Angelo. [...] Ma fra gl'ultimi scrittori, la raccoglie Sigonio da i Rituali antichi nelle sue historie dell'anno di Christo 589. Nonlascierò di far mentione di quella grandissima pestilenza, che venne l'anno seguente del 590.“ Vgl. neben Sigonio, De Regno Italiae, S. 27-29 auch den Eintrag in Mucanzios Tagebuch in BAV, Chig.L.II.30, f. 439r-443r, der sich über die Abwesenheit der advocati im Prozessionszug freute. Für den Pestausbruch in Mailand und Carlo Borromeos Eingriffe vgl. Bascapè, De vita et rebus gestis, c. 80-180; Guissano, Vita, S. 248-316. 
die spezifische Bezüge zur Bedeutung der Liturgie für die Kurie herstellen (Abb. 45a \& 45b). Die Zahlungsbelege der tesoreria segreta, die an die in diesen beiden Räumen tätige Malerwerkstatt gerichtet wurden, ergeben, dass mit der Ausmalung am 21. Februar 1576 begonnen wurde. Am Anfang der Arbeiten musste daher noch Lorenzo Sabatini für die Umsetzung des Bildprogramms zuständig gewesen sein. ${ }^{825}$ Nachdem Lorenzo Sabatini im August desselben Jahres starb, müssen die Arbeiten wohl von seinem Sohn Mario, der auch die Werkstattleitung übernahm, weitergeführt worden sein. Wie aber Eitel-Porter überzeugend darlegt, hatte Mario Sabatini nur geringen Anteil an der Ausführung dieses Programms. Stattdessen scheint Cesare Nebbia als hauptverantwortlicher Maler für die Bildkonzeption des Dekorationssystems in den beiden Sale dei Foconi gewirkt zu haben. ${ }^{826}$ Im ersten Raum nimmt das oktogonale Bildfeld mit der Szene des Messewunders Gregors d. Gr. die Mitte des Gewölbes ein. Im zweiten Saal ist ebenfalls in der Gewölbemitte, allerdings in einem der viereckigen Bildfelder, das Abendmahl Gregors d. Gr. zu sehen. Den Bildaufbau dieser Szene in der zweiten Sala dei Foconi zeigt eine im Martin von Wagner Museum in Würzburg aufbewahrte Vorstudie, die eindeutig der Hand Nebbias zugeschrieben werden kann (Abb. 45c). Die Bildkomposition bezieht sich auf eine zentrale Stelle in der Vita des Kirchenvaters, die sowohl in der von Paulus Diaconus verfassten Lebensbeschreibung Gregors d. Gr. als auch in der Legenda Aurea überliefert ist. ${ }^{827}$ Um das mittlere Bildfeld im Gewölbe des zweiten Raumes

825 ASR, Camerale I. Tesoreria Segreta, b. 1303, f. 48r: „E à di detto [21. Februar 1576] scudi centocinquanta di moneta pagati per ordine di N.S.re et dell'Ill.mo card. Filippo Guastavillani à Lorenzo Sabatini pittore, sono à bon conto di più pitture fatte et da farsi nella loggia al piano delle stantie del card.le S.to [Filippo Boncompagni], et nella Capella et Stantie al piano della Sala di Costantino“. Für eine Einordnung der beiden Sale dei Foconi innerhalb des Architekturorganismus des Palazzo Apostolico vgl. auch die Beschreibung in Taja, Descrizione, S. 192-198 sowie Cornini/De Strobel/ Crescenzi 1992, S. 156. Ihre Namensgebung geht auf die beiden Feuerstellen zurück, die für das Aufwärmen der Räume genutzt wurden. Die Zahlungsbelege aus ASR, Camerale I. Tesoreria Segreta, b. 1305, f. 75r, 80r \& ibid., b. 1306, f. 6v, 9r, 16r lassen einen Abschluss dieser Arbeiten im Jahr 1578 vermuten, die sich unmittelbar vor der Dekoration der beiden auf den Cortile del Triangolo einfallenden kleineren Räume befinden und welche im 18. Jahrhundert als Stanze della Credenza dei Cardinali bezeichnet wurden. Vgl. dazu Chattard, Nuova descrizione del Vaticano, II, S. 176, 178-179. An der zweiten Sala dei Foconi schliesst sich dann die von Johannes Paul II. am 28. November 1988 eingeweihte Cappella Redemptoris Mater an, die ursprünglich als antisala genutzt wurde, wo sich la minore Famiglia Pontificia e quella dei Cardinali versammelte. Vgl. hierzu BAV, Vat. lat. 9927, f. 54r. Nur das Wappen Gregors XIII. im Gewölbe bleibt von der ursprünglichen Dekoration dieser Kapelle erhalten. Vgl. hierzu die in BAV, Ferr. 140, f. 479r aufgezeichnete Inschrift: GREGORIO XIII PONT. MAX. ANNO IV.

826 Eitel-Poerter 1995, S. 19-24; eadem 2004, S. 63-68; Di Marco 2012, S. 37-56. Die Wände der beiden Sale sind bis auf einen Fries mit Landschaftsdarstellungen, die erst in den 1590er Jahren ausgeführt werden sollten, leer geblieben. Sie enthalten Wappen Gregors XIV. und Innozenz' IX. Vgl. hierzu v. a. Redig de Campos 1967, S. 172, 194.

827 Diaconus, Sancti Gregorii magni vita, in: PL, Bd. 75, Sp. 59-242, hier 95; Legenda Aurea, S. $170-182$. 
ordnen sich vier weitere, fast quadratische Bildfelder an. Während das Dekorationssystem in der ersten Sala für die vier Ecken im Gewölbe die Anbringung von vier weiblichen Allegorien vorsah, sollten die vier Eckfelder in der zweiten Sala mit weiteren Szenen aus der Lebensgeschichte Gregors d. Gr. ausgefüllt werden. In beiden Räumen ist zudem ein direkt über dem Gesims liegender Fries angebracht, der um die monumentalen Wandmalerein herumführt und acht Drachen, dem Wappentier des Boncompagni-Papstes, enthält.

Die Fresken in den beiden Sale dei Foconi stellen nicht nur ein detailgetreu umgesetztes Dekorationsprogramm in der Palastarchitektur des zweiten Cinquecento dar. Sie verfügen zudem über eine Bildsprache, die deutlich das im Cinquecento nachgelassene kirchenhistoriographische Interesse an diesem Kirchenvater anspricht. ${ }^{828}$ Das Bildprogramm rückt die humilitas und caritas Gregors d. Gr. in ein spezifisch liturgisches Verhältnis zum Kurienzeremoniell. Flacius Illyricus hatte in seinen Zwey Capitel Polydori Virgilij um die Jahrhundertmitte Gregor d. Gr. und seine Einführung der römischen Liturgie für den Niedergang des Messkanons verantwortlich gemacht. Illyricus zufolge verschwand ab diesem Zeitpunkt die Messe als gemeinsame Handlung der Kirchengemeinde. Auch wenn die Magdeburger Zenturiatoren und Fulgentius den Kirchenvater als Gelehrten anerkannten, stellten die Zenturiatoren im sechsten Band ihrer Ecclesiastica Historia die Zeit zwischen dem 5. und 16. Jahrhundert als Zeit der Zunahme der Adiaphora dar. Der Kirchenvater Gregor d. Gr. selbst habe mit seiner Heiligenverehrung und seiner Neuauslegung der Liturgie von der eigentlichen Verehrung des Gotteswortes abgelenkt. Mit dieser kirchenhistoriographischen Position, welche die Reformatoren gegenüber dem Kirchenvater und Papst Gregor I. einnahmen, begann sich die römische Kurie des Boncompagni-Pontifikates bereits ab dem anno santo eingehender auseinanderzusetzen. Bevor sich die kuriale Aufarbeitung dieses Kirchenvaters im Kurienzeremoniell durchsetzen liess, musste sie zuerst im Bereich der Bildproduktion umgesetzt werden. ${ }^{829}$

828 Vgl. in Bezug auf die Bildproduktion insbes. Meier 2006, S. 26-29.

829 Flacius, Zwey Capitel Polydori Virgilij, f. Aijv-Aiijr und idem, Catalogus Testium Veritatis, S. 4751. Vgl. auch Ecc. Hist., VI, S. 6-11, Sp. 186, 677-688 sowie dann auch ibid., VII, Sp. 243, 477-478: Bollbuck 2014, S. 69-70, 372-373; Olson 1976, S. 12-15. Bereits 1575 hatte der Kardinal und spätere Grossfürst der Toskana, Ferdinando de’ Medici, den Florentiner Maler Jacopo Zucchi für eine Tafel mit der Messefeier Gregors d. Gr. für das Oratorium der Bruderschaft der SS. Trinità dei Pellegrini beauftragt: Zuccari 1998, S. 278; Kat. Roma 1999, S. 270-271. Für Claudio Strinati zeichnet sich die Tafel Zucchis als eine stilistische Wegbereitung für Scipione Pulzone und den jungen Caravaggio aus. Vgl. Kat. Roma 1984, S. 391. Ferdinando de' Medici wurde 1573 zum Kardinalprotektor der Bruderschaft ernannt. Vgl. hierzu DBI 1996, Bd. 46, 258-278. Giovanni de’ Vecchi hatte ebenfalls für die Sala degli Angeli im Palazzo Farnese von Caprarola eine Szene des Pestwunders Gregors $d$. Gr. ausgeführt. Vgl. diesbez. Faldi 1981, S. 73; Tosini 1994, S. 309; Knorn-Ezernnieks 2013, S. 296-297. 


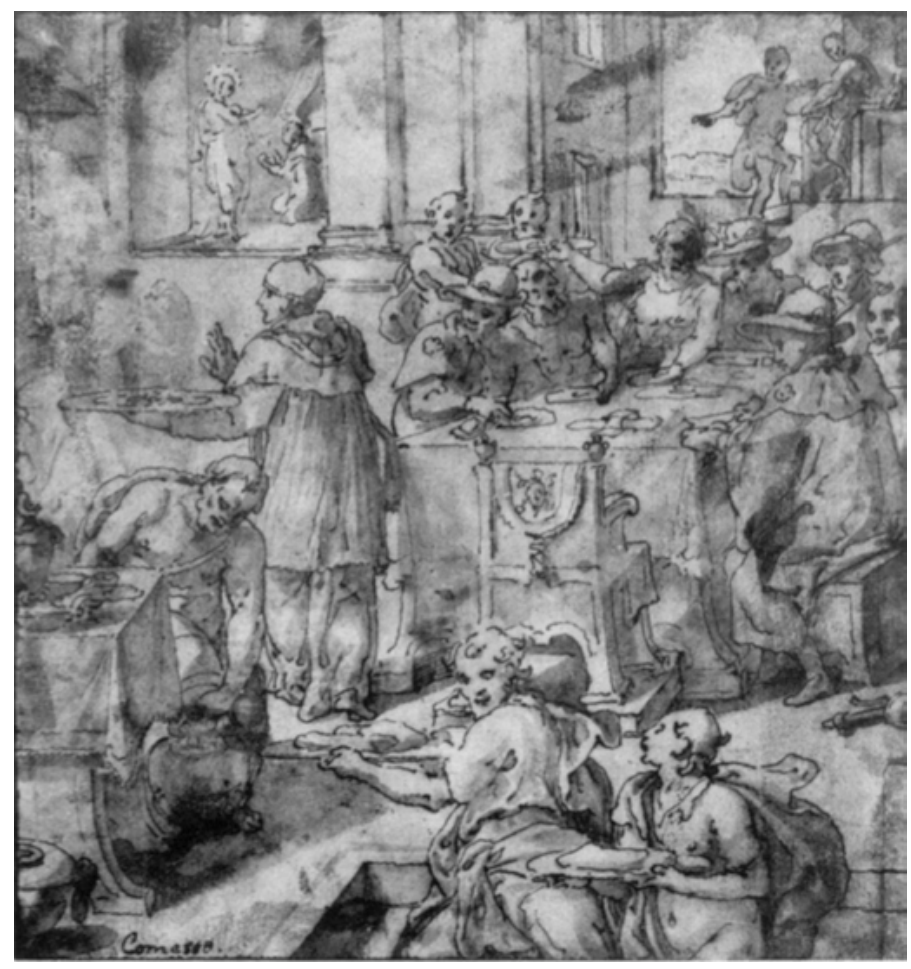

Abb. 45c: Cesare Nebbia, Das Abendmahl Gregors d. Gr., Federzeichnung in Brauntinte, 1576-1578, 19,3 x $18 \mathrm{~cm}$, Martin von Wagner-Museum, Würzburg.

Die Sale dei Foconi im Palazzo Apostolico stellt mit ihrem Bildprogramm ausgewählter Szenen aus dem Leben Papst Gregors d. Gr. einen Prototyp für die kurienzeremonielle Ausgestaltung einer Liturgie, deren ritueller Vollzug hauptsächlich in der Petersbasilika stattfinden sollte, dar. Mit der in San Pietro errichteten Cappella Gregoriana wurden die patristischen Grundlagen einer spezifisch römisch gekennzeichneten Liturgie gefestigt. Bevor die Cappella Gregoriana aber feierlich eingeweiht werden konnte, hatte das Bildprogramm für die beiden Sale dei Foconi dem Kirchenvater Gregor d. Gr. eine neue liturgische Plastizität verliehen. Der Kirchenvater, an dessen Heiligentag Ugo Boncompagni seinen Kardinalshut erwarb, sollte ein besonderes Bildnis Gregors XIII. vermitteln. Das Bedürfnis nach einer neuen Selbstdarstellung des Boncompagni-Papstes begann die Kurie zum Zeitpunkt zu beschäftigen, als am 14. April 1576 der Verurteilungsprozess gegen den Bischof von Toledo Bartolomé de Carranza abgeschlossen wurde. Obwohl Carranza nicht absolviert wurde, hatte ihn Gregor XIII. als vehementer suspectus befunden, wodurch seine Comentarios sobre el catecismo cristiano in den Index aufgenommen 
wurden. ${ }^{830}$ Der Ausgang der Verurteilung Carranzas unterschied sich somit deutlich von den Wünschen einer Verurteilung, wie sie Pius V. und der Kardinalinquisitor von Santa Severina, Giulio Antonio Santori, noch 1566 verfolgt hatten. In Bezug auf das Dekorationssystem der beiden Sale dei Foconi im Palazzo Apostolico wurde jüngst vorgeschlagen, dass sich das Bildprogramm aus deutlichen Parallelen zwischen der Lebensbeschreibungen Gregors d. Gr. und dem Boncompagni-Pontifikat im Zusammenhang mit der Verurteilung Carranzas 1576 zusammengesetzt habe. Die Szene der Mission Gregors $d$. Gr. in Konstantinopel beim Patriarchen Eutychios entspricht demgemäss Ugo Boncompagnis Entsendung nach Madrid auf Befehl Pius’ IV. im Jahr 1565, nachdem er am 12. März die Kardinalswürde verliehen bekommen hatte. Die Legende der Engelserscheinung über das Hadriansmausoleum, welche die Aktualität des Pestwunders Gregors d. Gr. für die angesprochenen Bittprozessionen Gregors XIII. von 1576 betont, wurde ebenfalls in einem hochrechteckigen Bildfeld in der zweiten Sala aufgenommen. ${ }^{831}$

Diese Übereinstimmung zwischen dem Carranza-Prozess und der Biographie Gregors XIII. lässt vermuten, dass für das Bildprogramm mehr als nur ein Programmstifter verantwortlich gewesen ist. Neben den politischen res gestae des Kirchenvaters betont der Bilderzyklus auch den besonderen Stellenwert, den Papst Gregor d. Gr. bei der Entstehung einer römischen Liturgik einnahm. Diese Bedeutung des Kirchenvaters hinsichtlich der Entwicklungsgeschichte der Liturgie wird in den beiden Szenen des Messwunders Gregors d. Gr. und des Abendmahls hervorgehoben. Im Bildprogramm der beiden Sale dei Foconi wird Gregor d. Gr. demgemäss in seiner Rolle bei der Sakramentsverwaltung bezüglich des rituellen Vollzugs

830 BAV, Chig.L.II.30, f. 417r-418r: „[...] ex parte S. D. N. ut veniremus ad Palatium, ut interessemus abiurationi Archiepiscopi Toletani et sententiae ferendae per eundem Sanctissimum. Itaque fecimus, ut nobis mandatum fuerat. Hora praedicta S. D. N. in habito suo quotidiano venit in Aula proximam Aulae Constantini ubi sedit in sede ibi parata sub baldacchino circumsedentibus Cardinalibus Cong.nis S.mae Inquisitionis videlicet de Pisis, Gambara, Madrutius, de Monte, et Sanctae Severinae, factaque modica more accesit antè Pontificem Procurator Fiscalis pro Inquisitione Hispaniae qui genuflexus paucis verbis prolatis instetit, ut per Sanctitatem Suam sententia profereto contrà eundem Archiepiscopum Toletanum iam pro ea die citatum. Tum de mandato S. D. N. fuit vocatus praedictus Archiepiscopis, qui expectabat in quadam Camera ibi proxima; quem medium inter nos Magistros Caeremoniarum deduximus ante Pontificem, ubi genuflexus permansit, donec Notarius S.me Inquisitionis legit citationem ad sententiam, qua lecta S. D. N. respondit [...]“. Ein Briefschreiben des Kardinals Francesco Giovanni Gambaras an Francesco Pacheco de Toledo vom 15. April 1576 ist erhalten in BAV, Urb. lat. 879, II, f. 360r-364r. Die Verurteilung findet sich abgedruckt in Tellecha Idígoras 1988, S. 162-166. Eine Kopie derselben wird in BAV, Vat. lat. 12016, f. 790r-795v, 683r-696r aufbewahrt. Vgl. hierzu dann Fragnito 2005, S. 120-121; Ricci 2002, S. $270-277$. Santori hatte selbst Aufzeichnungen zum Prozess hinterlassen, die sich aus BAV, Vat. lat. 12017, f. 810v-811r, 813r, 869r-872v, 878r-879r rekonstruieren lassen.

831 Di Marco 2009, S. 191-192; eadem 2012, S. 38. Für die Entsendung Boncompagnis nach Madrid 1565 vgl. Ciappi, Compendio, S. 3; Maffei, Degli Annali di Gregorio XIII, I, S. 10-13; Pastor 1893-1933, Bd. 9, S. 10-17. 
der Eucharistie, deren Bestimmungen im Kurienzeremoniell formuliert wurden, inszeniert. Die Episoden, welche die Gewölbemitte in den beiden Räumen einnehmen, verweisen auf das zentrale Verhältnis zwischen Abendmahl und Messe in der sakramentalen Verwaltung der Eucharistie. Dieses Verhältnis hat sich am deutlichsten im Zeremoniell der Osterliturgie, bei welchem die diesem Sakrament dargebotene Verehrung im Zentrum stand, offenbart. Einem Eintrag im Tagebuch des Zeremonienmeisters Mucanzio zufolge wurden spezifische Weisungen im Kurienzeremoniell der Karfreitagsliturgie von 1577 nicht eingehalten und eine unangemessene adoratio sacramentis durch eine Kniebeuge bei der Einsetzung des Weihrauchs in das Weihrauchfass (thuribulum) bestraft. ${ }^{832}$ Die Wiederholung der Kniebeuge, die als Zeichen der Verehrung des Heiligen Sakramentes gilt, wurde im Kurienzeremoniell für die Karfreitagsliturgie nun irrtümlicherweise auch im rituellen Vollzug der Aufsetzung des Weihrauches eingesetzt. Sowohl das 1570 erschienene Missale Romanum als auch Johannes Burckards Ordo missae sahen die Kniebeuge nur vor und nach der Elevation der Hostie vor. Aus den Aufzeichnung Gregory Martins kann entnommen werden, dass dieser Ritus einer priesterlich orientierten Sakramentsverehrung und -verwaltung entsprach:

The order and maner of communicating or geving the B. Sacrament generally in Rome is this. The priest in a surplise or stole (if it be out of masse time, otherwise in his vestment) attending to that purpose, turning to the communicantes, but at one side, not with his backe ful to the aultar for reverence of the Sacrament, hearing them and the assistant for them saying Confiteor, geving them the accustomed blessing or absolution. Then kneeling to the Sacrament, taketh the silver chalice, where the hostes are, in the leaft hand; and one of the hostes

832 BAV, Chig.L.II.30, f. 467r-468r: „Nam primo quando papa venit ad adorandum Crucem, nulli Assistentes sunt eum sectati, contrà librum Caeremonialem. Item Papa reversus ad solium ab adoratione non sumpsit mitram legendo Improperium, quod aliqui Card.les adverterunt rehendentes. Cantores non continuarunt cantum qusq. ad finem adorationis. [...] Non fuit etiam rito observatus ordo imponendi thus in thuribulum in Sacello Paulino antè Sacramentum, quia Papa illud imposuit genuflexus cum stare debuisset, et imposito thure iterum genuflectere. Pariter reversus ad Cappellam dedit genuflexus Sacramentum ad manus celebrantis, quod stand dare debuerat; et thus statim in thuribulum imponere, et mox genuflexus Sacramentum thurificare. Papa, Card. les, et alij omnes steterunt, dum celebrans extraheret Sanctissmum Sacramentum et Sanctitas Sua dum imposuit thus in thuribulum nihil dixit. Satis laboratum circa Card.lem celebrantem, cum esset valdè senex, et debilis, ac omnium ferè quae agenda erant immenior. Canotres non continuarunt Improperium usq. ad finem adorationis, pro ut deberent, nisi dum ipsi adorant. Funalia duodecim remanserunt accensa quo usq. celebrans communionem accepit. Sermonem habuit quidam ex Societatis Jesu, et benè“. Vgl. entsprechend die Regelung in Sacrorum caeremoniarum (1573), c. $165 v$-168r. Die entsprechenden Verbesserungen wurden im darauffolgenden Jahr folgendermassen festgehalten: „Post reportatum Sacramentum, et illud thurificatum non fuit amplis à Papa impositum thus in thuribulo, nec benedictum ut debuerat in thurificando oblata, seu vinum, quod in Calico ponitur, quod factum fuit per oblivionem nostram; sed nos ipsi imposuimus in thuribulum sinè benedictione cognito errore, ut citius ac sine scandalo officium expediretur“. Zit. n. BAV, Chig.L. II.30, f. $529 v$. 
in his right hand betweene his thumme and the forefinger over the brimme of the cuppe, and turning to them, sayeth once, Ecce Agnus Dei, ecce qui tollit peccata mundi: and then thrise in the vulgar tong, at every time bowing his knee, and fixing his eies upon the hoste [...]. As every course hath done, they rise not til the preist hath blessed them with these wordes, Benedictio dei patris omnipotentis, et filii, et sp. sancti descendat super vos, et maneat semper vobiscum $\left[\ldots . .{ }^{833}\right.$

Dass ein solcher priesterlich versehener Ritus der Kniebeuge in das zeremonielle System der Kurie anlässlich der Karfreitagsliturgie einfloss, ist als ein Resultat des Einflusses bruderschaftlicher Riten aus dem römischen Stadtraum in das Kurienzeremoniell zu betrachten. Indem die Ausgestaltung der kurienzeremoniellen Richtlinien für die Osterliturgie durch rituelle Ausführungen aus dem Stadtraum beeinflusst wurden, traten nach dem anno santo solche liturgische Unschärfen im Kurienzeremoniell hervor. ${ }^{834}$ Die Wahl des Messwunders Gregors $d$. Gr. für das achteckige Bildfeld in der Mitte des Gewölbes der ersten Sala dei Foconi deutet auf einen mittlerweile spürbaren Widerstand einzelner Kurienprälaten gegenüber dieser Einflechtung ritueller Vollstreckungen der Sakramentsverwaltung aus dem Stadtraum in das Kurienzeremoniell hin. Solche in römischen Bruderschaften praktizierten Riten waren nämlich nicht mehr länger mit den kurialen Massstäben zur liturgischen Ausgestaltung des Kurienzeremoniells vereinbar.

833 Martin, Roma Sancta, S. 67. Vgl. dann Miss. Rom. (MLCT, 2), S. 283-284 und Ordo missae Johannis Burckardi, S. 156: „[...] genuflexus eam adorat. Tum se erigit elevat in altum quantum commode potest hostiam [...]. Tum usque in terram genuflexus hostiam veneratur“. Hierzu auch Bölling 2006, S. 34, 88-89.

834 Für die Karfreitagsliturgie während des anno santo vgl. den Eintrag in BAV, Chig.L.II.30, f. 318r- $v$ : „In adoratione excalceatus traxit per terram caudam Cappae absque eo, quod ullus eam sblevaret. Cum duo Diaconi Card.les Assistentes adorarent Crucem fecu eorum loco manere duos rimos Praelatos assistentes hinc, inde à lateribus Papae genuflexos, cum non superesset nisi unus Card.lis Diaconus iuxtà traditionem Paridis de Grassis in suo Caeremoniali sub hac die, quod fuit reprehensum à pluribus Cardinalibus tamquam insolitum. Quid magis deceat alias discutietur. Fuit etiam reprehensum ab aliquibus Cardinalibus, quod immediate post Episcopos, et antè Protonotarios fecerim adorare Oratores Ragusinum, et Bononiensem simul eum Ill. D. Honorato inter ipsos [...]“. Bereits Patrizi Piccolomini erwähnte die in der Tradition des Durandus stehende Praxis, dass man sich zur Fürbitte nicht niederknie, weil die Juden den Erlöser mit derselben Geste verhöhnt hätten. Vgl. Dykmans 1980-1982, Bd. 2, S. 394, Z. $22-24$ (Mt 27, 29); Durandus, Rationale, S. $374-$ 375 (Buijssen 1966-1983); Suntrup 1978, S. 159; Bölling 2006, S. 88-89. Das Kurienzeremoniell für den Karfreitag im darauffolgenden Jahr hatte ebenfalls Störungen verursacht: „Cum Papa ivit ad adorandum, nullus Praelatus Assistens est eum sequntus pro ut in caeremoniali caveto. Cum Papa redijt ad solium non accepit mitram prout debeat. Celebrans egendo improperium dicens orata fratres non se vertit lateraliter, ut debuit versus cornu Epistolae nec in lotione manum post Communionem accepit mitram. Cum autem elevavit Sacramentum Papa, et Cardinalis non genuflexerunt, ut debeant. Celebrans etiam elevavit manu sinistra, non autem dextera, ut caveto in Caeremoniali. Haec ut dixi licet non sint magni momenti, tamen adnotare volui, ut memoriae sint pro sequentibus annis ne erretur“. Zit. n. BAV, Chig.L.II.30, f. 420v-421r. 
Die Bildlösung zeigt den Moment in der Messzelebration Gregors d. Gr., in welchem eine Bäckerin an der Wesensverwandlung des Brotes in das Leib Christi zweifelt. Der Kirchenvater konnte sie aber durch ein Verwandlungswunder des Brotes in Fleisch überzeugen. ${ }^{835}$ Die Bildprogrammatik für die Sale dei Foconi erhob dadurch die liturgische Bedeutung des Kirchenvaters und Namensheiligen des Boncompagni-Papstes auf dieselbe Ranghöhe wie die politischen Taten Gregors d. Gr. Der Messliturgie und ein ihr entsprechender Ritenvollzug des Mysteriums der Wesenswandlung verliehen der Gregorsmesse einen spezifisch römischen Wesenszug. Das Messwunder Gregors d. Gr. in der Sala die Foconi verweist im Zusammenhang mit den vorhin erwähnten Tagebucheinträgen des Zeremonienmeisters Mucanzio zur Karfreitagsliturgie auf die Bemühungen der Kurie, die in den rituellen Vorgaben zur Sakramentsverwaltung der Eucharistie dargebotenen Verehrungsformen deutlich voneinander zu unterscheiden. Das Kurienzeremoniell sollte dadurch der in den revidierten Büchern des Breviarium und Missale Romanum enthaltenen Berücksichtigung patristischer Richtlinien zur Sakramentsverwaltung nachkommen. Ein am 29. Juni 1570 verfasstes Briefschreiben des späteren Protonotars Pietro Galesini an Guglielmo Sirleto erklärte diesbezüglich die wichtige Rolle, die dem Kirchenvater im Zusammenhang mit der Altertümlichkeit des ambrosianischen Ritus zukam:

Veramente ho sodisfatto a Monsig.re mio Ill.mo quale nella correttione del salterio di questa chiesa è stato sempre d'opinione, che, se bene vi fusse corso errore alcuno per mutatione o aggiontione o diminutione di qualche lettera, non si havesse però a fare alteratione veruna se non con l'autorità de più libri antichi [...]. Quel che V.S.ria Ill.ma scrive, che non si faccia mutatione alcuna contra l'edizione volgata, ela conseglia santamente. Voglio ben dirgli, che il salterio, quale usa questa chiesa, non è secondo l'edizione volgata, il che attestano [...] molti altri piu antichi, quali scrivendo dell'editione volgata, dicono che la chiesa Ambrosiana ha usato, et usa editione diversa quale invero e quell'istessa, che s'usava nella chiesa romana avanti S. Gregorio il primo; il che se puo anche conoscere da questo, che esso S. Gregorio allegando versi del salterio, spesse volte adduce, come V.S.ria Ill.ma sa, sentenze secondo questa editione Ambrosiana; oltre che questo parimenti si vede dalla Messa romana, nella quale si legono Graduali et Offertorii secondo che e questa edizione [...]. ${ }^{836}$

Das für die Sale dei Foconi konzipierte Bildprogramm stellte demgemäss eine Strategie dar, wie der Nachlass der Kirchenväter - insbesondre derjenige Gregors d. Gr. bei der Formulierung einer spezifisch römischen Liturgik im Kurienzeremoniell berücksichtigt werden sollte. Indem das Dekorationsschema in den beiden Räumen der eucharistischen Sakramentsverwaltung einen zentralen Stellenwert im Bildnarrativ der Vita Gregors d. Gr. anhand ausgewählter Episoden einräumt, wird dadurch eine

835 Legenda Aurea, S. 178; PL, Bd. 75, Sp. 55. Zum spätmittelalterlichen Bildtypus der Gregorsmesse im Zusammenhang mit der Transsubstantiationslehre vgl. insbes. Krauss/Uthemann 1998, S. 422-423; Rubin 1992, S. 12-35; Meier 2006, S. 30-54, 96-97; Gärtner 2007, S. 125-153.

836 BAV, Vat. lat. 6184, f. 37r-v. Vgl. diesbez. auch die entsprechenden Stellen für das officium proprium in Miss. Rom. (MLCT, 2), S. 474-475; Brev. Rom. (MLCT, 3), S. 723-724. 
rituelle Auslegung der Messefeier vorgeschlagen. Der liturgischen Andacht des Kreuzes- und Messopfertodes Christi wird im Bildprogramm somit ein patristischer Charakter verliehen. Die patristische Färbung der sakramentalen Verwaltungspraxis, die sich allen voran auf die Eucharistie bezog, setzte sich aus der im Abendmahl betonten Transsubstantiationslehre und aus dem Kreuzes- und Messopfer Christi an Ostern zusammen. Diese besondere Auslegung der Messzelebration, die aus Abendmahl und Kreuzestod besteht, findet auch im ersten Band der Annales Ecclesiastici Cesare Baronios einen Nachhall. Baronio unterscheidet darin die Einsetzung des Sakraments im Abendmahl selbst vom rituellen Vollzug der Sakramentsverwaltung in der Messe. Baronio zufolge bedeutete die Einsetzung der Eucharistie noch nicht eine Ablösung vom herkömmlichen jüdischen Ritus des gemeinsamen Mahls (mensa). Diese rituelle Unterscheidung zwischen jüdischer und christlicher Sakramentsverwaltung trat erst im Vollzug der Messe als eigentlicher Andachtsmoment an das Kreuzes- und Messopfer Christi hervor. Diesem Gedenken an das Messopfer Jesu war gleichzeitig das Heilsversprechen der Wiederauferstehung eingeschrieben. Dieses in der Messe eingelöste Heilsversprechen überführte die Messzelebration aus ihrer jüdischen Abstammung in eine christliche Auslegeordnung. ${ }^{837}$ Cesare Baronio nimmt somit in seinen Annales zuerst eine Erzählung der Passionsgeschichte anhand ihrer evangelischen Überlieferung im Neuen Testament vor, um dadurch die rituellen Unterschiede zwischen jüdischem und christlichem Verständnis des Messopfers deutlich herausarbeiten zu können. Die Erzählung der Passionsgeschichte gehört noch einer Historia Evangelica an. Erst die Behandlung der sakramentalen Verwaltungspraxis und ihrer rituellen Entwicklungen verleiht ihr die Charakteristik einer Historia Ecclesiastica. Baronio behandelt deshalb im ersten Band seiner Annales Ecclesiastici sowohl die dem Kreuzes- und Messopfer Christi dargebotene Andachtspraxis als auch die auf das Mysterium der Wiederauferstehung gestützte Liturgik und verleiht dadurch der Sakramentsverwaltung ihre ekklesiologische Bedeutung als usus Eucharistiae a temporibus Apostolorum.

Damit schloss der Oratorianer Baronio eine zentrale Lücke in der bisherigen kirchenhistoriographischen Behandlung der Sakramentsverwaltung und ihrer Entwicklung nach dem Kreuzes- und Messopfertod Christi. Für Baronio zeichnete sich diese Sakramentsverwaltung als eine rituelle Praxis aus, welche gemäss Augustinus „die Kirche über die Zeiten stets für sich behalten konnte“ (quod semper retentum est). Durch diesen Rückgriff auf die Patristik schloss Baronio den Kreis, der mit dem

837 Ann. Ecc., I, S. 164: „Quod enim in nostra vulgata legitur spntanea oblatio, Hebraice \& Chaldaice dicitur, Missah, quam offerebant Domino in gratiarum actionem de fructibus terrae, qua \& vescebantur in templo cum recordatione praeteritae servitutis \& ab eadem liberationis. Quae quidem omnia cum optime conveniant praedicto a Christo instituto sacrificio, eo potius maiores nostri usi sunt nomine, quam ciuispiam alterius sacrificij [...] sane quidem creditur eiusmodi nomen ab ipsis Apostolis Petro \& Paulo, ex Hebraicis fontibus, traditum esse Romanis, quod \& Iacobus Hierosolymorum Episcopus idemque Apostolus \& frater Domini tradidit suis: nam eadem usus est voce in sua, quam posteris reliquit Missa de cuius certa fide ac veritate suo locopluribus agemus“. 
Empfang des Eucharistiesakraments als Leib Christi gemäss dem ersten Korintherbrief (1 Kor 11, 20-26) anfängt und in der Weitergabe des Sakraments innerhalb der Liturgie endet. ${ }^{838}$ Baronio meint damit in der Verwaltung der Sakramente einen allgemeingültigen Ausweis der Ecclesia selbst gefunden zu haben. Die Bedeutung des Paulusbriefes an die Korinther sowie seiner Auslegung durch Augustinus lag für Baronio darin, dass noch vor den ersten Konzilsbeschlüssen im frühen Christentum die Sakramentsverwaltung rituell bereits vorgelebt wurde. Dieselbe Bedeutung der sakramentalen Verwaltungspraxis taucht im Bildprogramm der beiden Sale dei Foconi auf, da besonders im ersten Raum die Szenen aus dem Leben Gregors d. Gr. in den quadratischen Feldern durch ihren Bezug zum oktogonalen Bildfeld in der Gewölbemitte und damit zum Mysterium des Wesenswandels Christi selbst ausgewählt wurden. Sowohl die Thematik der Messe Gregors d. Gr. als auch deren zentraler Stellenwert im Leben des Kirchenvaters färbt die übrigen Episoden mit demselben Wesenszug der sakramentalen Wirkung, die Cesare Baronio in seinen Annales Ecclesiastici erläuterte. Die Patristik ist damit fester Bestandteil einer kirchenhistoriographischen Rekonstruktion der Frage, wie sich die Verwaltungspraxis der Sakramente in der Entwicklung der Kirche entfaltete. Damit scheint Baronio seine Annales konzeptuell an die kurialen Arbeiten an einer neuen Ausgabe der Vulgata angenähert zu haben, denn ab 1577 begann die Indexkongregation, die opera des Kirchenvaters Ambrosius herauszugeben und das theologische Werk dieses Kirchenvaters zum Bestandteil der römischen Liturgie umzuwandeln. ${ }^{839}$

838 Ibid., I, a. 57, S. 470: „Cum igitur Paulus Apostolus Corinthios redarguisset, quod tam ea, quae ad communem, quam quae ad sacram cenam essent statuta, negligerent; \& ad legitimam rituum observationem, quantum liceret per epistolam, restituere conatus esset [...]. Quae nam vero ea fuerint, quae Paulus circa sacrum Eucharistiae ritum praesens Corinthios admonuerit: licet nec ab ipso, nec a Luca, qui Pauli acta potissimum est prosecutus, scriptorum monumentis tradita reperiantur: tamen [...] illa ipsa fuisse, quae sine scriptis ex traditione Apostolica universa in posterum Ecclesia observavit, pari consensione patres omnes affirmant; \& inter eos Augustinus, dum dicit: Cum vero ait Apostolus, de hoc sacramento loquens: Propter quod fratres, cum convenitis, \&c. statim subtexuit. Cetera autem, cum venero, ordinabo. Unde intelligi datur; quia multum erat, ut in epistola totum illum agendi ordinem insinuaret; quem per universum orbem servat Ecclesia, ab ipso ordinatum esse, quod nulla morum diversitate variatur. [...] Quod universa tenet Ecclesia nec concilijs instituta, se semper retentum est; non nisi auctoritate Apostolica traditum, rectissime creditur".

839 Briefschreiben Cesare Specianos an Cardinal Borromeo vom 8. Juni 1577 in BAM, F 80inf., f. 256r-257v, 257r: „Il Card.le Sirleto mi ha detto di scrivere a V.S.Ill.ma in casa sua si fa una Congregat.ne, nella quale interviene il Card.le Montalto [Felice Peretti] et altri Theologi per accomodare tutte le opere di sant' Ambrosio, massime nelle cittationi di questo s.to che sono o corrotte o difficillissime da trovare, perchè egli citta la scrittura assai diversa da quella ch' è secondo la vulgata [...].“ Der spanische Theologe Pedro Chacon sammelte bereits aus den Väterschriften die entsprechenden Zitate der alten lateinischen Bibelübersetzung und kollationierte sie zusammen mit Fulvio Orsini zum sogenannten Codex Vaticanus. Vgl. hierzu die Briefkorrespondenz zwischen Pierre Morin und Silvio Antoniano in BAV, Reg. lat. 2023, f. 366r. Chacon starb aber bereits am 16. Oktober 
Die Sale dei Foconi hatten somit eine Bildformulierung der Vita des Kirchenvaters Gregor d. Gr. vorgestellt, in welcher die Patristik in die kurienzeremoniellen Vorschriften zum rituellen Vollzug der Liturgie eingeflochten wurde. Noch bevor sich der Oratorianer seinen Annales Ecclesiastici widmete, musste Cesare Baronio an den Arbeiten der Indexkongregation, welche die Drucklegung der Gesamtwerke lateinischer und griechischer Kirchenväter vorsan, teilgenommen haben. Im Boncompagni-Pontifikat sollten zuerst die operae omniae Gregors d. Gr. und des mailändischen Kirchenvaters Ambrosius gedruckt werden. Jedoch konnte die Drucklegung dieser Werkausgaben erst im Nachfolgepontifikat Sixtus' V. zum Abschluss gebracht werden. Als letzter der sieben Bände umfassenden opera omnia des Ambrosius wurde 1587 Cesare Baronios Biographie des Mailänder Bischofs durch die Vatikanische Druckerei herausgegeben. Die Widmung an den Kardinal Montalto hatte Baronio bereits im Jahr 1583 verfasst, das somit als Abschlussdatum dieser Arbeiten betrachtet werden kann. ${ }^{840}$ Maffeis Annali zufolge stellte Gregor XIII. dem Kardinal Peretti eine von der Indexkongregation unabhängige Kardinalskommission zur Verfügung, welche die Ambrosius-Gesamtausgabe zum Druck bringen sollte:

E nel medesimo tempo andando l'Opere di Sant'Ambrogio tanto segnalato Dottore della Chiesa per le mani degl' uomini indegnamente scorrette, e lacere, diede carico al Cardinal Montalto con adjutorij eletti di rivederle con somma diligenza, e di ridurle alla nettezza ed integrità, che si potesse maggiore. La qual cosa siccome eseguì egli con la debita cura e diligenza, così assunto al Pontificato la fece assai tosto per benefizio pubblico dare alla stampa. ${ }^{841}$

Diese Kardinalskommission muss allerding noch vor dem 8. Juni 1577 mit ihren Arbeiten an der Ambrosius-Ausgabe angefangen haben, wie dies das bereits erwähnte Briefschreiben Cesare Specianos gleichen Datums bezeugt. Cesare Baronios Wid-

1581, worüber sich der Kardinal Granvelle an Fulvio Orsini in einem Briefschreiben vom 14. Januar 1582 folgendermassen äusserte: „Crudele è stata questa volta in Roma la morte, che ci ha privato in cosi breve tempo del buon Ciaccone, d'Achille Statio [...].“ Zit. n. Nolhac, Lettere inedite del Card. Granvelle, S. 263. In der Biblioteca Vallicelliana sind die Bruchstücke alter griechischer Übersetzungen, die Morin mit Unterstützung des Antonius Agellius sammelte, überliefert: BVR, R 2-5. BVR, R 5, f. 126r$127 v$ enthält die von Morin angegebenen Handschriften, die er Carafa und Sirleto entlehnte.

840 Alberici, Epistulae et opuscula, I, S. 167-168. Baronios handschriftliche Fassung seiner Vita S. Ambrosii befindet sich in BVR, Q 35. Diese Handschrift ist als Pendant zu der in ivi, Q 34 enthaltenen Version zu betrachten, welche mit einem weiteren, wiederum in ivi, Q 37 enthaltenen Manuskript identisch ist. Die Drucklegung dieser Gesamtausgabe begannen bereits im Januar 1578, wie dies der Kardinal Felice Peretti in seinem Briefschreiben an Carlo Borromeo vom 6. Dezember 1577 berichtet: BAM, F 97inf., f. $174 r$.

841 Maffei, Degli Annali di Gregorio XIII, II, S. 76-77. Vgl. auch das Briefschreiben Morins an Silvio Antoniano, welches auch Pedro Chacon als Kommissionsmitglied nennt, in BAV, Vat. lat. 6177, I, f. 366r: Petrus Ciaconus, qui ei valde familiaris erat, adiutaratque in S. Ambrosii operum commentatione. 
mung seiner Ambrosius-Biografie an den späteren Peretti-Papst Sixtus V. betont zudem die entscheidende Rolle, welche die Kirchenhistoriographik bei der Wiederherstellung einer integrità der Werke des Mailänder Bischofs und Kirchenvaters einnahm. In dieser sollten nämlich die Bibelzitate des Kirchenvaters bezüglich ihrer Übereinstimmung mit der Vulgata überprüft werden. ${ }^{842}$ Die Kurienprälaten, die sich um Felice Peretti scharten, meinten ursprünglich, dass es sich bei diesen Bibelzitaten des Ambrosius um Textkorruption handle. Deshalb beabsichtigten die Kommissionsmitglieder ursprünglich, die vom Kirchenvater aufgeführten Schriftstellen der Vulgata entsprechend zu verbessern. Die Kommission musste aber bald feststellen, dass sich die Bibelzitate der Kirchenväter von denjenigen in der Vulgata deutlich unterschieden, woraufhin Gregor XIII. Antonio Carafa damit beauftragte, eine lateinische Textversion dieser Schriftzitate, die der Septuaginta entnommen wurden, vorzulegen. ${ }^{843}$

Cesare Baronios Vita Sancti Ambrosii scheint somit als eine spezifische Dienstleistung für eine kuriale Klientel gewesen zu sein. Dadurch wurde die Kongregation des Oratoriums nach 1575 noch stärker an die Kurie angebunden, wodurch 1576 die Anerkennung der Kongregation auch seitens des Kardinalvikars Giacomo Savelli zustande kam. ${ }^{844}$ Sowohl die Dekoration der beiden Sale dei Foconi als auch der

842 Alberici, Epistulae et opuscula, S. 167-168: „Tu vero [...] resque ab eo mirabiliter gestas pervulgare studes. Cumque Paulinus, qui primus Ambrosii Vitam scripsit, paullo tibi contractior ac jejunior videretur; caeteri vero, qui in eodem argumento versati sunt, verbis potius, quam rebus copiosi, ipsa etiam historiae veritate, ac fide non omnino tibi satisfaciant: id mihi oneris imposuisti, ut quae in Annalibus nostris Ecclesiasticis, in quibus contexendis multos annos laboravimus, de Ambrosio ex probatissimis auctoribus, atque adeo ex ipsomet Ambrosio, accurate descripta notavimus [...]. Id mihi imprimis propositum fuit, ut nihil, nisi exploratum, afferrem, \& veritati potissimum, quae prima historiae est lex, inservirem: deinde omnia per annorum, \& temporum feriem, ordine digessi, qua una maxime historia illustratur. Eam vero scribendi rationem, quae mihi iampridem in historia Ecclesiastica maxime probatur, fequutus sum, nimirum, ut scriptorum sententias, ex quorum fontibus haurimus".

843 Vgl. hierzu das spätere Schreiben Morins an Sixtus V. in BAV, Vat. lat. 6177, I, f. 308r-v sowie den Eintrag im Konsistorialtagebuch Carafas aus BAV, Barb. lat. 2877, f. 199r. 1588 wurde dieses Werk unter dem Titel Vetus Testamentum secundum LXX latine redditum bei Flaminius Nabilius gedruckt. Der Olivetaner aus Neapel Alessandro Archirota hatte bei dieser Arbeit auch eine Bibbia cavata tutta de verbo ad verbum de tutte le opere d'Augustino zusammengestellt: BAV, Reg. lat. 2020, f. 454r. Der Fortgang dieser Arbeiten lässt sich ab 1582 entlang BAV, Vat. lat. 6194, II, f. 329r; BAV, Vat. lat. 6195, I, f. 96r, 223r rekonstruieren. Achirotas Notizen sind in BAV, Barb. lat. 5728, f. $1 r-19 v$ enthalten.

844 Savelli war hauptsächlich auch dafür verantwortlich, dass die ersten bereits erwähnten Patronate für die Kapellendekorationen in der Chiesa Nuova an wichtige Kurienmitglieder wie Pietro Vittrici, guardaroba e cameriere segreto del Papa, vergeben wurden. Savelli gewährte nämlich Vittrici im Mai 1577, also fast zeitgleich mit Baronios Briefschreiben an Sirleto, zwei domunculas zu erwerben, die pro constructione fabricae dictae Ecclesiae verwendet wurden. Der Beleg dieser Konzession findet sich in ASR, Congregazione dell'Oratorio. Casse pergamene, 32, f. VIIIv-XIr. Zwei weitere Schriftstücke, deren Adressat beim zweiten sicher Savelli war, der daher wahrscheinlich 
Plan, eine Gesamtausgabe der Werke des mailändischen Kirchenvaters Ambrosius mitsamt einer Biographie des Heiligen vorzulegen, zeigen, dass die Kommission um Felice Peretti während der Arbeiten der Indexkongregation an einer neuen VulgataEdition den Stellenwert lateinischer Kirchenväter gegenüber dem verstärkten Interesse an der Förderung griechischer Doctores Ecclesiae seitens des BoncompagniPapstes wiederherzustellen suchte. Bereits 1573 hatte Gregor XIII. auf Anregungen des Kardinals Santori eine eigenständige Congregazione dei Greci, die sich der Anbindung der griechischen, aber auch anderer orientalischer Kirchen an Rom widmen sollte, einberufen. ${ }^{845}$ Innerhalb der Kurie mussten Felice Perettis Anstösse zu einer Gesamtausgabe der Werke des Kirchenvaters Ambrosius ein gewisses Span-

auch beim ersten als Empfänger identifiziert werden kann, zeigen ebenfalls diese Bindung zum vicarius urbis: ACR, Misc. VIII, f. 43r-44v sowie ASV, Arm. 17, caps. 4, n. 16. Damit blieb Baronios Name in der vom Oratorianer Antonio Talpa für den 15. März 1577 festgehaltenen ersten Versammlung der Kongregation unerwähnt: Collectanea, S. 101. Cistellini 1989, Bd. 1, S. $216-218$ meinte, Baronio hätte seit der Auffindung des Grabes der heiligen Priscilla am 31. Mai 1575 an seinen Annales Ecclesiastici gearbeitet und hätte daher gewollt, „restar fuori da tutto rifiutando ogni incarico“ (Zit. n. ibid., S. 218). Calenzio, Vita, S. 146 hingegen vertrat die Ansicht, dass diese Abwesenheit Baronios mit einer möglichen Kandidatur für den Bischofssitz seiner Heimatstadt Sora zusammenhängen könnte, deren Episkopat seit Tommaso Giglis Wechsel nach Piacenza ab dem 23. März 1577 vakant geblieben war. Vgl. dazu Ughelli, Italia sacra, I, S. 1248; ibid., II, S. 235.

845 Mitglieder dieser Kongregation waren neben Santori die Kardinäle Sirleto, Carafa und Savelli. Vgl. hierzu neben Santori, Autobiografia, XII, S. 358; idem, Diario concistoriale, in Tacchi-Venturi 1903, S. 115-116; Pastor 1893-1933, Bd. 9, S. 737-746; Jedin 1969, S. 14-15; EP, Bd. 3, S. 198; Peri 1975, S. 78-81; idem 1972, S. 300-301. Die Arbeiten dieser Kongregation, welche auch entscheidend für das 1577 entstandene jesuitische Collegio dei Greci waren, gerieten unter Sixtus V. Peretti deutlich ins Stocken. Der Peretti-Papst war persönlich gegenüber den griechischen Kirchengemeinden negativ eingestellt: Borromeo 2000, S. 198. Dass Baronio aller Wahrscheinlichkeit nach dieses Interesse an der griechischen Patristik teilte, belegt seine bislang kaum beachtete Chrysostomos-Homilie in BVR, Q 40, f. 229r-239r, 243r259r-261v. Das neu entstandene Interesse an den griechischen Kirchenvätern hatte sich bereits 1567 mit der in der Petersbasilika vom Kardinal von Santa Severina vollzogenen Weihe des Chrysostomos-Altars offenbart. Vgl. diesbez. Santori, Autobiografia (1889), S. 344: „Nello anno seguente 1567 dedicai l'altare del ss. Crocifisso per ordine di Sua Beatitudine nella sacrestia di S. Pietro, ove riposa il corpo di san Giovanni Grisostomo mio avvocato, con le reliquie de' santi Sebastiano e Cristofano, sotto il titolo di detto S. Giovanni Crisostomo, S. Lamberto e S. Gervasio, come era prima innanti che detto altare fosse violato.“ Dieser für Gläubige schwer zugängliche Ort innerhalb der Petersbasilika, nämlich die südlich des Langhauses gelegene Rundkirche von Santa Maria della Febbre, die auch als Sakristei genutzt wurde, bewahrte die Körperreliquie des griechischen Kirchenvaters. Vgl. hierzu insbes. dann auch Alfarano, De basilicae Vaticanae, S. 140-141: In hoc item sacello nostris temporibus, ut supra retulimus, Corpus sancti Joannis Chrisostomi sub Altare honorifice collocatum est in nobili marmoreo labio aegyptiaco, cuius etiam honori dictum Altare fuit consecratum a Julia Antonio Sanctorio Cardinali sancti Bartolomei in Insula, tunc S. Severinae Archiepiscopo ad praeces Antonij Caraffae Cardinalis, tunc huius Basilicae Canonici, anno Domini 1566. Fuit etiam in hoc sacello magna crux argentea ducentarum librarum pondo, quae aliquando ad Altare sanctorum Philippi et Jacobi in mediana Basilicae navi stetisse putatur. Item multae Reliquiae sanctorum in theca hic supra Altare posita honorifice conservantur. 
nungsverhältnis mit der Congregatione dei Greci hervorgerufen haben. Dieser Konflikt, in den sich Cesare Baronios Vita des mailändischen Kirchenvaters einordnen lässt, sollte mit der 1578 fertiggestellten Cappella Gregoriana in der nordöstlichen Eckkapelle der Petersbasilika beseitigt werden. In dem für die Überführung der Reliquien des griechischen Kirchenvaters Gregor von Nazianz ausgestalteten Kurienzeremoniell sollte ein Gleichgewicht zwischen der griechischen und lateinischen Patristik hergestellt werden, das ebenfalls in die zeremonielle Ausgestaltung der Cappella Gregoriana und ihres Bilderschmucks einfliessen sollte. Die Herstellung eines solchen Gleichgewichts, das gegen die Pläne Felice Perettis für eine Ambrosius-Ausgabe gerichtet war, sollte Cesare Baronios Zusammenarbeit mit der Indexkongregation und der Congregazione dei Greci weiter festigen.

\subsection{Patristisches Kurienzeremoniell in der Cappella Gregoriana}

Die Auseinandersetzungen mit dem Vermächtnis sowohl der lateinischen als auch der griechischen Kirchenväter im Zusammenhang mit der Entstehung einer spezifisch römischen Liturgik können als ein Laboratorium der sakramentalen Verwaltungspraxis innerhalb der Kurie betrachtet werden. Cesare Baronios Annales Ecclesiastici sind demgemäss eines mehrerer Produkte dieser kurialen Werkstatt. Sie zeigen deutlich, dass eine Kirchengeschichte erst dann ihre Anerkennung seitens der Kurie bekommen konnte, wenn sie sich einen zentralen Platz innerhalb dieser liturgischen Werkstatt sichern konnte. Diesen zentralen Platz verschafften Cesare Baronio seine kirchenhistoriographischen Auseinandersetzungen mit der kurienzeremoniellen Ausstattung der Cappella Gregoriana.

Der ab 1574 für die fabbrica von San Pietro eigesetzte Papstarchitekt Giacomo della Porta stellte im Januar 1578 den Rohbau der an der nordöstlichen Ecke des Hauptaltars gelegenen Cappella Gregoriana fertig. Sowohl Tiberio Alfarano als auch der spätere Archivar von Sankt Peter, Giacomo Grimaldi, berichten darüber, dass am 12. Februar desselben Jahres das am muro divisorio der alten Basilika angebrachte Bild der Madonna del Soccorso in einer feierlichen Prozession in die neue Papstkapelle Gregors XIII. überführt worden sei. ${ }^{846}$ Folgt man den Einträgen im Ze-

846 Grimaldi, Descrizione della Basilica antica di S. Pietro in Vaticano, S. 406; Alfarano, De basilicae Vaticanae, S. 89-91. Vgl. hier auch das am 12. Februar 1576 datierte breve für die Spende der Indulgenzen in Bull. Bas. Vat., III, S. 113. Die Bildüberführung, an welcher das gesamte Kapitel der Petersbasilika sowie molti illustrissimi et Reverendissimi Cardinali teilnahmen und unter denen sich auch Alessandro Farnese befand, ist in BAV, Arch.Cap.S.Pietro.H.85, cc. 134-136 sowie in BAV, Arch.Cap.S.Pietro. G.5, f. cc. 223-225, festgehalten. Das Zeremonialtagebuch Francesco Mucanzios erwähnt diese Überführung nicht, da an demselben Tag die liturgischen Feierlichkeiten zum Aschermittwoch (feria 4 a cinerum) durchgeführt wurden. Vgl. hierzu die entsprechenden Einträge in BAV, Chig.L.II.30, f. 512v-515r; BAV, Vat. lat. 12286f. 255r-256v; BAV, Barb. lat. 2803, f. 418r-419v. Für eine vollständige Chronologie des Baus vgl. insbes. Zollikofer 2016, S. 38-48; Bellini 2002, 
remonialtagebuch Francesco Mucanzios wurde ein Monat nach dieser Überführung nämlich am 16. März 1578 -beschlossen, dass die Reliquien des kappadokischen Heiligen und Kirchenvaters Gregor von Nazianz ebenfalls in die Cappella Gregoriana überführt werden sollten. Diese Reliquienübertragung musste aber wegen des schlechten Wetters abgesagt werden. ${ }^{847}$ Alfaranos Augenzeugenbericht hält fest, dass sich am 16. März 1578 trotz Regen eine grosse Menschenmenge auf den Strassen zwischen Santa Maria in Campo Marzio, der Engelsbrücke und San Pietro eingefunden habe, um an der geplanten Reliquienüberführung teilnehmen zu können. Trotz der Absage wegen der andauernden Regenfälle, die den Abbruch der Feier verursachten, hätten die Gläubigen dennoch die Kirchen von San Pietro und Santa Maria in Campo Marzio besucht. Den Einträgen im Zeremonialtagebuch Mucanzios zufolge gewährte Gregor XIII. den für diese Überführung versprochenen Ablass all jenen, die an diesem Tag eine der beiden Kirchen besuchten. ${ }^{848}$ Alfarano und der Zeremonienmeister Mucanzio sind sich darüber einig, dass die starken Regenfälle als göttlicher Eingriff verstanden werden sollten. Sie sollten den Papst dazu veranlassen, mit der Übertragung der Reliquien zu warten und die Innenausstattung der Cappella Gregoriana noch viel prächtiger und aufwendiger zu dekorieren als ursprünglich vorgesehen war. Alfarano hielt zusätzlich fest, dass man mit der Überführung tatsächlich gewartet habe, bis die Gregoriana im Juni 1580 weitgehend fertiggestellt wurde und liturgisch genutzt werden konnte:

Ma detto ostaculo delle acque quel giorno hanno cagionato che il detto sommo pontefice con magior amore et zelo si desse tutto a far più presto adornare et finire detta Cappella gregoriana et con magior ornamanti et bellezze che non si sarebbeno fatte se il detto corpo santo fosse allora trasferito; et così il S.re Dio de ogni cosa ne cava magior frutto. ${ }^{849}$

Es muss somit zuerst auf die Innenausstattung des seit 1578 fertiggestellten Rohbaus der Cappella Gregoriana eingegangen werden, denn dieser sollte im Zeremoni-

S. 334-335; idem 2011, Bd. 2, S. 237, 263-264, wo auch die Zahlungen aus dem Archivio della Fabbrica di San Pietro aufgeführt werden.

847 BAV, Chig.L.II.30, f. 526r: Fuerunt intimata Processio pro Corpore B. gregorij Nazianzeni transportando ad Basilicam S. Petri supradicta die ad Sacellum, ubi diximus collocatam fuisse Imaginem Gloriosae Virginis del' Soccorso, attamen de mandato S. D. N. ob talem intemperiem pluviarum causa talis Processio fuit in aliud tempus translata. Voluit nihilominus ut Indulgentiae iam concessae tam in Ecclesia B. Mariae in Campo Martio, ubi situm erat Corpus dicti Sancti, quam in Basilica S. Petri, et dicto Sacello ad quod dictum Corpus Sancti erat transferendum remanerent. Vgl. auch das am 14. März desselben Jahres verfasste päpstliche breve in Acta Sanctorum Maii II, S. 459.

848 BAV, Arch.Cap.S.Pietro.H.85, c. 136 und BAV, Arch.Cap.S.Pietro. G.5, c. 226. Zum Wortlaut des Ablasses vgl. BAV, Vat. lat. 12286, f. 259v, 321v; BAV, Barb. lat. 2803, f. 424v; Grimaldi, Descrizione della Basilica Antica di S. Pietro in Vaticano, S. 405.

849 BAV, Arch.Cap.S.Pietro.H.85, c. 136. Dasselbe hielt auch Mucanzio in BAV, Chig.L.II.31, f. 681v folgendermassen fest: Quo intermedio tempore, et Gregorianum sacellum opere mirifico, picturis, musaico, peregrinis lapidibus, et auro exornatum est, et ad perfectionem, quam nunc videmus redactum [...]. Derselbe Eintrag findet sich ebenfalls in BAV, Vat. lat. 12286, f. 321v. 
ell der bevorstehenden Reliquienüberführung als feierlicher Apparat dienen. Auf Anordnung des Boncompagni-Papstes wurden am 13. Juli 1578 Girolamo Muziano 100 scudi für seine Leistungen in der Cappella Gregoriana und am 17. August nochmals 25 scudi für seine malerische Beteiligung an den Mosaiken in den Eckzwickeln der Kapelle entrichtet. ${ }^{850}$ Die Eckzwickel zeigen vier Bildnisse von je zwei lateinischen und griechischen Kirchenvätern, nämlich von Gregor d. Gr. und Hieronymus sowie Gregor von Nazianz und Basileios (Abb. 46a-d), und präsentieren ein Gleichgewicht zwischen den Altären und Bildern lateinischer und griechischer Kirchenväter. Am 4. September 1579 besuchten die vier aus Venedig nach Rom gesandten Mosaizisten, die Muziano bei der Ausführung der Mosaiken in der Gregoriana assistierten, die Papstkapelle in San Pietro und fragten bei Gregor XIII. an, ob sie eine der in der Gregoriana vollzogenen officium ähnlichen Liturgie in ihrer Heimatstadt organisieren dürften. ${ }^{851}$ Muzianos Malereien der vier Kirchenväter mussten somit bis zu diesem Zeitpunkt fertiggestellt worden sein.

Im Zusammenhang mit der Figurenwahl der Kirchenväter muss diejenige des griechischen Kirchenvaters Gregors von Nazianz gesondert erklärt werden. Louise Rice bemerkte nämlich, dass es keinerlei Anhaltspunkte dafür gebe, dass der Boncompagni-Papst den kappadokischen Heiligen vor der Reliquienüberführung in die Cappella Gregoriana besonders verehrt habe. ${ }^{852}$ Tiberio Alfarano meinte, dass Gre-

850 ASR, Camerale I. Tesoreria Segreta, b. 1306, f. 11r, 16r. Die 25 scudi sind als Monatsgehalt zu betrachten, welches Muziano bis zum 2. April 1584 erhielt. Vgl. hierzu Tosini 2008, S. 536-538; Bellini 2011, Bd. 2, S. 241. Tiberia 1974, S. 125, bemerkte folgerichtig, dass sich diese und die folgenden Zahlungen an Muziano auf seine Arbeit an den Kartons der Mosaike bezogen. Für das Färben der Mosaiksteine, wie jüngst Zollikofer 2016, S. 45, eingehend untersuchte, wurde der Nuntius in Venedig, Alberto Bolognetti, vom Kardinal Tolommeo Galli kurz vor Weihnachten damit beauftragt, spezielle Pinsel zu kaufen, welche die fabbrica der Gregoriana benötigte. Vgl. diesbez. die in ASV, Segr. di Stato. Venezia, 20, f. 38r, 45r-46v, 114r-115r, 128r-v, 130r-v, 135r-138r, 142r-v, 154r-v, 165r enthaltenen Briefschreiben Gallis an Bolognetti.

851 Zit. in Francia 1989, S. 87, der sich auf ein nicht mehr auffindbares Dokument im Archivio della Reverenda Fabbrica di San Pietro, Serie Armadi, f. 79r-v bezieht. Sowohl Pistolesi 1829, Bd. 1, S. 120 als auch Lanciani, Storia degli scavi di Roma, IV, S. 55-62 berichten ferner, dass sich unter der Figur des heiligen Hieronymus die Inschrift Hieronymus Mutianus Brixianus A. D. 1579 befand. Die heutigen Mosaikbilder in den Pendentifs sind aber Neuschöpfungen aus dem 18. Jahrhundert, weshalb sich die Frage aufdrängt, woher die beiden Verfasser die Inschrift gekannt haben konnten; denn bereits im 18. Jahrhundert wurden die Mosaike Muzianos in den Eckzwickeln durch Kalkablagerungen und Wulst zerstört. Vgl. hierzu insbes. Tosini 2008, S. 538-539. Über den Fortschritt der Arbeiten berichtet ein avviso vom 7. März 1579 in BAV, Urb. lat. 1047, f. 87v: „[...] il lunedi di Carnivale S. B. accompag.ta solamente da alcuni Cam.ri senza Card.li andò a vedere la vaga sua Cappella Gregoriana, dove stette p. spatio di due hore.“ Dies bestätigt auch Mucanzios Tagebucheintrag in BAV, Chig.L.II.30, f. 591r-592r, da an diesem Tag der Festtag des heiligen Thomas v. Aquin in Santa Maria sopra Minerva gefeiert wurde, und zwar absente Papa.

852 Rice 1997, S. 24; Zollikofer 2016, S. 107. Pastor 1893-1933, Bd. 9, S. 797, hatte noch unbegründet behauptet, Gregor XIII. hätte Gregor v. Nazianz besonders verehrt. 
gor XIII. von einem „griechischen Gelehrten“ über die Wiederauffindung der Reliquien informiert worden sei:

\begin{abstract}
Mi parse anco agiongervi come fu trovato dal Papa detto corpo santo. Brevemente et in prima alli 25 de gennaro prossimo passato che è la festa di S. Gio. Chrisostomo Arcivescovo Constantinopolitano doctor greco il corpo del quale è nella Sacrestia di S. Pietro: essendo gran concurso di populi al detto corpo santo et maxime delli dotti homini greci di Roma. Uno de quelli tali dattissimo et venerando disse al Sacristano questo corpo santo glorioso dottore della chiesa è tenuto in S. Pietro rinserrato in questa sacrestia peggio che non è tenuto il corpo di S. Gregorio Nazianzeno dentro al monastero di S. Gregorio Nazianzeno dentro al monastero di S. Maria di Campo Marzo che non possono essere visitati ne honorati dalli devoti populi; perciò saria bene fosse posto in publico in uno altare in Chiesa acciò fosse visto et adorato da tutti. Inteso questo il Sacrestano più che si havesse trovato un tesoro, senza strepito fa a sapere a sua beatitudine questa cosa, quale poi bene certificata che era vera deliberò transportarlo alla sua Cappella gregoriana come per un breve pare. ${ }^{853}$
\end{abstract}

Alfarano stellt die Auffindung der Reliquien Gregors von Nazianz im Zusammenhang mit dem ursprünglichen Plan des Boncompagni-Papstes, die Gebeine des Johannes Chrysostomos in eine der Eckkapellen von San Pietro zu überführen, dar. Damit wäre gemäss Alfarano der „griechische Gelehrte“ mit dem Kardinal Giulio Antonio Santori gleichzusetzen. Jedoch war es der Brevensekretär und portugiesische Gelehrte Achille Stazio (Aquiles Estaço), der Gregor XIII. den entscheidenden Hinweis gab, dass sich die Gebeine Gregors von Nazianz in der Kirche von Santa Maria in Campo Marzio befanden. Stazio verfasste nämlich selbst ein Gedicht, das er dem Boncompagni-Papst widmete und das auch der Zeremonienmeister Mucanzio in seine Aufzeichnungen zur Translationsfeier vom Juni 1580 aufnahm. ${ }^{854}$ Der Beitrag, den die Mitglieder der 1573 ins Leben gerufenen Congregazione dei Greci

853 BAV, Arch.Cap.S.Pietro.H.85, c. 137. Vgl. auch das avviso vom 15. März 1578 in BAV, Urb. lat. 1046, f. 80 .

854 Ebenso wie Alfarano stellte Mucanzio dieselbe Konstellation zwischen den beiden Reliquien der heiligen Chrysostomus und Nazianzus in seinem Tagebuch dar: „Et quoniam de huius Beati Viri Corpore transferendo, et de his, quae ad eiusdem translationis honorem pertinent nunc agimus non erit extra rem in medium afferre, et hic annotare qua occasione, seu persuasione motus S. D. N. potius hoc Gregorij Nazianzeni, quam alterius S.ti Viri corpus eius Sacellum Gregorianum esse transferendum decrevit, maxime cum notum sit ipsum S. D. N. ab initio cogitasse de transferendo in dicto Sacello non Beati Gregorij sed Beati J.nis Chrisostomi corpore, quod in Sacristia Principis Apostolorum ad huc asservatur, sed ex his qua mox subijcimus San.te Suam sententiam mutasse credi potest“. Zit. n. BAV, Chig.L.II.31, f. 682r-v. Stazios Gedicht findet sich dann abgeschrieben in BAV, Vat. lat. 12286, f. 322v-324r, das offensichtlich von Giovanni Paolo Mucanzio, Francesco Mucanzios Bruder, erst nach 1585 eingefügt wurde, da sich der Eintrag auf Fortuno Lelio bezieht, der Stazios Gedicht in Lelio, Pompa et apparato, c. 5v-6v, abdruckte. Der spätere Zeremonienmeister Giovanni Paolo Mucanzio berichtet nämlich in BAV, Vat. lat. 12286, f. 373r-v, dass Krankheiten und Tod Francesco nicht mehr erlaubt hätten, einen eigenen Bericht über die Translation auszuarbeiten, weshalb er dann auf der Grundlage der von seinem Bruder hinterlassenen Materialien und mit Hilfe von Augenzeugenberichten nachträglich die Translation rekonstruiert habe. 
zu der Ausgestaltung der Gregoriana leisteten, sollte dabei aber nicht unberücksichtigt bleiben.

Die malerische Ausschmückung des Innenraums der Cappella Gregoriana, die Girolamo Muziano bis zur Überführung der Reliquien Gregors von Nazianz mit den Figuren der vier genannten Kirchenväter in den Pendentifs fertiggestellt hatte, fällt in denselben Zeitraum, während welchem Santori sich bemühte, die Kirche für das seit dem 13. Januar 1577 approbierten Collegio Greco dem Heiligen Athanasios zu weihen. Für das am 3. November 1580 stattgefundene Konsistorium hielt der Kardinal von Santa Severina fest, er habe mit dem Boncompagni-Papst das Projekt für die Kirche von Sant'Atanasio dei Greci, die den Jesuiten gehörte, begutachtet. Santori Begründung, weshalb die Kirche diesem griechischen Heiligen geweiht werden sollte, stimmt mit derjenigen Cesare Baronios für die Weihe von Santa Maria in Vallicella aus seinem später verfassten De origine Oratorii überein:

Del disegno nuovo della chiesa del Collegio greco - lo viddimo insieme, che si seguiti. Dell'invocatione di S. Atanasio da imporsi alla chiesa nuova - gli piace et che è ben fatto per le raggioni dette e che di questo anno santo non vi è chiesa, ma de altri dottori greci vi è S. Basilio, la Cappella Gregoriana sua di S. Gregorio Nazianzeno e di S. Giov. Crisostomo vi sarà l'altra all'incontro in S. Pietro. ${ }^{855}$

Beim Bauvorhaben für Sant'Atanasio, mit welchem unmittelbar nach der von Santori am 23. November 1580 durchgeführten Grundsteinlegung begonnen wurde, trat bei der Papstaudienz vom 17. Dezember desselben Jahres eine grundlege Problematik, welche die Architektur des Kirchenraumes betraf, auf: entweder sollte die Kirche in zwei Räume aufgeteilt werden, in einen lateinischen und einen griechischen,

855 ASV, Arm. LII, 18, f. 26r-v. Auch zit. in Krajcar 1966, S. 36 und auszugsweise bei Pastor 18931933, Bd 9, S. 878. Für den Erwerb der zwei stime Martino Longhis, in denen die Lage der Kirche um das Jahr 1578 dargestellt ist, zwischen November 1578 und Februar 1579 seitens der Camera Apostolica vgl. Tancredi 1998, S. 15, 47. Die Erlaubnis zum Beginn des Baus der neuen Kirche erhielt Santori als Protektor des Collegio Greco in der Papstaudienz vom 20. Oktober 1580. Den Grund dieser mehr als achtzehn Monate umspannenden Verzögerung wurde anlässlich einer am 24. März 1580 stattgefundenen Audienz damit erklärt, dass man mit dieser erst beginnen wolle, wenn alle ,anderen Arbeiten“ fertiggestellt seien: „Di applicatione per far la chiesa del Collegio Greco - Quod aliis completis reminiscetur.“ Zit. n. ASV, Arm. LII, 18, f. 6r. Mit diesen „,anderen“ Arbeiten müssen demnach diejenigen in San Pietro für die Cappella Gregoriana gemeint gewesen sein. Ein avviso vom 10. Dezember 1575 in BAV, Urb. lat. 1044, f. $634 r$ berichtet bereits von einem Vorschlag der Jesuiten, ein griechisches Kolleg zu gründen. Zur Gründungsgeschichte des Collegio Greco vgl. neben der päpstlichen Bulle vom 13. Januar 1577, Apostolicae Seid Specula, in Bull. dipl. rom., VIII, S. 159-162 und Pastor 1893-1933, Bd. 9, S. 179-181 auch Maffei, Degli Annali di Gregorio XIII, I, S. 249-250 sowie die Arbeiten von Netzhammer 1905; Fyrigos 1983; Nin 2007, S. 391-396. Bez. der Formulierung Baronios in seinem Traktat vgl. supra, Kap. 1.2. Über die Besuche Gregors XIII. vgl. die avvisi vom 3. September 1578 und vom 5. Mai 1582 in BAV, Urb. lat. 1046, f. 303v; resp. BAV, Urb. lat. 1050, f. $145 r$. 
oder man solle zwei separate Kirchen bauen. ${ }^{856}$ Sowohl aus den Zahlungsbelegen an den Architekten Giacomo della Porta als auch aus dem Bericht zur Audienz vom 20. April 1581 geht hervor, dass dieses Problem schnell gelöst worden sein muss, denn der Bau an der Kirche wurde in den ersten Monaten des folgenden Jahres ohne Unterbrechungen fortgeführt. Ursprünglich wurde die Kirche für ihre liturgische Nutzung gemäss dem griechischen Ritus mit nur einem Hochaltar, der all'uso de' Greci hergerichtet wurde, geplant. ${ }^{857}$ Idealerweise sollte sich im Kirchenraum von Sant' Anastasio dei Greci ein Gleichgewicht zwischen griechischem und römischem Ritus widerspiegeln, sodass sich die Kirche des Collegio Greco auch für den Vollzug einer römischen Liturgie eignen könnte. Leone Allacci, ehemals Mitglied des Kollegs, beobachtete allerdings 1645, dass Sant'Atanasio nichts mit einem griechischen Kirchenbau gemein habe. Die übliche Anordnung von narthex, naos und bema sei nicht eingehalten worden. Die Innenausstattung des Kirchenbaus folgte deshalb dezidiert einem römisch-lateinischen Ritus. ${ }^{858}$ Demzufolge kann der Wunsch nach einer Koexistenz zwischen den beiden Riten als alleiniges Bestreben der Mitglieder des Collegio Greco betrachtet werden. Innerhalb der Congregazione dei Greci wurde somit nicht derselbe Anspruch verfolgt. Insbesondere die Kardinäle Santori und Sirleto sahen keine Koexistenz verschiedener Riten vor, sondern verfolgten bewusst das Ziel, den griechischen Ritus innerhalb eines kurienzeremoniellen Rahmens einzugliedern. Diese rituelle Eingliederung ging mit den Zielen Gregors XIII., die schismatischen Griechen wieder mit der römischen Kirche zu vereinigen, einher - auch wenn der Boncompagni-Papst dieses Ziel niemals errei-

856 ASV, Arm. LII, 18, f. 35r: „[...] che pare che la chiesa si divida o se ne faccino due, una greca e una latina." Die Grundsteinlegung hielt neben Santori, Autobiografia, XII, S. 367, auch Mucanzio in seinem Tagebuch in BAV, Chig.L.II.31, f. 719v-722v. Vgl. auch diesbez. Martinelli, Roma ex ethnica sacra, S. 73-74.

857 Bedon 1983, S. 50-52; Tancredi 1998, S. 16-20. Der Hochaltar wurde zudem von zwei kleineren Altären flankiert, einem diakonikon auf der rechten für die Priesterkleidung und einer prothesis auf der linken Seite für das Herrichten der Eucharistie. Vgl. diesbez. insbes. Fortino 1970, S. 1920. Hinsichtlich des Baufortschritts vgl. den Bericht von der Papstaudienz im April 1581 in ASV, Arm. LII, 18, f. $67 r$ und die Zahlungsbelege an della Porta in ASR, Camerale I. Tesoreria Segreta, b. 1309, f. $33 r, 53 r, 59 r, 80 v, 84 v, 88 r, 90 v, 94 r-v$.

858 Allacci, De templis graecorum recentioribus, S. 36-37: „Et primum, ante alia illud observo, Templum D. Athanasio sacrum, quod Romae est, non ita ex nationis illius more extructum esse, ut ad constituendas Graecorum hodiernas Ecclesias in exemplum, adduci possit \& debeat: cum potius Latinae Ecclesiae modum, eumque non ita antiquum, referat, \& non nisi Bemate à Latinis distinguatur. Quod si excipias spatium, inter muros sub fornicem excurrens, nihil habet cum Graecorum Ecclesiis commune; quando \& ingressus ipse diversus, nec Embolum nec Narthecem habeat, neque Templum ab aliis partibus separetur, altaribus utriunque excavatis, nec mulieres à viris secludat cancellis. Templum tamen est, \& pro juvenum ibidem Deum colentium usu satis accommodatum. Aliunde itaque Templorum recentiorum imagines petendae sunt. Quae, ut alias diximus, tribus praecipuis partibus constituuntur, Narthece, Nao, \& Bemate [...]“.. Demzufolge meinte Tancredi 1998, S. 21, dass in diesem Kirchenbau der römisch-lateinische Ritus über dem griechischen vorherrsche. 
chen sollte. ${ }^{859}$ Dieser Prozess der rituellen Einflechtung diente schliesslich dem Ziel, der römischen Liturgie im Kurienzeremoniell einen Universalitätsanspruch einzuräumen. Diese Allgemeingültigkeit der römischen Liturgik scheint erstmals nach der erfolgreichen Überführung der Gebeine des Heiligen Gregors von Nazianz innerhalb der Cappella Gregoriana realisiert worden zu sein.

Die Wahl der Figur des kappadokischen Kirchenvaters Gregor von Nazianz im Ensemble der Eckzwickel der Cappella Gregoriana kann daher auf die Strategie der Eingliederung griechischer Kirchenlehrer in die kuriale Rezeption der Patristik zurückgeführt werden. Die Kurie begann mit dieser Aufarbeitung der Schriften der Kirchenväter die Konturen einer liturgischen Dominanz des römischen Ritus zu entwerfen. Die Wirkung der Bilderwelt in der Kapelle des Boncompagni-Papstes enthüllte bei der feierlichen Reliquienüberführung vom 11. Juni 1580 diesen Universalitätsanspruch. Der Bilderschmuck sollte nämlich, wie bereits angesprochen, als zeremonieller apparato für den rituellen Vollzug der Prozessionsliturgie dienen. An diesem Umstand lässt sich auch festmachen, dass die Cappella Gregoriana ursprünglich keineswegs als Grabkapelle des Boncompagni-Papstes konzipiert sein konnte. Eine Woche vor dem Anlass hielt der Franziskaner Francesco Panigarola am 4. Juni 1580 in der Petersbasilika eine Predigt über den Heiligen Gregor v. Nazianz. Diese oratio war als spirituelle Vorbereitung auf die Reliquientranslation gedacht. ${ }^{860}$ Panigarolas Predigt sollte dem Zweck einer geistlichen Vorbereitung der in der Petersbasilika versammelten Zuhörer dienlich sein, indem sie den griechischen Kirchenvater der römischen Stadtgesellschaft vorstellte. Der Franziskaner Panigarola, der enge Verbindung zum Mailänder Kardinalsbischof Carlo Borromeo pflegte und der die Grabrede auf den 1584 verstorbenen Borromeo hielt, kann als einer der erfolgreichsten und berühmtesten Kanzelredner seiner Zeit betrachtet werden. ${ }^{861}$ Seine Pre-

859 Die in BAV, Vat. lat. 6792 aufbewahrte Exhortatio ad Graecos des Kardinals Sirleto wurde dem Neudruck der Dekrete des Konzils von Florenz beigefügt. Sirleto, der auch Protektor des Basilianerordens war, gelang es in Kalabrien, die dortigen Basilianerklöster dem römischen Ritus zu subsumieren. Im Gegensatz dazu scheiterten die Bemühungen des Boncompagni-Papstes, zwischen 1580 und 1584 durch insgesamt drei Missionen nach Konstantinopel den neuen römischen Kalender dort einzuführen. Vgl. hierzu v. a. dann Peri 1975, S. 80-81, 179.

860 Für die Prozessionsfeier selbst vgl. neben den avvisi aus BAV, Urb. lat. 1048, f. 97v, 145r, 157r, $160 v, 165 r, 172 r$ auch Sebastiano Torellis Beschreibung der Cappella Gregoriana in BAV, Vat. lat. 11049, f. 63r-70v. Panigarolas Predigt ist dann in ibid., f. 179r-223v abgedruckt. Zwei weitere Berichte desselben Umzugs hatten Rastelli, Descrittione della pompa in BAV, Racc.I.IV.1, c. 31v-36r sowie Lelio, Pompa et apparato, c. 4r-12r, 21r-28r vorgelegt. Die ausführlichste Schilderung dieser zeremoniellen Reliquienüberführung bleiben jedoch die Einträge im Tagebuch des Zeremonienmeisters Mucanzio aus BAV, Chig.L.II.31, f. 683v-713r.

$861 \mathrm{Zu}$ Panigarolas Bewunderern gehörte Torquato Tasso. Über Panigarola hat sich der Dichter folgendermassen in Tasso, Gioie di Rime e Prose, S. 52 ausgedrückt: „Quest'è la bocca, anzi queal chiaro fonte/ ond'esce di eloquenza un aureo fiume.“ Ein avviso vom 23. März 1577 stellte Panigarola zusammen mit Francisco de Toledo und dem Kapuziner Alfonso Lupo in einem Dreigestirn der damals aktivsten Kanzelredner dar: in BAV, Urb. lat. 1045, f. 283r: „[...] Toletus docet, Panicarola 
dica in laude di San Gregorio Nazianzeno kann als eine besondere Betonung der Strategie kurialer Arbeiten hinsichtlich der Frage verstanden werden, wie dieser kappadokische Kirchenlehrer in eine Liturgie, deren Charakterzüge im Kurienzeremoniell der Reliquienüberführung eine spezifische romanitas offenbaren sollten, zu integrieren sei. Panigarola nutzte diese Gelegenheit auch dafür, mit seiner Predigt coram papam die zur Zeit des Tridentinums angesprochene Frage, ob für die Predigtpraxis eine zusätzliche Ausbildung auf dem Gebiet der Rhetorik notwendig sei oder ob die Ausbildung in scholastischer Theologie allein genüge, zu lösen. ${ }^{862}$

Panigarolas laudatio in der 1580 fertiggestellten Cappella Gregoriana verfolgte primär das Ziel, den kappadokischen Heiligen und Kirchenlehrer als Vorbild eines Predigers aus der Ostkirche vorzustellen. Wie Panigarola in seiner Predigt auf der Grundlage der lateinischen Kirchenväter Augustinus und Gregor d. Gr. ausführte, lag die wahre Tugend Gregors v. Nazianz in der vas electionis. Panigarola verwies mit diesem Begriff - dem in der Apostelgeschichte tradierten Beiwort des Apostelfürsten (Apg 9, 15) - auf den vorbildlichen Tugendcharakter des griechischen Kirchenlehrers,. Ebenso wie Christus den Apostel Paulus zum Prediger berief, war die Berufung Gregors v. Nazianz zum Prediger mit denselben apostolischen Grundlagen gekennzeichnet:

San Girolamo discipolo di cosi degno maestro, nel catalogo degli scrittori ecclesiastici, gregorius Nazianzenus vir eloquentissimus praeceptor meus. Il medesimo nella prima Apologia contra Ruffino: Quo ego magistro glorior, \& exulto. L'istesso sopra il quinto a gli Efesi: Vir valde eloquens, \& in scripturis apprimè eruditus. Santo Agostino nella episto. 3 Ad Fortunatum: Grego-

delectat, et Lupus movet“. Francisco de Toledo verzeichnete in seiner am Festtag der Epiphanie gehaltenen Predigt coram papam im Jahr 1576 Panigarolas Teilnahme. Die Predigt ist enthalten in BAM, G 40inf., f. 319r-323r. Hinsichtlich der Grabrede Borromeos, welche in BAM, Trotti 540, cc. 181-240 aufbewahrt wird, vgl. insbes. Bramante 2007, S. 291-294; McGinness 1995, S. 16; Ardissino 2003, S. 97. Panigarolas posthum gedruckter Il Predicatore erfuhr mehrere Auflagen und galt als eines der verbreitetsten Lehrbücher über die kirchliche Redekunst. Zum Traktat vgl. jüngst Giunta 2012, S. 109-116. Zwischen 1579 und 1582 stellte Panigarola bereits sein Modo di comporre una predica vor, in welchem er sowohl die inventio als auch die dispositio der Predigtpraxis darlegte. Der Traktat wurde aber erst 1584 gedruckt und erschien danach in sechs Auflagen. Der Franziskaner wurde 1578 zum ersten lettore in Theologie innerhalb des Konvents von Santa Maria in Aracoeli berufen. Vgl. zu Panigarola auch DBI 2014, Bd. 80, S. 773-777.

862 Panigarola, Prediche, c. 273r-v: „E certo non ha hà bisogno di essere sostentata con pontelli di eloquenza humana la parola di Dio; mà Dio stesso, quali ritrova gl'istromenti, tali gli usa: Trovò Amosse rozzo, e rozzamente lo fece predicare. Trovò Esaia eloquente, \& eloquentemento lo fece predicare, cosi trovò Cirpiano, cosi trovò Lattantio, cosi Grisostomo cosi finalmente trovò la bocca del nostro Nazianzeno, e sua la fece Et fuit os Christi. Vgl. hierzu v. a. McGinness 1995, S. 53-55. Agostino Valier hatte sich ebenfalls dieser Problematik in Valier, De rhetorica ecclesiastica, I.1.2 gewidmet: „Hanc divinam potius, quam humanam dicendi facultatem, sanctamque eloquentiam etsi Spiritus Sanctus sine ulla doctrina, et labore interdum solet suggere: observationes tamen sermonum, quibus sancti homines eodem spiritu afflati, Christiano populo profuerunt eam percipi, et in artem redigi posse, nemo negaverit“. 
rius Sanctus Episcopus Orientalis. Pure egli nel primo contra Giuliano Pelagiano: Sed non tibi deerit magui nominis, \& fama celeberrime illustris Episcopus, de partibus Orientis. S. Gregorio Papa, nel prologo della terza parte della cura pastorale: Ut longè ante nos reverendae memoriae Gregorius Nazianzenis docuit. [...] Ma chi puo stringere il mare in minor vase di quello, che fece Basilio quando disse: Vas electionis puteus profundus os Christi, dico Gregorium. Bella e maravigliosa sentenza, sonora voce, delicato fiore, che basta sola a far tutto il concerto, e tutto il mele. [...] Vas electionis. Bello, e maraviglioso titolo. Per cominciar dal quale, vi raccordate, ove fanno mentione le scritture, ascoltatori, di questo titolo? Ne gli atti al nono. Sapete chi lo trovò? Christo istesso. Parlando con chi? Con Anania. Dove? In Damasco. Quando? Nel principio della primitiva Chiesa. Per honorarne qual persona? Quella di Paolo Santo. ${ }^{863}$

Panigarolas weitere Bezeichnung Gregors von Nazianz als os Christi verweist auf die Bedeutung des anlässlich der Reliquienüberführung gestalteten Kurienzeremoniells. Die feierliche Translation der Gebeine des kappadokischen Kirchenvaters erreichte in der Verehrung des Heiligen Sakramentes der Eucharistie ihren Höhepunkt und präsentierte dadurch die Knochen des griechischen Kirchenvaters im Wesenswandel des Leibes Christi. Zum Zeitpunkt von Panigarolas laudatio lagen die Knochen des Heiligen noch in Santa Maria in Campo Marzio und waren demgemäss von dem in der Cappella Gregoriana aufbewahrten Leib Christi entfernt. Das Zeremoniell der Reliquienüberführung kam somit einem Neubegräbnis des Kirchenvaters gleich, der durch seine Heiligkeit den Ruhm erlangte, gemeinsam mit dem konsekrierten Leib Christi begraben zu werden. Sinnbildlich wurde dadurch der Cappella Gregoriana im Kurienzeremoniell der Stellenwert einer Sakramentskapelle zugeschrieben, indem die Gregoriana als gemeinsames sepulchrum der Gebeine des kappadokischen Kirchenvaters und des in der Eucharistie verwandelten Leibes Christi aufgeführt wurde. ${ }^{864}$ Der Zeremonienmeister Francesco Mucanzio erhielt vom BoncompagniPapst das Mandat, die Reliquienüberführung mittels des Kurienzeremoniells zu organisieren. Mucanzio schlug vor, die kurienzeremonielle Überführung auf der Grundlange des nur wenige Tage vorher stattgefundenen Fronleichnamsfests (Corpus Domini)

863 Panigarola, Prediche, c. 265v-266v.

864 Diese funktionelle Kennzeichnung der Gregoriana als Sakramentskapelle, die nur als solche im Kurienzeremoniell genutzt wurde, um die Nähe zwischen der konsekrierten Hostie und den sich in demselben Grab befindenden Reliquien stärker zu betonen, scheint weder von Rice 1997, S. 26, 37 noch von Zollikofer 2016, S. 89-90 berücksichtigt worden zu sein. Der zu überbrückende Abstand zwischen Reliquienheil und Sarkamentswirklichkeit wird in Panigarolas Predigt in Bezug auf seine Beschreibung der Gregoriana als si bel vaso vorweggenommen: „Si si, non si può negare: questa, questa Gregoriana in così poco tempo cresciuta, e stabilita, così santamente superba, questi pretiosissimi Mosaici, che fan più caro il vetro, che non l'oro; e che mai non si veggono usati, se non a cose sacre, questi finissimi marmi, questi vaghissimi, e richissimi mischi, queste colonne, anzi queste gioie, che non cedono ponto alle famose antiche, questa fabrica tutta, così vasta, così ricca, e così ornata, che fa scorno all'antichità, che ci fa spregiar le ruine di Roma, questa, questa, Romani, mostra quale sia il Santo per ricever l'osse del quale, è stato preparato sì bel vaso.“ Zit. n. Panigarola, Prediche, c. 261v-262r. Vgl. hierzu dann auch Alfaranos Informazione in BAV, Arch.Cap. S.Pietro. G.5, f. 305r-309v. 
zu gestalten. Am 20. April 1580 traf sich die seit November 1572 einberufene Zeremonialkongregation im Palast des Kardinals Alessandro Farnese. An diesem Treffen nahm der Zeremonienmeister Mucanzio ebenfalls teil. Die Kongregationsmitglieder sollten die kurienzeremoniellen Bestimmungen zur Translationsfeier ausarbeiten und entsprechend umsetzen. ${ }^{865}$

Ludovico Bianchetti, päpstlicher Kämmerer und Kanoniker des Peterskapitels, traf sich mit Monsignore Bartolomeo Ferratini, Alessandro Musotti und mit einigen Priestern der Petersbasilika am Freitag, dem 10. Juni 1580, in der zum Kloster von Santa Maria in Campo Marzio gehörenden Kirche von San Gregorio Nazianzeno. Ferratini, der die Leitung über die Fabbrica di San Pietro hatte, öffnete dort die capsa aus Zypressenholz und nahm die Gebeine Gregors von Nazianz heraus. Anschliessend wurden sie in einen anderen aus gleichem Holz gefertigten und kurz zuvor geweihten Behälter gelegt. Dieser neu angefertigte Behälter wurde dann auf den Hauptaltar der Kirche von Santa Maria in Campo Marzio gestellt. Am selben Tag brachte Kardinal Santorio in San Pietro verschiedene in der Sakristei aufbewahrte Reliquien auf den Hauptaltar der Basilika, die für den Altar der Cappella Gregoriana bestimmt waren. Damit wurde in Bezug auf den heilsversprechenden Charakter der Reliquien der Aufbewahrungsort mit der neuen Grablege rituell in Einklang gebracht. ${ }^{866}$ Der darauffolgende Tag, an welchem die Reliquienüberführung stattfand, wurde zum Feiertag erklärt. Rastelli notierte, dass an diesem Tag Kutschfahrten, Reitanlässe und Arbeit untersagt wurden. Weder Läden noch Werkstätten waren in Rom geöffnet. ${ }^{867}$ Santori weihte am frühen Morgen den Altar der Cappella Gregoriana more solito zu Ehren der heiligen Jungfrau Maria und des heili-

865 BAV, Chig.L.II.30, f. 656r-v: „Die 20 eiusd. fuit Congreg.o Rev.mus D D. Card.lium ad Reformationem Caeremoniarum in qua interfuere Card.les octo in Domo Ill.mi Decani super modo servando in translatione Croporis B. Gregorij Nazianzeni de mandato S.mi, et fuerunt resoluta quaedam capita quae erunt firmanda à S.mo D. N. videlicet“. Vgl. denselben Eintrag in BAV, Vat. lat. 12286, f. 307r-v, der die daran beteiligten Kardinäle nennt: „Die 20. eiusd. fuit congregatio Ill.mor. Car.liu ad reformat.nem cerimoniar. in qua interfuere viij Card.les in domo Ill.mi Decani, v(idelicet) ipse Decanus Farnesius, Perusinus, Sabellus, Gambara, Sfortia, S. Severina et Carraf. super modo servando in Translatione corporis beati Gregorij nazianzeeni de m(anda)to S.mi et fuerunt resoluta quedam capita que erunt firmanda a S.mo tenoris infrascipti v(idelicet). Ordo quem R.mi D. iudicarunt si S. mo D. N. videbitur servandam in Transferendo corpore S.ti Gregorij Nazianzeni ad Bas.cam S.ti Petri“. Die entsprechenden Empfehlungen an den Boncompagni-Papst für die Durchführung sind ebenfalls enthalten in BAV, Chig.L.II.31, f. 656v-659r, resp. in BAV, Vat. lat. 12286, f. 307v-308r. Das Mandat wurde im Mai 1580 auch gedruckt: BNCR, 68. 13.Busta.30BI. Zwei Tage später kehrte der Papst aus Frascati nach Rom zurück, wo er im Konsistorium die Richtlinien guthiess. Die Prozession zu dem am 2. Juni 1580 stattgefundenen Frohnleichnahmsfest ist in BAV, Chig.L.II.31, f. 678r$680 r$ festgehalten.

866 BAV, Chig.L.II.31, f. 686v-688r; BAV, Vat. lat. 12286, f. 352r-v.

867 Rastelli, Descrittione, in BAV, Racc.I.IV.1, c. 32v: „In tanto fu ordinato, che in quel giorno alcuno non andasse ne in Cocchi ne a cavallo, ne si essercitasse nessuna arte ne tampoco si aprissero boteghe, ma che ciscuno dovesse devotamente accompagnare quella Santa Reliquia.“ 
gen Gregor von Nazianz, woraufhin in tempore congruo die tags zuvor auf dem Hauptaltar von San Pietro deponierten Reliquien auf den Altar der Gregoriana überführt wurden und der Sarg aus Blei, in dem sich die Überreste des Heiligen befanden, gesegnet wurde. Die Translationsfeier begann in Santa Maria in Campo Marzio mit der Überführung des Reliquienschreins, der über Nacht auf dem Hauptaltar gestanden hatte und nun auf einer reich verzierten Bahre in Begleitung von Chorgesang und der Rezitation eines auf Griechisch komponierten „Gesangs“ (carmen) von der Kirche entfernt wurde. Die Schwestern des Klosters riefen dabei unter Tränen und Wehklagen den Namen des kappadokischen Kirchenvaters an. ${ }^{868}$ Der feierliche Prozessionszug bewegte sich anschliessend durch die Via della Scrofa nach Sant' Agostino, wo er an der Torre Sanguigna vorbeizog und sich nach Santa Maria dell' Anima zur Piazza del Pasquino bewegte. Der weitere Weg führte dann durch die heutige Via del Governo Vecchio, die Via dei Banchi Nuovi und den Rione Parione bis zur Engelsbrücke. Dort überquerte die Prozession den Tiber und gelangte über die Engelsburg und den Borgo Nuovo schliesslich auf die Piazza San Pietro. An diesem Prozessionsweg ist zu erkennen, dass der Festzug nicht den kürzesten Weg von Santa Maria in Campo Marzio nach San Pietro wählte, nämlich denjenigen, der durch die Via dei Coronari geführt hätte. Stattdessen zog der Prozessionszug bewusst auf der weiter südlich, fast parallel verlaufenden Via papalis - auf dem Strassenzug also, durch welchen die neu gewählten Päpste für die Inbesitznahme des Laterans als ihres Bischofssitzes (possesso) ritten. ${ }^{869}$

Beim päpstlichen Empfang des Katafalks, den die Bischöfe dann in die Basilika trugen, hatte der Boncompagni-Papst nicht nur die Bahre umarmt, sondern auch das dort angebrachte Bildnis des Heiligen geküsst. Der Schrein wurde danach in Be-

868 BAV, Chig.L.II.31, f. 969r: „Quibus vocibus lacrimabilibusq. lamentationibus omnium abstantium, et audientium viscera commota sunt erga ipsas Moniales, sed ne earum planctus et ululatus letitiam omnium turbaret, quanto forius ipse plangibant, tanto alibus Cantores Voces extollebant, planctus, et ululatus [...] Voces Armonia confudentes“. Derselbe Eintrag findet sich auch in BAV, Vat. lat. 12286, f. 358v-360r.

869 Der von der Prozession zurückgelegte Weg kann gem. Rastelli, Descrittione, in BAV, Racc.I. IV.1, c. 32v folgendermassen im heutigen Strassennetz Roms rekonstruiert werden: Piazza di Santa Maria in Campo Marzio - Via della Stelletta - Via della Scrofa - Via delle Coppelle - Piazza di Sant' Apollinare - Via di Santa Maria dell' Anima - Piazza Pasquino - Via del Governo Vecchio (Via papalis) - Via dei Banchi Nuovi (Via papalis) - Via del Banco di Santo Spirito - Ponte Sant' Angelo Via del Borgo (Via della Conciliazione) - Piazza San Pietro. Damit tangierte der Prozessionszug entlang der Via papalis die Kirche der Kongregation des Oratoriums von Santa Maria in Vallicella. Hinsichtlich der Teilnehmer an der Prozession und der Reihenfolge des Zuges vgl. neben dem Eintrag in BAV, Chig.L.II.31, f. 697v-707r auch Rastelli, Descrittione, c. 34r-35r; Pastor 1923, Bd. 9, S. 798; Zollikofer 2016, S. 125-126; Malesevic 2018a, S. 86-87. Gregor XIII., begleitet von Kardinälen, Bischöfen sowie anderen kurialen Würdenträgern und auf der sedia gestatoria vom Portikus der Basilika bis an das Ende der Treppe heruntergetragen, ging zu Fuss bis zum Katafalk, um die Reliquien auf dem Petersplatz zu empfangen. 
gleitung von Glockengeläute, Fanfaren, Trommeln und Böllerschüssen durch das Atrium und den Portikus der Petersbasilika bis zur Cappella Gregoriana getragen. Dort wurde anschliessend der Schrein auf den Altar gestellt, wo er von Priestern und Soldaten bewacht nachts bei brennendem Kerzenlicht ausgestellt blieb. ${ }^{870}$ Die kurienzeremoniellen Vorschriften dieser Nachwache sind als bewusste Nachahmung der dem Heiligen Sakrament der Eucharistie darzubringenden custodia zu verstehen. Dadurch fand ein ritueller Wandel der Reliquien Gregors von Nazianz os Christi in einen „Leib“ (corpus) statt. Erst dadurch liess sich im Kurienzeremoniell die Reliquienüberführung als Nachahmung der Feierlichkeiten zum Corpus Domini aufführen. Am darauffolgenden Tag feierte der Boncompagni-Papst nämliche eine Messe zu Ehren des kappadokischen Kirchenlehrers, woraufhin er den Schrein - assistiert von zwei Bischöfen - segnete und diesen zusammen mit den Reliquien aus der Sakristei der Petersbasilika im Hauptaltar der Cappella Gregoriana beisetzte. Abschliessend erteilte er dem stadtrömischen Volk den feierlichen Segen mit einem Plenarablass. Das Zeremoniell der Reliquienüberführung wurde somit mit der gleichzeitigen Weihe der Cappella Gregoriana abgeschlossen. ${ }^{871}$

870 BAV, Chig.L.II.31, f. 713r: Sacrum vero Corpus B.ti Gregorij cum luminibus accensis remansit supra d(icto) Altari usq. ad Carstinum a pluribus sacerdotibus, et militibus totam nocte custoditum. Derselbe Wortlaut ist ebenfalls in BAV, Vat. lat. 12286, f. 371v zu finden. Vgl. auch Rastelli, Descrittione, in BAV, Racc.IIV.1, c. 35v, der die Leibwache weglässt: „Con questo ordine adunque venne S. Santità a ricevere quello santo Carpo, facendosi portare nella seggia ifino apie le scale di S. Pietro, \& sotto al Baldachino, ma quando fu apie le scale scese di seggia \& andogli incontro alquanti passi à piede, \& pervenuto al Corpo buttosi in terra con le genocchie facendo alquanta di oratione dopo rilevato in piedi abbraciò il Cataletto gia posto in terra dal un de capi, dove era l'Imagine del santo, \& quella baciò con molta divotione, ne senza lacrime a gli occhi, nel qual tempo pigliato il Cataletto dalli Vescovi che erano con Sua Santità lo condussero in san Pietro [...] \& arrivato questo santo Corpo alla porta della Chiesa nuove che tutto era pieno di populo [...] inde N. S. comandò che si conducesse nella capella, nella quale arrivata che fu la santa Reliquia fu posta sopra l'altare avanti al quale ardevano molte torcie, \& subito fu cantato un vespro Pontificale solennissimo standovi presente N. S. con tutti gli altri prelati ancorche fosse l'hora assai tarda poi che era durato il passare di si copiosa Processione infino a sette hore [...].“

871 BAV, Chig.L.II.31, f. 713r-714r: „Die seq.ti quae fuit Dom. in eiusdem mensis Junij S.mus D. N. processionali ritu praecedentibus familiaribus, officialibus, et Cruce, ac Pluvialis, et Cardinalibus pararis eo ordine et moro prout solet in die s. Petri eo quomodumq. processionaliter descendit, et personaliter volebat delatus in sede sub baldachinum descendit ad Basilicam Divi Petri, et in sacello Gregoriano missam solemnem in honorem Beati Gregorij Nazianzeni celebravit cum omnibus caeremonijs servati solitis quando Summus Pontifex celebrat sedes autem paramentorum fuit à parte sinistra Altaris ferè cum solium accommodata, et super Altare semper mansit capsa cum sacro Corpore id est usque ad finem missae, qua finita ante solemnem benedictionem amoris ex Altari Candelabris, et Cruce, et discoperto in loco super Altari vasus Parietem ubi erat marmoreus crater plumbeis laminibus undiq. intus crcumdatus R.mus D. N. ascendens per quoasdam gradus ductiles super Altare, et auxilatus hinc inde à duobus Episcopus San.tis Suae Assistentibus capsam praedictam cum sancto Corpore in d(ict)o Cratere deposuit, quistatim coopertus fuit, et repositis Cruce, et Candelabris super Altari Sanc.tas Sua solemnem benedictionem more solito Populo dedit, 
In den zeremoniellen Vorschriften zur Weihe der Kapelle findet sich eine anspruchsvolle Eingliederung Gregors v. Nazianz in den rituellen Vollzug des römischen Ritus vor. Der kappadokische Kirchenvater wurde als Teil der Ecclesia Romana und ihres patristischen Nachlasses der Kurie und der römischen Stadtgesellschaft vorgeführt. Die vier Kirchenväter ordneten dann bildsprachlich Gregor von Nazianz einen Platz im Architekturorganismus der Cappella Gregoriana zu. Gemeinsam mit den drei dort dargestellten Kirchenvätern trug Gregor von Nazianz zum universellen Anspruch der Romana Ecclesia als alleinige Verwalterin der Liturgie bei. Mit den Überresten dieses Kirchenvaters, die als os Christi bezeichnet wurden und denen ein Altar geweiht wurde, wurde ein weiterer „Leib“ neben dem konsekrierten corpus Christi in die zeremonielle Architekturordnung der Gregoriana eingefügt. Die anspruchsvollen Richtlinien, die der Zeremonienmeister Mucanzio zusammen mit der Zeremonialkongregation entwarf, stellten den kappadokischen Kirchenvater allerdings noch nicht in einen Bezug zu den drei weiteren Kirchenlehrern, die ebenfalls in der Cappella Gregoriana eine besondere Anerkennung fanden. Dieser Aufgabe sollte sich der Oratorianer Cesare Baronio widmen. 1583 legte er eine dem BoncompagniPapst gewidmete Vita des Heiligen Gregors v. Nazianz vor. Baronios Lebensbeschreibung des Kirchenvaters stellt eine Folge der zeremoniellen Reliquienüberführung dar.

In einem bislang undatiert gebliebenem Briefschreiben Baronios an den Boncompagni-Papst erklärte der Oratorianer dieses Vorhaben, eine Vita des Heiligen Gregors von Nazianz zu verfassen: Nach der erfolgreichen Reliquienüberführung wünschten sich viele Gläubige - worunter sich auch enge Mitarbeiter Baronios innerhalb der römischen Kurie befänden - Näheres sowohl über Leben als auch über die Taten des kappadokischen Kirchenvaters zu erfahren. Baronio erkennt Gregor von Nazianz als „wahrhaftigen Priester“ (vero Presbyterum) an. Dies bestätigt, dass Baronio der Predigt Panigarolas von 1580 beigewohnt haben musste. Seine Vita wollte der Oratorianer allerdings nicht als eine Wiederholung von Panigarolas laudatio schreiben. Vielmehr beabsichtigte Baronio mit dieser, das Leben des kappadokischen Kirchenvaters auf der Grundlage der „historischen Wahrheit“ (historiae veritate) zu erzählen. ${ }^{872}$ Ein weiteres Element in diesem Schreiben Baronios, das ebenfalls seine Teilnahme an der feierlichen Reliquientranslation bestätigt, ist

cui etiam Indulgentiam plenariam concessit, quam publicavit Proor Episcoporum Cardinalium qui in missa officio Assistentiae functus fuit“. Vgl. auch denselben Eintrag in BAV, Vat. lat. 12286, f. 372r-v, in welchem noch abschliessend die Rückkehr des Papstes in den Palast angefügt wurde.

872 Alberici, Epistolae et opuscula, I, S. 165-167, hier 166: „Ex ea tam ingenti Reliquiarum translatione, \& collocatione factum est, Pater Beatissime, ut multi ad Sancti hujus memoriam colendam vehentius inflammati, ejus \& res gestas, vitamque cognoscere percuperent; e quorum numero nonnulli amici, saepius ea de re mecum egerunt, rogaveruntque impensius, ut onus hoc susciperem [...]. Gregorium vero Presbyterum, ajebant, non tam vitam, quam laudationem conscipsisse, multa itidem ab eo omissa, brevius, quam par erat, nonnulla alieno loco narrata, quaedam etiam parum cum historiae veritate consentanea [...]“. Itaque non tam volens, quam obediens, opus magnum ag- 
seine Beschreibung der vier Mosaiken Girolamo Muzianos in den Eckzwickeln der Cappella Gregoriana. Baronio preist dabei vor allem die Darstellung der Figur Gregors v. Nazianz, der im Schreibakt gezeigt wird. Seiner Meinung nach sind die Kirchenväter als viri admirabilis nicht wegen ihrer „Leiber“ (corporis), sondern wegen ihrer Schriften zu bewundern. ${ }^{873}$

Mit seiner Vita Gregors v. Nazianz legte Cesare Baronio eine Lebensbeschreibung des Kirchenvaters, die mit den kurienzeremoniellen Vorschriften zur Reliquienüberführung übereinstimmte, vor, ohne dabei dem kappadokischen Kirchenvater hagiographisch huldigen zu wollen. Baronios Vita legte demnach einen Konflikt zwischen einer vom Kurienzeremoniell beeinflussten Liturgie der Verehrung des Kirchenvaters und einem hagiographischen Verständnis desselben bei. Den bisherigen hagiographischen Darstellungen des Lebens Gregors von Nazianz fehlte eine Ausarbeitung seiner Freundschaft sowohl mit dem heiligen Basileios d. Gr. als auch mit dem Kirchenvater Hieronymus, die ebenfalls in den Eckzwickeln der Cappella Gregoriana aufgeführt sind. Baronio musste sich daher bezüglich der Freundschaft zwischen Gregor v. Nazianz und Basileios d. Gr. eng an die 1583 von Jacques de Billy herausgegebenen und in verschiedenen Auflagen in Paris gedruckten Opera omnia Gregors von Nazianz angelehnt haben. In seinem erwähnten Brief an den Boncompagni-Papst drückte Baronio nämlich seine Hoffnung, diese Opera omnia edieren zu können, aus. ${ }^{874}$ Demgemäss musste die von Baronio verfasste Vita noch vor 1583 fertiggestellt worden

gressus, Vitam Gregorii Nazianzeni scribere institui. Eine handschriftliche Überlieferung der Vita konnte sowohl in BVR, Q 34 als auch in BAV, Bonc.B.3, f. 1r-107v aufgefunden werden. Die handschriftliche Fassung in BVR, Q 48, f. 113r-122v bildet eine spätere Abschrift aus BVR, Q 34. Die Lebensbeschreibung Baronios wurde erstmals in Acta Sanctorum Maii II, S. 373-429 abgedruckt, bis sie Alberici in idem, Epistolae et opuscula, II, S. 241-396 wieder auflegte. Die folgenden Ausführungen beziehen sich auf letztere Drucklegung und werden im Folgenden als Baronio, Vita Greg. Naz. aufgeführt.

873 Baronio, Vita Greg. Naz., S. 166: „Conatus sum autem, etsi rudis plane artifex, egregias illas Gregoriani Sacelli picturas aliquo modo imitari. Ut enim ibi pictor eximus ex tesserulis, \& lapillis miro artificio musivo opere compositis, \& coagmentatis, cum aliorum quorumdam Ecclesiae Doctorum, tum Gregorii nostri effigiem venustissime expressit; ita ego ex ipsius Nazianzeni potissimum scripts, quae ille de se ipso variis in locis alio currens, aliud agens, obiter scripsit, aut etiam data opera commemorat, selecta fragmenta, tanquam gemmas \& lapillos, accurate collegi; quos, servato temporum ordine, suis locis collocavi, \& quasi inter se conglutinavi, ut ex iis, velut ex splendidissimis coloribus, vivam viri admirabilis, non tam corporis, quam animi imaginem, si non omnino expressam, saltem adumbratam haberemus“.

874 Alberici, Epistolae et opuscula, I, S. 166-167: „Neque enim diffiteor, multa adhuc desiderari posse: \& nos fortasse aliquando opus diligentius perpoliemus, praesertim si quampluriam Gregorii carmina, \& alia quaedam ex vetustis codicibus nondum edita, ad manus nostras, ut speramus, pervenerint“. Ob Baronio schliesslich die Opera omnia dann selber zu Druck bringen wollte, kann aus dem Briefschreiben nicht erschlossen werden. Diese 1583 erschienene Auflage wurde ebenfalls dem Boncompagni-Papst gewidmet. Aus der Widmung an Gregor XIII. geht hervor, dass die lateinische Gesamtausgabe der Werke Gregors von Nazianz für die Widerlegung calvinistischer Theologie die- 
sein, da er diese offensichtlich für die Revision der geplanten Gesamtausgabe zu verwenden beabsichtigte. Im zweiten und letzten Band der 1583 erschienenen Opera omnia fügte Jacques de Billy das ein Jahr zuvor gedruckte und über 520 lateinische Hexameter zählende Gedicht Lorenzo Frizzolis, Sacellum Gregorianum, ein. ${ }^{875}$ Das Gedicht stellt die anspruchsvollste literarische Schrift über die Cappella Gregoriana dar, indem sie eine ästhetisch-theologische Betrachtung derselben vorlegt. Frizzoli stellte in seinem Gedicht eine besondere Konstellation der in den Eckzwickeln der Gregoriana dargestellten Kirchenväter fest, die „,auf einem Berg wie eine Gemeinde“ wirkten. ${ }^{876}$ Frizzoli stützt diese Konstellation allein auf die beiden kappadokischen Kirchenlehrer, Gregor v. Nazianz und Basileios d. Gr., deren Freundschaft in Baronios Vita das Zentrum des späteren Kampfs Gregors v. Nazianz gegen die arianische Häresie einnimmt. Nach Gregors Ankunft in Athen hatte sich dort erstmals eine Versammlung von scholares gebildet, deren Versammlungscharakter derjenigen Gemeinde glich, die Frizzoli in seinem Gedicht beschrieb. ${ }^{877}$ Cesare Baronios Be-

nen sollte. Vgl. D. Gregorii Nazianzeni opera omnia, I, S. 1-2: „[...] cum tot seminariis tot orbe Christiano sumptuosissimè excitatis, cum tot tamque variarum linguarum typis Romae cusis, Theologiam ab ipso traditam tabulis signifique instruxisti. [...] qui eo praesertim tempore Auctoris elegantissimam editionem fidissimamque orbi Latino exhibuit, quo erat utilissima ac prope necessaria. Isto videlicet, quo Caliniana pestis totum terrarum nostrarum orbem depasci conata, cuncta illa monstra, quae Theologus olim labore plusquam herculeo domuerat, \& in orcum transmiserat [...]. Quis posterum tantam copiam in blasphemando credet, cui deinceps ad istam impiè fandi licentiam non horrebunt pili; Procreavit Calvinianas vomicas hand ecunciationem à patribus Nicenis contra inferorum portas dulcissimè personatam [...] ut duram, ut improriam, ut maximè periculosam abhorrentes“. Johannes Herwagen besorgte bereits 1550 die erste gedruckte Ausgabe der Opera omnia in griechischer Sprache, welche in Basel erschien. Vgl. hierzu TRE 1985, Bd. 14, S. 164-173, 170 sowie zu de Billys Ausgabe, deren Drucklegung ab 1575 Kardinal Antonio Carafa entschieden mitgestaltete, indem er de Billy eine griechische Handschrift von Johannes Damascus' Sacra Parallela sandte, Backus 1993, S. 124-125; eadem 2003, S. 235.

875 D. Gregorii Nazianzeni opera omnia, II, S. 1556-1560.

876 Frizzoli, Sacellum Gregorianum, S. 14: Ille viros solis agitantes montibus una/ Communem ad $\operatorname{vita}(\mathrm{m})$, moresque, habitumq. coegit./ Sub sanctis hos suave iugum tolerare magistris/ Edocuit, castaq. inopes spendescere vita/ Secretos populo, \& fallacis imagine mundi. Vgl. dementsprechend auch D. Gregorii Nazianzeni opera omnia, II, S. 1557.

877 Baronio, Vita Greg. Naz., S. 260-261: Post aliquot temporis spatium ab adventu Gregorii Athenas, Basilius, quem Caesarea Palestinae Constantinopolim litterarum studio profectum diximus, inde Athenas se contulit. Quibus humanitatis officiis gentilem suum Gregorius susceperit, vix credi potest. Nam non tantum inter suos intimos adnumeravit, sed \& contubernalem habere voluit: quem non tantum communis patria, sed paria studia, mores consimiles sociabant, arctissimoque amoris vinculo vinciebant. Venienti quamprimum affuit, insultantibusque in eum Armenis discipulis, ac captiosis quibusdam disceptationibus deprimere saragentibus, continuo praesto fuit: cautumque insuper reddidit ne jocis illis, quibus veterani scholares tironobus consuevissent illudere [...]. Hisce amicitiae officiis Gregorius adeo sibi conciliavit Basilium, contraque ille morum suavitate Gregorium adeo devinxit [...]. De communibus autem vitae studiis haec ibidem enarrat. [...] Quod quidem nobis ob oculos proponentes, vitam actionesque omnes nostras dirigebamus, tum divini praecepti ductum sequentes, 
handlung der kontroverstheologischen Problematik um die arianische Häresie diente ihm in seiner Vita dazu, die Beziehungen zwischen Gregor v. Nazianz und dem lateinischen Kirchenvater Hieronymus ausarbeiten zu können. Als Bischof des kleinen Ortes Sasima bemühte sich der kappadokische Kirchenlehrer um einen Ausgleich zwischen nizänischen und arianischen Bestrebungen. Diesen Ausgleich stellte Baronio in seiner Vita auch in den Äusserungen Hieronymus', in denen der lateinische Kirchenvater Gregor v. Nazianz als Vorbild einer einheitlich gestalteten Ecclesia bezeichnet, fest. Durch den kappadokischen Heiligen bleibe die Kirche nach jedem „Erdbeben“ (terraemotus) standhaft. ${ }^{878}$ Der Kirchenvater Hieronymus stellt in Baronios Vita eine entscheidende Verbindungsfigur zwischen westlich-römischer und östlich-byzantinischer Liturgik dar, da seine Schriften eine Überführung griechisch-byzantinischer Theologie nach Rom ermöglicht hätten. Die Figur des Kirchenvaters im Eckzwickel der Cappella Gregoriana stellte Hieronymus nicht als Kirchenprälaten, sondern als gelehrten Theologen, dar. Baronio präsentierte für die Kurie mit seiner Vita des heiligen Gregor v. Nazianz eine entscheidende Grundlage dafür, wie ein griechischer mit einem lateinischen Kirchenvater in Beziehung zu setzen war. Diese Beziehung zeichnete sich auch durch das in den kurienzeremoniellen Vorschriften zur Reliquienüberführung enthaltene Gleichgewicht zwischen lateinisch-römischer und griechisch-byzantinischer Liturgik aus.

Cesare Baronios Lebensbeschreibung ist somit als ein Produkt der kurienzeremoniellen Durchführung der feierlichen Reliquientranslation zu betrachten. Die rituellen Vorschriften dieses Zeremoniells nahmen sich das anlässlich des Fronleichnamsfestes ausgearbeitete Prozessionszeremoniell zur Grundlage und ergänzten dieses um die spirituellen Vorbereitungen, die Francesco Panigarola in seiner Predigt coram papam vorgestellt hatte. Baronios Lebensbeschreibung lässt sich daher in ein Spannungsfeld zwischen Liturgik und Hagiographie einordnen. Baronio nahm seine Vita

tum alter alteri virtutum studium extimulantes [...]. Vgl. auch die Stelle in Frizzoli, Sacellum Gregorianum, S. 13: Demittit, Basili nomen cognomine magni/ Illustrat: claris rediens qui dctus Athenis/ Cappadocum patria(m) decoravit laudibus urbem. [...] Exemplis iter ad sedes monstravit, \& innis/ Mortales terris erexit ad athera curas. Zur Bedeutung Athens als sinnstiftender Ort innerhalb der Lebensbeschreibung Gregors von Nazianz vgl. auch die entsprechenden Zitate aus dem autobiographischen Gedicht, Carmen de vita sua, in Baronio, Vita Greg. Naz., S. 264-266.

878 Baronio, Vita Greg. Naz., S. 270: [...] ab Arianis [...] ingens clades Catholicae Ecclesiae secuta est, utar verbis Hieronymi, ingemuitque orbis, \& Arianum se esse miratus est: de qua etiam hic Gregorius. (Ego vero, inquit, terraemotum hunc nostra tempestate coortum, nullo eorum, qui jam extiterunt, inferiorem esse existimo, per quem omnes monasticae philosophiae sectatores, Dei timore praediti, \& ante tempus in coelis civium numero fungentes, a nobis dimoveretur) \&c. Revera Catholicae fidei terraemotus dicendus, quo solidae templi columnae prostrataem, vel saltem loco motae atque inclinatae sunt [...]. Zur Bekämpfung der arianischen Häresie vgl. dann auch das 11. Kapitel, Arianorum injuriae toleratae, pervicacia superata a modestissimo in omnibus Gregorio; hujus discipulus S. Hieronymus, in ibid., S. 317-324, insbes. S. 322-323. 
Gregors v. Nazianz nicht als eine hagiographische Darstellung des kappadokischen Kirchenvaters wahr. Für den Oratorianer hatte die Darstellung von zentralen kontroverstheologischen Problemen Priorität, die Gregor v. Nazianz Zeit seines Lebens durch seinen Austausch mit Basileios d. Gr. und Hieronymus zu lösen beabsichtigte. Diese kontroverstheologische Beleuchtung des Lebens Gregors v. Nazianz lag auch den rituellen Richtlinien zu dem anlässlich der Reliquienüberführung gestalteten Zeremoniell zu Grunde. Baronios Vita gibt eine gezielte Antwort auf eine innerhalb der Kurie lange Zeit ungelöst gebliebene Frage: Wie lässt sich nämlich eine Lebensbeschreibung eines Kirchenvaters anhand eines für dessen Heiligenverehrung ausgearbeiteten und angemessenen Kurienzeremoniells schreiben? Dadurch zeichnete sich der Oratorianer Baronio gegenüber seiner kurialen Klientel als einer ihrer produktivsten Dienstleister auf dem Gebiet der römischen Liturgik aus. Baronios Dienstleistungen für die Kurie stellten für ihn eine geeignete Strategie dar, um sich ab 1576 von seinen Mitbrüdern innerhalb der Kongregation des Oratoriums abgrenzen zu können. Durch diese Profilierung verschaffte er sich einen Platz als Mitarbeiter derjenigen Kurienprälaten, die der Boncompagni-Papst mit der Revision des Martyrologium Romanum betraut hatte. Bei dieser Zusammenarbeit konnte Baronio seiner Begeisterung für die rituelle Gestaltung liturgischer officia nun auf dem grösseren Gebiet der Verehrung frühchristlicher Märtyrer und Heiliger nachgehen.

\subsection{Patristische Liturgie im neuen Martyrologium Romanum}

Sowohl das Dekorationsprogramm der Cappella Gregoriana als auch deren Nutzung im Kurienzeremoniell anlässlich der Reliquienüberführung führten das mit der Ausmalung der Sale dei Foconi im Palazzo Apostolico begonnene Projekt der Kurie, das Vermächtnis der Kirchenväter in die Ausgestaltung und Formulierung einer dezidiert römischen Liturgik einzubinden, zu einem erfolgreichen Abschluss. Dieses Projekt wurde parallel zu den weiterführenden Arbeiten der Kurie in Bezug auf die Überarbeitung liturgischer Bücher betrieben. Guglielmo Sirleto hatte bereits 1568 mit seinem revidierten und gedruckten Breviarium Romanum das Stundengebet in einem neuen rituellen Rahmen gefasst. Die Kurie sollte sich bei ihren bevorstehenden Arbeiten zu einem überarbeiteten Druck des Martyrologium Romanum dieser rituellen Neubegründung des Stundengebetes annehmen und für die einschlägige Formulierung einer für das Proprium Sanctorum vorgesehenen Liturgie umsetzen. Mit dem Martyrologium sollte das für die Rezitation der Heiligen und Märtyrer der Universalkirche vorgesehene Stundengebet ebenfalls in einem rituellen Rahmen entsprechend neu formuliert werden. Dabei sollten in diesem liturgischen Buch die „hagiographischen Koordinaten“, die sich aus dem Todestag eines Märtyrers oder Heiligen und dem ursprünglichen Verehrungsort zusammensetzten, korrekt wiedergegeben werden. Dementsprechend waren die Märtyrer- und Heiligenfeste mit dem neuen liturgischen Kirchenkalender Gregors XIII. abzugleichen, wodurch ein Gleich- 
gewicht zwischen dem hagiographischen Stellenwert der Heiligen und Märtyrer und dem Ritus ihrer liturgischen Verehrung hergestellt werden sollte. Die Kurie konnte bei dieser ehrgeizigen Revisionsarbeit ihr Ziel daher erst 1584 mit dem in der römischen Druckerei Domenico Basas herausgegebenen Martyrologium Romanum erreichen, das der Boncompagni-Papst mit der Bulle Emendato iam vom 14. Januar desselben Jahres zum offiziellen liturgischen Buch erklärte. ${ }^{879}$

Im selben Jahr der feierlichen Reliquienüberführung berief der BoncompagniPapst Gregor XIII. eine Kardinalskommission, welche das Martyrologium Romanum revidieren und herausgeben sollte, ein. Die Leitung dieser Revisionsarbeiten hatte der Papst Kardinal Sirleto anvertraut. Die Einberufung dieser kurialen Arbeitsgruppe für das Martyrologium musste sich noch vor dem Abschluss des Jahres 1580 ereignet haben, wie dies Cesare Baronio in einem Briefschreiben an den Vater Camillo vom 6. Dezember 1580 berichtete:

Sua Santità si serve di me nella riformatione del Martirologio, per la quale si fa una Congregazione d'huomini eccellenti, et il Reverendissimo Sirleto mi ha eletto per uno di quelli, il che certo è cosa di qualche importanza. Si son fatte finqui parecchie congregationi e per gratia del

879 Zum Begriff der „hagiographischen Koordinaten“ vgl. Delehaye 1934, S. 7-17; Ditchfield 2005b, S. 300; Guazzelli 2012a, S. 68-69. Zum neuen Kirchenkalender Gregors XIII. vgl. BAV, Vat. lat. 6417, f. 51r, 52v; Malesevic 2018b, S. 142. Die Bulle Gregors XIII. zum neuen Martyrologium findet sich entsprechend abgedruckt in Mart. Rom. (MLCT, 6), c. a2r-a3r, hier dann insbes. c. a2r-v: Ecclesiae more in Choro legendum proponi, ad Dei gloriam, ad Sanctorum ipsorum, quorum memoria celebratur, laudem; ad eorum, qui legunt, quiq. audiunt, fructum. Habet enim Sanctorum innocentiae, charitatis, fortitudinis, ceterarumq. virtutum commemoratio stimulos quosdam acerrimos [...] cum illorum propositis exemplis nostram defidiam agnoscimus; quamq. procul ab illorum laude \& perfectione absumus, cogitamus. Der Text der Bulle hatte dabei keineswegs die Verwandtschaft der neuen Edition mit früheren Martyrologien verneint. Zu den mittelalterlichen Martyrologien vgl. diesbez. v. a. Dubois 1978; idem 1965; Osborne 1985, S. 278-328; Rose 2009, S. 140-142. Bereits 1582 sowie ein Jahr später erschienen die ersten Editionen des neuen Martyrologium, welche Pietro Galesinis 1578 herausgegebene Fassung deutlich verbesserten. Dieses Martyrologium Galesinis kann im Zusammenhang mit den am 31. Mai 1578 aufgefundenen Katakomben betrachtet werden. Der Fund, an welchem neben Alonso Chacón, Pompeo Ugonio und Cesare Baronio auch der vicarius Urbis, Giacomo Savelli, teilnahm, wurde sowohl in den beiden avvisi vom 28. und 29. Juni sowie dem vom 2. August 1578 in BAV, Urb. lat. 1046, f. 232r, 256r, 302r, in Maffei, Degli Annali di Gregorio XIII, II, S. 376 wie auch in Baronius, Ann. Ecc., II, S. 75 festgehalten. Vgl. dann Pastor 1893-1933, Bd. 9, S. 191-192 und die neueren Forschungsergebnisse in Spera 2012, S. 394-398; Herklotz 2012, 425434; Deckers/Mietke/Weiland 1991; Giordani 2007, S. 277-315; Fiocchi Nicolai 1995, S. 105-130; Oryshkevich 2003, S. 6, 12-15; eadem 2012, S. 256; Magill 2015, S. 87-115. Chacón und der Niederländer Philips van Winghe hielten die Wandmalereien der Katakomben erstmals fest. Chacóns Zeichnung findet sich aufbewahrt in BAV, Vat. lat. 5409, von welcher Federico Borromeo dann eine Kopie in BAM, F 299inf. verschaffen konnte. Kopien von van Wnighes Zeichnungen finden sich sowohl in BAV, Vat. lat. 10545 als auch in BVR, G 6 aufbewahrt. Alfonso Chacóns Traktat De cimiterio S.tae Priscillae Romae invento de anno 1578 konnte Herklotz 2012, S. 429 auch am Getty Research Institute in Los Angeles (Nr. 840005, f. 70r-78v) ausfindig machen. 
Signore sono in maggior concetto di quello che la mia bassezza merita. Datene laude a Dio benedetto: Qui de stercore erigit pauperem, ut collocet eum cum principibus populi sui. ${ }^{880}$

Weder der Brief Baronios noch die Papstbulle Emendato iam vom 14. Januar 1584 erwähnen die genauen Mitglieder dieser Kardinalskommission - sie werden einzig als „ausgezeichnete Männer“ (viros eruditos/ huomini eccellenti) erwähnt. Die Forschung stufte diese Bemühungen des Oratorianers und anderer möglicher Kommissionsmitglieder als „schwierig “ ein. ${ }^{881}$ Es bleibt daher immer noch unklar, inwiefern Cesare Baronio bereits an der Revision der beiden ersten Martyrologien teilgenommen haben könnte. Guazzelli konnte feststellen, dass ein Teil der Auseinandersetzungen Baronios mit diesem liturgischen Buch die Frage der Einbindung von weiteren Hinweisen auf zeitgenössische Märtyrer betraf. Dieses Bedürfnis, dass auch zeitgenössische Märtyrer in das Martyrologium aufgenommen werden sollten, drückte der Kanoniker der Petersbasilika Curzio de Franchi in einem Briefschreiben an Guglielmo Sirleto aus. Baronio sah aber anscheinend auch eine Aufnahme solcher Heiliger vor, denen gegenüber er und seine Eltern eine besondere Andacht gepflegt hatten. ${ }^{882}$

Eine weitere Problematik bei der Neuausgabe des Martyrologium, mit welcher sich Baronio auseinandergesetzt haben muss und die ebenfalls seitens der Forschung unbeantwortet blieb, musste der nach der erfolgreichen Reliquienüberführung vom 11. Juni 1580 neu gewonnene Stellenwert der Patristik im Zusammenhang

880 BVR, Q 46, f. 49r; Laemmer, De Martyrologio Romano, S. 10; idem, De Caesaris Baronii literarum, S. 55; Calenzio, Vita, S. 173; Paschini 1923, S. 8; Guazzelli 2012a, S. 67.

881 Sodi 2009, S. 292; Guazzelli 2005, S. 47-89; idem 2012a, S. 71-84; idem 2012c, S. 179-181. Laemmer, De Martyrologio Romano, S. 15-16 schlug die Zusammensetzung dieser Kommission aus folgenden Mitarbeitern neben Sirleto und Baronio vor: Aloysius Lilus (Luigi Giglio), Pedro Chacón, der Belgier Gerhard Bossius, der Theologe Latino Latini, der Kanoniker des Peterskapitels Curtio Franco, Antonio Geronio von Tarragona sowie der Regularkanoniker Antonio Agellio. Cistellini 1989, Bd. 1, S. 324 hatte auch Silvio Antoniano als ein weiteres Mitglied ansehen wollen. Da die Revisionsarbeiten für das neue Martyrologium parallel zur Veröffentlichung des neuen Kalenders verliefen, erscheint eine Zusammenarbeit mit der Kalenderkommission nicht unwahrscheinlich: Malesevic 2018b, S. 142.

882 BAV, Vat. lat. 6194, I, f. 63r: „Anzi vorrei che de i martiri de nostri tempi si potesse haver certa historia per honorarli anch'essi e per mostrar che in ogni tempo la chiesa santa è stata illustrata dal martyrio [...].“ Auch zit. in Paschini 1923, S. 14. Vgl. dann Guazzelli 2012a, S. 73. In diesem Zusammenhang beabsichtigte Baronio, wie aus einem an ihn adressierten Briefschreiben des Vaters Camillo vom 7. August 1581 hervorgeht, die Heiligen Caesidius und Rufinus in das neue Martyrologium aufzunehmen. Das Briefschreiben Camillo Baronios an den Priester Francesco di Messer Pietro in Trasacco findet sich in BVR, Q 47, f. 33r aufbewahrt und zit. in Calenzio, Vita, S. 200-201. Vgl. hierzu die entsprechende Aufnahme in Mart. Rom. (MLCT, 6), S. 241, 265. Hinsichtlich dieser Auseinandersetzung mit den beiden Heiligen vgl. Scorza Barcellona 2002, S. 256-285; Mezzazappa 2009, S. 344-351. Baronio hielt in seiner Briefkorrespondenz mit seinem Vater Camillo den Fortschritt des Drucks ab 1582 fest. Vgl. hierzu neben dem Schreiben vom 10. Januar 1582 in BVR, Q 46, f. 50r auch Laemmer, De artyrologio Romano, S. 23, 25-26; idem, De Caesaris Baronii literarum, S. 58,61 . 
mit der rituellen Gestaltung solcher liturgischer officia, welche die Märtyrer- und Heiligenverehrung betrafen, gewesen sein. Noch bevor der Boncompagni-Papst am 24. Februar 1582 die erste überarbeitete Ausgabe des Martyrologium mit seiner Bulle Inter gravissimas verkündete, teilte Baronio dem Vater Camillo in einem auf den 10. Januar datierten Briefschreiben seine Auseinandersetzung mit den Werken des Kirchenvaters Ambrosius mit:

Domenica passata mi mandò a chiamare il Cardinal Sirleto, e conferissimo insieme un pezzo sopra del Martirologio; dandoli bon conto delle cose, che dubitava mit disse: si cominciarebbe a stampare il mese di febraio, o al più al mese di Marzo, che già le fatighe sono a bon termine: però fin che non sia finito di stampare, non si puol levare le mani di sopra, che bisogna attendervi fin all'ultima riga. Venerdi di prossimo passato, mi mandò a chiamare il Cardinal Montalto, qual ha fatigato un pezzo per la corretione dell'opere di S. Ambrosio, et essendo hormai in precinto di farle stampare, mi pregò ch'io pigliassi una fatiga in mettere insieme quanto si trovasse di quà di là disperso nell'autori antichi sopra dell'attioni di detto Santo: e correggere alcune cose, quale altri havessero poste, non come dovevano pare. Promesi di farlo, e farlo con diligentia. In quanto del studio dell'historia non posso attendere a rivedere, e corregere, come havemo incominciato. ${ }^{883}$

Baronios Beschäftigung mit dem mailändischen Kirchenvater auch im Zusammenhang mit der Märtyrer- und Heiligenverehrung scheint seine Mitarbeit am Druck der Opera omnia des Ambrosius weiter zu bestätigen. Die Beschäftigung mit der ambrosianischen Patristik, die innerhalb der römischen Kardinalskongregation für die Neuausgabe der Vulgata bereits ab 1577 mit der Herausgabe der Opera omnia begonnen hatte, muss Baronios Arbeiten an seinen Annales Ecclesiastici zu einem Stillstand gebracht haben. Baronios Arbeiten an der Revision des Martyrologium Romanum sind aber nicht als Unterbrechung der Arbeit an den Annales aufzufassen. Vielmehr musste Baronio zuerst dieses liturgische Buch als eine entscheidende Brücke zwischen Kirchenhistoriographik und Patristik auffassen. Erst nachdem Baronio die Bedeutung der liturgischen Bücher als Verbindungsquelle seiner kirchenhistoriographischen Rekonstruktionen mit dem Nachlass der Kirchenväter ausgearbeitet hatte, konnte er seine Annales als eine vollumfängliche Kirchengeschichte gestalten.

Obwohl über die Arbeitsvorgänge der Kommission, die das Martyrologium Romanum überarbeiten sollte, nur einige Blätter mit note, minute e traduzioni dal greco del Sirleto unterrichten, machten die Arbeiten nur langsame Fortschritte. In einem Briefschreiben Curzio Franchis vom 14. Mai 1581 an Sirleto warf der Kanoniker vom Peterskapitel der Kommission vor, dass man troppi santi greci in das Martyrologium aufgenommen habe. Ein weiterer Vorwurf Franchis war, dass sich die Kommission für ihre Überarbeitungen dieses liturgischen Buches an Schriftquellen bediene, die bezüglich der Mitberücksichtigung der Kirchenväter entscheidende

883 BVR, Q 46, f. 49r; Calenzio, Vita, S. 180. Die päpstliche Bulle Inter gravissimas findet sich abgedruckt in Bull. dipl. rom., VIII, S. 386-387. 
Konsequenzen nach sich zögen: Auch wenn man die Heiligenviten den Werken Gregors d. Gr., Hieronymus’ oder „anderer angesehener Autoren“ entnommen habe, bedeute das noch lange nicht, dass diese Heiligenleben von autori irrefragabili verfasst worden seien. ${ }^{884}$ Wie konnte aber ein Gleichgewicht zwischen griechischen und lateinischen Kirchenvätern innerhalb des neuen Martyrologium Romanum hergestellt werden, wenn dabei die Kurie den Vorwürfen Franchis zufolge die Verweise auf die griechischen Kirchenväter reduzieren sollte?

Die entscheidende Frage, wie mittels des Martyrologium das reiche Vermächtnis der Kirchenväter für die rituellen Formulierung einer Liturgik zu verwenden war, musste sich mit der Herausgabe des Breviarium Ambrosianum durch Pietro Galesini in Mailand besonders zugespitzt haben. ${ }^{885}$ Mit diesem liturgischen Buch hatte der Mailänder Erzbischof und Kardinal Carlo Borromeo die Unabhängigkeit des ambrosianischen vom römischen Ritus endgültig bestätigen wollen. Angesichts der Drucklegung des Breviarium Ambrosianum erschien der römische Ritus als eine $\mathrm{Zu}$ sammenstellung fremder liturgischer Praktiken und konnte sich daher nicht mittels individueller liturgischer Charakterzüge ausweisen. Die Ecclesia Romana konnte mit dem 1568 erschienenen Breviarium Romanum nur über ausgewählte lectiones die universelle Gültigkeit ihrer Liturgie erklären. Im Zusammenhang mit der Frage, wie ein angemessenes Gleichgewicht zwischen griechischer und lateinischer Patristik hergestellt werden könne, müssen Cesare Baronios erste Arbeiten auch vom Spannungsverhältnis zwischen ambrosianischem und römischem Ritus beeinflusst worden sein.

Baronio scheint sich allerdings diesem Zwist zwischen Rom und Mailand erst ab 1583 gewidmet zu haben. Am 28. Juni dieses Jahres teilte er nämlich seinem Vater Camillo in einem Briefschreiben mit, dass der Kardinal Sirleto ihn persönlich darum gebeten habe, für das neue Martyrologium sogenannte scholia zu besorgen, mit denen der Oratorianer „die vielen Mehrdeutigkeiten“ im Martyrologium Romanum erklären sollte:

Il cardinal Sirleto mi ha pregato ch'io facci una scholia sopra il Martirologio Romano, nella quale si darra conto, cosa per cosa, e si risolveranno molte ambiguità. Sarra opera che avanzarà di tre volte tanto il volume del Martirologio, e già è in bon porto, e sarra in ordine a darsi a stampa questo anno che viene, quel opera è d'importanza e si leggera per tutta la Christianità, e se stamperà sotto il mio nome, quale ho speranza che vederete e goderete. ${ }^{886}$

884 BAV, Vat. lat. 6194, I, f. 53r: „So che V. S. l'ha illustrato di molti belli santi, et io so che vene ha posti da s. Gregorio, da s. Hieronimo e presi da altri buoni autori (se ben son stati posti dal Molano o dal Gallesino che importa) se ce e qualche cosa da risecare chi gli lo nega? Ma V. S. Ill.ma stia salda che il buono non si levi, nè quello dove non vi è cosa di contratio.“ Auch abgedruckt in Paschini 1923, S. 206-207.

885 Cattaneo 1943, S. 83; idem 1966, S. 2-42; idem 1964, S. 38-43.

886 BVR, Q 46, f. 50r; Calenzio, Vita, S. 198; Laemmer, De Martyrologio Romano, S. 25-26; idem, De Caesari Baronii literarum, S. 22-23. 
Guazzelli weist darauf hin, dass unter dem Begriff der scholia Baronios Annotationen zum Martyrologium gemeint sind. Diese wurden in der 1586 gedruckten Ausgabe des Martyrologium ebenfalls aufgeführt. ${ }^{887}$ Die liturgische Andacht des Kirchenvaters Ambrosius teilte das neue Martyrologium in die Feierlichkeiten zu seinem Begräbnis, die am 4. April stattfanden, und in den Festtag seiner Weihe zum Bischof am 7. Dezember ein. Die zur Bischofswahl dazugehörige scholia Baronios beinhaltet den entscheidenden Zusatz, dass an dieser Bischofsweihe sowohl die griechische als auch die lateinische Kirche Anteil nahmen. Baronio erwähnt dabei in seiner Annotation zur Bischofsordination des Kirchenvaters den Umstand, dass nicht nur die lateinische, sondern auch die griechische Kirche diese Bischofswahl feiere. Gleichzeitig hält er in dieser scholia den Fortschritt an der Opera omnia des Kirchenvaters, deren fünfter Band 1585 gedruckt wurde, fest. Baronio scheint damit die im Breviarium Romanum enthaltenen lectiones für diese Feier erweitert haben $\mathrm{zu}$ wollen. $\mathrm{Zu}$ diesem Vorhaben trug seine bereits 1583 fertiggestellte Vita Sancti Ambrosi, in welcher Baronio die Freude Basileios' d. Gr. an dieser Bischofswahl schilderte, bei. Für Baronio ergab sich daraus im Martyrologium Romanum eine Gleichwertigkeit zwischen den griechischen und den lateinisch-römischen Kirchenvätern. ${ }^{888}$ Baronio verfolgte dadurch das Ziel, das Martyrologium an das ihm von Guglielmo Sirleto überlassene $M e$ nologium Graecorum anzunähern. Diese Annäherung von griechischem und einem lateinisch-römischen Martyrologium sollten eine kirchenhistoriographisch präzise Rekonstruktion von Heiligen- und Märtyrerfesten des im Breviarium Romanum enthaltenen Proprium Sanctorum erlauben.

Zwischen dem Zeitpunkt, als Sirleto Baronio damit beauftragte, das Martyrologium Romanum von $1583 \mathrm{zu}$ annotieren, und der Drucklegung des fünften Bandes der Opera omnia des Kirchenvaters Ambrosius bahnte sich innerhalb der kurialen Revisionsarbeiten am Martyrologium ein Neuverständnis des Verhältnisses von griechischer und römisch-lateinischer Patristik an. Die beiden kappadokischen Kirchenlehrer Basileios d. Gr. und Gregor v. Nazianz wurden nicht mehr länger als

887 Guazzelli 2012a, S. 76-77. Die handschriftliche Überlieferung dieser annotationes befindet sich in BVR, B 13.

888 Baronio, Vita S. Ambrosij, S. 5-6; BVR, Q 35, c. 6. Vgl. dann neben Brev. Rom. (MLCT, 3), S. 714; Mart. Rom. (1586), S. 548, nota a: Non tantum Latini, sed \& Graeci eadem celebrant solemnitatem; Nataemq dicunt, ut constat ex eorum Menologio, hac diem Paulinus [...] sanctissimi viri res praeclarissimè gestas conscripsit. Rursus autem ex recentioribus Costerius legi in bibliotheca Sfortiana cod. man. scrip. vitam S. Ambrosij Graece scriptam sine auctore: quibus omnibus cum nonnulla adhuc deesse conspicerem, eademq. non parui momenti \& auctoritatis; singula in unum collegi, atque ordine temporum disposui. Habes eam editam, ac tomo quinto operum sancti Amros. Rom. edit. affixam. Offensichtlich musste Baronio auch Anteil an diesem fünften Band der Opera omnia genommen haben, wenn er in der Vita S. Ambros., S. 6, ein Schreiben Ambrosius' über die Diözesanverwaltung von Vercelli aus Operum Sancti Ambrosii, V, S. 186-196, 193 wiedergibt. Baronios Ausführungen zur Bischofsweihe des heiligen Ambrosius in seiner Vita stützen sich weitestgehend auf Theodorets Historia Ecclesiastica. Vgl. die entsprechenden Passagen in PG, Bd. 82, Sp. 1131-1134. 
Vorbilder und primäre Referenzfiguren für die lateinischen Kirchenväter verstanden. Die Kurie begann die lateinischen Kirchenväter unabhängig von ihren griechischen Pendants zu begreifen. Diese Selbständigkeit lateinischer Patristik stellte die prinzipielle Grundlage zu einer ekklesiologisch-liturgischen Gestaltung der Ecclesia Romana dar. Der Eigenwert lateinischer Kirchenväter hatte sich in der Herstellung zweier Altarbilder für die Cappella Gregoriana ab 1583 angebahnt, indem deren Altarpatrozinien unabhängig voneinander gestaltet wurden. Die beiden Nebenaltäre der navi piccole wurden Hieronymus und Basileios d. Gr. geweiht. Für deren Altarschmuck erhielt Girolamo Muziano am 29. März 1582 den Auftrag, zwei auf Leinwand gemalte Altarbilder anzufertigen. Diese Altarbilder wurden aber erst in den 1590er Jahren angebracht. Der Zeremonienmeister Francesco Mucanzio berichtet in seinem Tagebuch, dass am 11. März 1583 Gregor XIII. in Begleitung von Kardinälen die Altäre der Gregoriana besucht habe. ${ }^{889}$ Obwohl der Hauptaltar ausser Gregor v. Nazianz auch der Muttergottes Maria geweiht war, herrschte innerhalb der Cappella Gregoriana ein Gleichgewicht zwischen den drei Altarpatrozinien. Mucanzios Altarbilder der Predigt des Heiligen Hieronymus mit Eremiten und der Messefeier des heiligen Basileios sollten einen Anstoss dafür geben, dem griechischen Kirchenvater Basileios Wesenszüge einer der römischen Liturgik entnommenen Bildsprache zu verleihen. Die Realisierung der beiden Altarbilder konnte aber weder Gregor XIII. selbst noch sein Nachfolger Sixtus V. erleben (Abb. 46e \& 46f).

\footnotetext{
889 BAV, Chig.L.II.31, f. 846v: Die xi. eiusdem fer.a 6.a Papa descendit ad Basilicam cum is Cardinalibus, et visitaris Altaria [...] et ultra ea Altare s. Gregorij cum esset Vigilia eius festa, et ultimo loco Altare Vultus S.ti. in ingressu Aula Rev.mus Farnesius tamquam Archipresbyter dictae Aulam dedit Aspersorium Papae. Der Auftrag selbst lässt sich einerseits über die Briefkorrespondenz Cesare Nebbias mit dem Camerlengo der Bauhütte des Doms von Orvieto, Silvio Bisenzi, aus Archivio Opera del Duomo di Orvieto, Lettere originiali, b. 70b (1566-1597), fasc. 3, Nr. 461, 465, rekonstruieren. Zit. n. Tosini 2008, S. 540-541; eadem 1999, S. 282-283. Andererseits erwähnte der stuccatore, Fernando Fancelli, in einem Brief an dieselbe Bauhütte, dass Muziano noch nicht an den für den Dom vorgesehenen Altarbildern arbeitete, da er zuerst andere „per il papa che vanno nella Gregoriana“ schaffen musste. Zit. n. Marciari 2000, S. 451-452. Am 6. Oktober 1584 erhielt Muziano die Zahlung für die dafür zu verwendenden Pigmente, am 27. Oktober desselben Jahres für die Pinsel und schliesslich am 13. März für die Farben. Vgl. hierzu die entsprechenden Dokumente in ASR, Camerale I. Fabbriche, 1526, f. 14r, $15 \mathrm{r}$ und ASR, Camerale I. Giustificazioni di Tesoreria, 15, fasc. 6; Lanciani, Storia degli scavi di Roma, IV, S. 55; Tosini 2008, S. 538; Zollikofer 2016, S. 310. Zu den beiden Altarbildern vgl. neben Baglione, Vite, II, S. 409 auch Borghini, Il Riposo, S. 577, der anmerkt, dass sich die beiden Altarbilder noch im Ausarbeitungsstadium in Muzianos Atelier befänden. Valentino, Saccelli Gregoriani Descriptio, S. 12-13, 15 erwähnt ebenfalls den vorgesehenen Bilderschmuck der beiden Nebenaltäre in folgender rhetorischer Formulierung: [...] in concha proponitur picta tabula insignis magnitudinis apud D. Hieronimum in eremo Anachoretarum habitum conventum referens, illumque e loco superiore disserentem de Christo in crucem acto, quem sinistra complectitur [...] Arae quae hoc loco sita est, concha tabulam habet pictam insignis magnitudinis, quae D. Basilium proponit sacrum facientem [...].
} 
Während sich das erste kolossale Leinwandbild Muzianos noch in Santa Maria degli Angeli befindet, wohin es wahrscheinlich 1733 gebracht wurde, gilt das Altarbild der Messefeier als verschollen. Jacques Callot fertigte von den beiden Bildern aber kleinformatige Stiche an, welche eine Deutung des zweiten Leinwandbildes erlauben. ${ }^{890}$ Obwohl jüngst davon ausgegangen wurde, dass Muziano sich für das Altarbild der Predigt des Heiligen Hieronymus auf keine visuellen Vorlagen stützte, scheint eine bislang nur wenig berücksichtigte Serie von Vorstudien Muzianos aus den Uffizi darauf hinzuweisen, dass die Dekoration der Nebenaltäre auf die für einen Eckzwickel vorgesehene, aber unausgeführt gebliebene Bildkonzeption zurückzuführen ist. Anstelle der sitzenden Figur des Kirchenvaters im Pendentif neben der Figur Gregors d. Gr. sah Muziano ursprünglich die Darstellung eines Streitgesprächs unter Kirchengelehrten vor. Die Bildkonzeption dieser Szene scheint aber aufgrund der einzelnen Figuren in den Eckzwickeln fallengelassen worden zu sein. Die Vorstudien aus den Uffizi enthalten ein Blatt Muzianos, welches die vorgesehene Gesamtdarstellung des Streitgesprächs präsentiert. Vier Figuren umgeben die zentrale Gestalt eines Kirchenlehrers, der sehr wahrscheinlich den heiligen Hieronymus dargestellt haben muss (Abb. 49g). Muziano übertrug diesen Bildaufbau auf das Leinwandbild für den Hieronymus-Altar und stellte den Kirchenvater vor versammelten Zuhörern predigend dar. Die Gruppe lässt sich anhand der Kleidung einzelner Figuren als eine Schar von Mönchen ausmachen. In seiner Bildlösung für das Altarbild der Predigt verbindet Muziano den lehrenden Kirchenvater mit der im landschaftlichen Hintergrund eingefügten Architektur einer Einsiedelei mit Kapelle. Muzianos Bildlösung ist nicht zwangsläufig als Referenz auf Hieronymus’ Aufenthalt in einer Gemeinschaft von Anachoreten in der syrischen Wüste zu deuten, wie dies jüngst vorgeschlagen wurde. ${ }^{891}$ Vielmehr geht Muzianos Altarbild mit der im bereits 1584 gedruckten Martyrologium Romanum aufgeführten Stelle zum Todestag

890 Zollikofer 2016, S. 61, 63-64; Tosini 2008, S. 228-229, 470-471. Ein Visitationsbericht vom 19. Mai 1624 teilt jedoch mit, dass das Bild der Messefeier noch nicht geweiht gewesen sei, wohingegen der Hieronymus-Altar schon in Gebrauch gestanden habe, ohne mit Messestiftungen verbunden zu sein: A sinistro latere in ingressu sacelli est altare sub invocatione Sancti Hieronymi decenter instructum suppellectilibus necessarijs refertum, quod nullum habet onus annexum. [...] $\mathrm{Ab}$ altero latere e regione est altare sub Invocatione Sancti Basilij, quod non est consecratum, habet tamen Altare portatile. Zit. n. ASV, Congr. Visita Ap., 2, f. 54r; auch zit. in Rice 1997, S. 289. Luigi Vanvitelli stellte 1727 eine Kopie her, da das auf Leinwand aufgetragene Altarbild stark beschädigt war, woraufhin 1740 Pierre-Hubert Subleyras von Papst Benedikt XIV. den Auftrag erhielt, Entwürfe für ein neues Altarbild desselben Sujets auszuführen, welches 1748 fertiggestellt wurde und als Vorlage für das in Mosaik ausgeführte Altarbild in Santa Maria degli Angeli angebracht wurde. Vgl. hierzu Savettieri 2000, S. 670-671.

891 Zollikofer 2016, S. 62. Zur Episode vom Aufenthalt Hieronymus' in dem fünfzig Kilometer östlich von Antiochia, am Rande der Wüste gelegenen Dorf Maronia vgl. TRE, Bd. 15, S. 304. Für die zeichnerischen Studien vgl. zudem Tosini 2008, S. 231-232, 433-435; Ostrow 2000, S. 666-667; Marciari 2000, S. 423-459. 
des Kirchenvaters, die Hieronymus als Vorbild des Mönchtums charakterisiert, einher. ${ }^{892}$ Diese Betonung der Vorbildhaftigkeit des Kirchenvaters Hieronymus für das Eremitentum hebt den lateinischen Heiligen im Bildprogramm der Altäre der Gregoriana als Wüstenvater und damit als Vater des Busssakraments schlechthin hervor. Für die Bildkonzeption seines Altarbildes griff Muziano auf seine zwischen 1573 und 1575 in Zusammenarbeit mit dem Kupferstecher Cornelis Cort geschaffene Stichserie heiliger Bussväter zurück. In dieser Serie liegt ein Stich des Kirchenvaters Hieronymus vor, auf dem - gleich wie im Altarbild für die Gregoriana - der Heilige vor dem Hintergrund einer landschaftlichen Szenerie das Kruzifix anbetend dargestellt wird. Muziano muss sich für diese Stichserie auf die Vorbildhaftigkeit venezianischer Landschaftsmalerei und ihre funktionellen Eingliederungsmöglichkeiten für Figuren in eine bildnarrative Szene gestützt haben. Dieser bildrhetorische Kunstgriff Muzianos wird in der Gregoriana nun gezielt auch für die kurienzeremoniellen Vorschriften zur Liturgik eingesetzt. ${ }^{893}$ Die landschaftliche Einsiedelei, vor der sich die Figurengruppe um den Kirchenvater versammelt, bezieht sich auf den in der Legenda Aurea aufgenommenen Brief des Hieronymus an Eustochium, in welchem der Kirchenvater seine „grosse Einsamkeit“ in der Wüste mit Rom gleichsetzt: „Da ich in der Wüste war, in der grossen Einsamkeit, welche den Mönchen eine fürchterliche Wohnung ist, von den Strahlen der Sonne ausgebrannt, da dünkte mir, ich wäre zu Rom in aller Lust und Freude“. ${ }^{894}$ Muzianos Predigt des Heiligen Hieronymus griff somit in ihrer Bildsprache die sich ab dem Jubeljahr $1575 \mathrm{zu}$ einer neuen Heilslandschaft verwandelnde Stadttopographie Roms auf. Das Dekorationssystem der Cappella Gregoriana bot daher einen geeigneten zeremoniellen Rahmen, worin dieser Wandel auch liturgisch in einer Ritualsprache formuliert werden konnte.

Die beiden Nebenaltäre der Gregoriana ergänzen liturgisch den dem Gregor v. Nazianz und der Muttergottes geweihten Hauptaltar. Während mit dem Hieronymus-Altar auf die Sakramentsverwaltung der Busse hingewiesen wird, stand der Ba-

892 Mart. Rom. (MLCT, 6), S. 334: [...] probatorum monachorum imitator factus [...]. Das Martyrologium hatte für den lateinischen Kirchenvater auch als Feier den 9. Mai im liturgischen Kalender vorgesehen, der mit dem Geburtstag Gregors v. Nazianz zusammenfiel und an welchem Hieronymus' Gebeine aus Jerusalem nach Rom in die Kirche von Santa Maria Maggiore überführt wurden. An dieser Stelle ist auch der Eingang folgender Worte Baronios zu erwähnen, die er dem heiligen Gregor v. Nazianz widmete: in ibid., S. 166: „Nazianzeni natalis beati Gregorij episcopi, ob singularem divinarum rerum doctrinam cognomento Theologi: qui collapsam Constantinopoli catholicam fiem restituit, haeresq. insurgentes compressit“. Dies bestätigt die vorhin vorgeschlagene Datierung der Vita S. Gregorii Nazianzeni auf das Jahr 1583.

893 Corts Stichserie stellte diesbezüglich eine entscheidende bildkompositorische Verbindung zwischen Muzianos Stichen aus Breara und Tizians Hieronymus im Escorial her. Eine Reproduktion von Tizians Gemälde als Kupferstich war innerhalb von Corts eigener Sammlung venezianischer Stiche wiederzufinden. Vgl. hierzu Baglione, Vite, I, S. 51; Kat. London 2003, Nr. 40; Tosini 1996, S. 206; eadem 2008, S. 262-263.

894 Zit. n. Legenda Aurea, S. 582. 


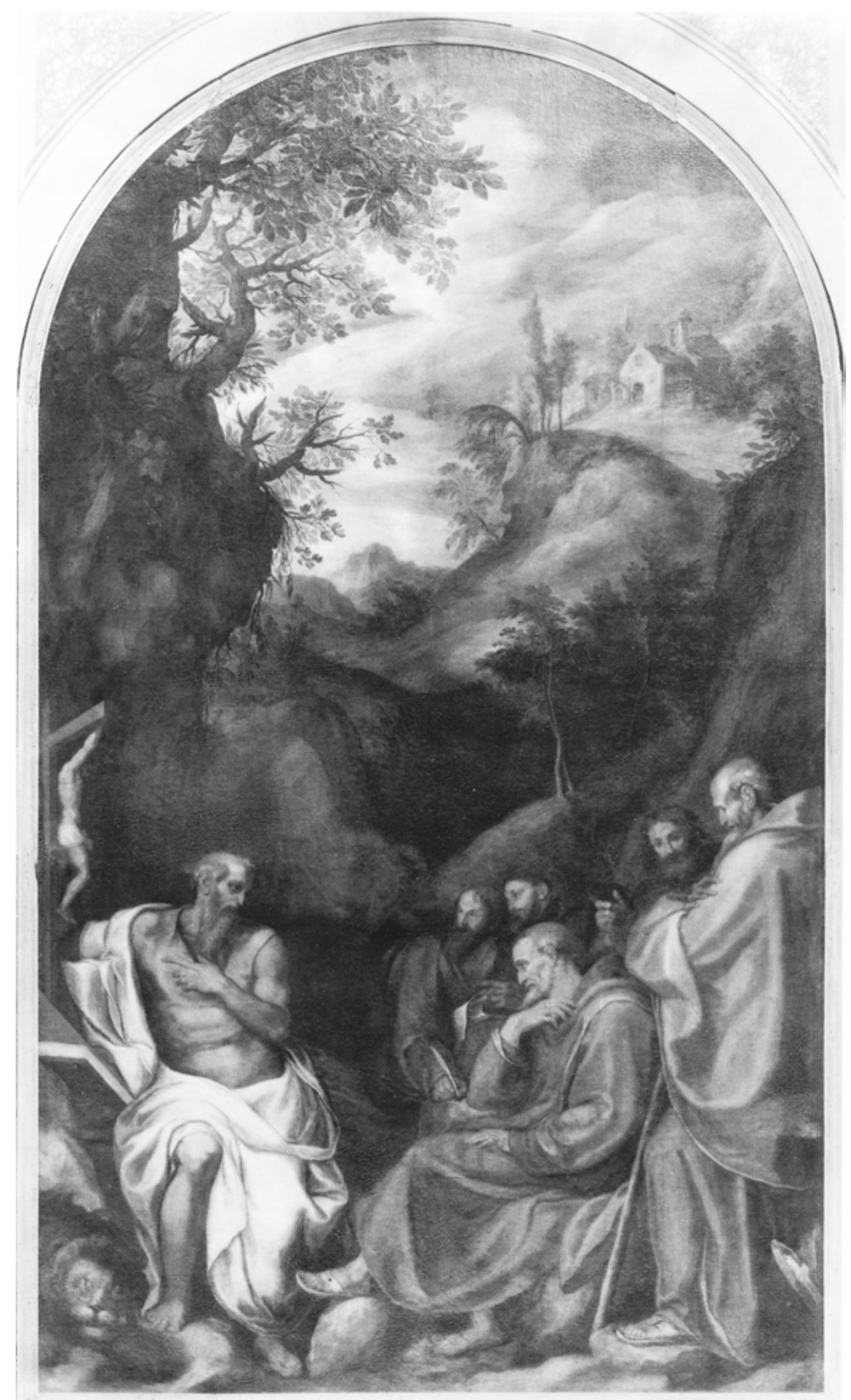

Abb. 46e: Girolamo Muziano und Cesare Nebbia, Die Predigt des Heiligen Hieronymus, Öl auf Leinwand, ca. 1582-1593, 550 x 400 cm, Santa Maria degli Angeli, Rom. 
sileios-Altar mit seinem Altarbild der Messefeier für die Suprematie des Sakraments des eucharistischen Kreuzes- und Messopfers. Girolamo Muzianos Predigt des Hieronymus vergegenwärtigt in ihrer szenischen Bildsprache das Busssakrament im rituellen Zeitintervall der Fastenzeit. In der Messefeier des Heiligen Basileios wird hingegen die Zelebration des der Eucharistie dargebotenen officium direkt mit den kurienzeremoniellen Bestimmungen für diesen Kapellenraum verknüpft. Das für diesen zweiten Nebenaltar der Gregoriana vorgesehene Leinwandbild Muzianos, zu welchem sich Studienzeichnungen des Malers aus Brescia erhalten haben, ist als eine Bildlösung zu verstehen, deren Grundlage die lange Rede Gregors v. Nazianz auf seinen Freund Basileios bildet und für deren Ikonographie sich Muziano scheinbar auf die bereits besprochene Gregorsmesse stützte. ${ }^{895}$ Im erwähnten Stich Callots wird ein Kirchenraum präsentiert, in dem der in Dreiviertel-Rückansicht dargestellte und von Zuhörern umgebene Basileios mit erhobenen Händen vor einem Altar, der sich in einer von Säulen eingerahmten Nische befindet, steht. Im Bildvordergrund neigt sich eine männliche Figur, die sich mit ihrem Gewand die Augen reibt, nach vorne. Der Totenrede Gregors v. Nazianz zufolge, die er auf den verstorbenen Basileios hielt, stellt diese Figur den römischen Kaiser Valens dar. Am Festtag der Epiphanie des Jahres 371 besuchte der Kaiser die von Basileios v. Caesarea gefeierte Messe, von dessen Charisma und der Feierlichkeit des Anlasses er tief berührt war. Als ein Kaiser, der dem Arianismus nahestand, wollte Valens seine Geschenke zum Altar bringen. Keiner der an der Messe teilnehmenden Gläubigen wusste, ob der Messzelebrant Basileios als rechtgläubiger Nizäer diese Gaben überhaupt annehmen würde, weshalb keiner dem Kaiser half, die Geschenke zum Altar zu bringen. Valens war daraufhin derart erschüttert, dass er zu taumeln begann. Hätte ihn keiner der an der Messefeier Teilnehmenden mit der Hand festgehalten, wäre der Kaiser hingefallen. Gregor v. Nazianz berichtet auch, dass diese Episode den Anfang einer Annäherung des Kaisers an die Nizäische Kirche bildete. ${ }^{896}$ Ob-

895 Die Oratio in laudem Basilii ist überliefert in D. Gregorii Nazianzeni opera omnia, I, S. 545-583. Als literarische Quelle des Altarbildes Muzianos wird sie von Savettieri 2000, S. 671; Marciari 2000, S. 454; Zollikofer 2016, S. 64 erwähnt. In Acta Sanctorum Junii VII, S. 875-876 wird sie entsprechend nicht als dreiundvierzigste, sondern als zwanzigste Rede aufgeführt. Eine edierte Fassung der Rede in italienischer Übersetzung liegt in Nazianz, Orazioni, S. 1031-1121 vor. Zu den Vorstudien Muzianos vgl. Tosini 2008, S. 228-229, 470-471.

896 D. Gregorii Nazianzeni opera omnia, I, S. 563: „Nam cum, universa satellitum manu stipatus, in templum ingressus fuisset (erat autem Epiphaniae dies, coetusq. amplissimus) ac laicorum numerum auxisse, ad hunc modum deunctorie cum eo se conunxit. Ac ne hoc quidem praetermittendum est. Postquam enim intus fuit, atque ipsius aures Psalmorum cantu, non secus ac tonitruo quodam personuerunt, plebisque pelagus vidit, omnemque ordinem \& concinnitatem, quae tam in sacrario, quam prope sacratium erat, angelicam potius quam humanam, atque ipsum quidem ante populum rector corpore stantem, qualem Scriptura Samuelem describit, nec corpore, nec oculis, nec animo, perinde ac si nihil novi contigisset, ullam in partem se meventem, sed Deo, ut ita dicam, \& altari affixum [...] Verum cum dona, quae ipsemet effecerat, divinae mensae offerenda 
wohl die Kirchenraumarchitektur in Callots Kupferstich nur summarisch dargestellt ist, weist sie starke Ähnlichkeiten mit den Ädikula-Altären der Cappella Gregoriana auf. Ähnlich wie in der Kapelle steht der Altar im Bild auf einem gestuften Podest in einer flachen Nische und grenzt sich, wie die übrigen Altäre in der Gregoriana, durch eine Balustrade vom Kirchenraum ab.

Das Altarbild der Messefeier bietet in Anbetracht der beiden Nebenaltäre der Gregoriana eine bildnarrative Erweiterung des liturgischen Kerns der Papstkapelle in der Petersbasilika, der sich auf eine angemessene Darbietung der Reliquien Gregors v. Nazianz konzentriert. Muzianos Basileios-Bild zeigt, wie der Hauptzelebrant mit Priestern die Messe feiert. Auf einer Tragebare im Bildhintergrund werden die Geschenke des Kaisers dargebracht. Die zahlreichen Zuhörer, die sich um den rituellen Vollzug entlang der Balustrade scharen, heben darüber hinaus die Bedeutung der Messefeier als eines von der Gemeinschaft der Gläubigen begangenen Anlasses hervor, der sich innerhalb eines Kirchengebäudes vollzieht. Aus der Bildkomposition geht allerdings nicht eindeutig hervor, ob der Heilige Basileios die Messe alla Greca, wie es Baglione in seiner Biographie Muzianos beschrieb, oder nach römischem Brauch feiert. ${ }^{897}$ Die von Muziano gewählte Bildsprache, die sich auf die im Boncompagni-Pontifikat einheitlichen Darstellungen der Gregorsmesse bezieht, worunter das von Jacopo Zucchis für den Kardinal Francesco de` Medici hergestellte Altarbild insbesondere zu nennen ist, scheint dennoch eine Messefeier nach römischem Ritus zu unterstützen. Zudem fiel 1582 der Festtag des Kirchenvaters Basileios mit dem des Fronleichnamsfestes zusammen, weshalb die kurienzeremoniellen Vorschriften von der Corpus Domini-Feier übernommen wurden. ${ }^{898}$ Das vorgesehene Altarbild für die Capella Gregoriana ist daher im Zusammenhang mit dem HieronymusAltar innerhalb der Altarhierarchie der Papstkapelle als liturgische Ergänzung zu dem der Verehrung der Reliquien Gregors v. Nazianz geweihten Hauptaltar zu be-

essent, nec quisquam, ut mos ferebat, simul ea caperet (quod non satis liqueret, an ea Basilius accepturus esset) tum verò manifeste se affectus prodidit. Ita enim titubare coepit, ut nisi quispiam ex sacrarij ministris vacillantem supposita manu retinuisset, misere utique \& luctuose prolapsurus fuerit“. Vgl. auch die etwas ungenaue italienische Übersetzung dieser Stelle in Nazianz, Orazioni, S. 1086-1087. Die Legenda Aurea, S. 110-111 weiss auch von der Begegnung zwischen dem Kaiser und dem Heiligen zu berichten, doch hat diese Erzählung mit der laudatio Gregors v. Nazianz nichts gemeinsam.

897 Baglione, Vite, Bd. 1, S. 51.

898 Dabei hielt der Zeremonienmeister Mucanzio in seinem Tagebuch insgesamt zwölf Missstände fest, welche sich bei der Prozessionsfeier nach der Messe ereigneten: in BAV, Chig.L.II.31, f. 810v811v. Die dadurch entstandene Verwirrung führte sogar dazu, dass sich der Papst in den Palazzo von San Marco zurückzog und dort „bis zum letzten Tag vor den Feierlichkeiten zu den beiden Apostelfürsten blieb“: „[...] et sic relinquunt Processionem in confusione cum possent multiores illi recurrere. Nota quod hoc Papa init habitum dum in Palatio s.ti Marci, quod nonnullis retro Annis intermiserat, et perultimo die ante festum SS.ti Petri et Pauli redijt ad Vaticanum [...]“.. Zit. n. ibid., f. $811 v$. 
trachten. Die Bedeutung des griechischen Kirchenlehrers Basileios wird nämlich über die Reliquienverehrung seines Freundes Gregor v. Nazianz geschaffen, die Baronio bereits in seiner Vita Gregorii Nazianzeni von 1583 vorwegnahm. ${ }^{899}$ Baronio hatte damit eine grundlegende Abhängigkeit griechischer Kirchenväter von ihren lateinischen Pendants im neuen Martyrologium Romanum einführen können. Allerdings schien diese Wechselwirkung nicht für die lateinischen Kirchenväter zuzutreffen. Sowohl im Martyrologium Romanum als auch in der Cappella Gregoriana wurden die lateinischen Kirchenväter - spezifisch Gregor d. Gr., Hieronymus und Ambrosius - eigenmächtig formuliert. Hatten die kurienzeremoniellen Schriften für die Cappella Gregoriana in der Petersbasilika anlässlich der Reliquienüberführung Gregors v. Nazianz eine Ökumene im rituellen Vollzug der Verehrung lateinischer und griechischer Kirchenväter betont, strebte sowohl die Kurie als auch der Oratorianer Cesare Baronio bei ihren Revisionsarbeiten am neuen Martyrologium Romanum nach einem angemessenen liturgischen Verständnis des Orbis Christianum, dessen Zentrum Rom und die mit der Stadt verbundenen Kirchenväter einnahmen. ${ }^{900}$

\subsection{Die Sakramentsverwaltung des römischen Messritus in der Liturgie der Civitas Subterranea}

[...] movetur urbs sedibus suis et inundans populus ante delubra semiruta currit ad martyrum tumulus. ${ }^{901}$

899 Baronio, Vita S. Greg. Naz., S. 309: „Ad cumulum afflictionum Gregorii accessit morbus, itemque amantissimi Basilii obitus [...] Quaeris quo statu res nostrae sint? Admodum acerbo, Basilium non habeo; Caesarium non habeo, fratrem meum secundum carnem \& spiritum: Pater meus \& Mater mea dereliquerunt me, ut cum Davide loquar: corpus adversa valetudine laborat, senectus capus premit, curae aliae aliis intexuntur; incursant negotia, infidi amici, Ecclesiae res pastore \& gubernatore carent, pereunt bona, nuda \& aperta sunt mala, navigatio in nocte, fax nusquam, Christus dormit. Quid faciam? Una mihi malorum depulsio mors. At res alterius vitae mihi formidolosae sunt, ex hujus vitae rebus conjecturam ducenti“. Vgl. dann entsprechend die Stelle in Mart. Rom. (MLCT, 6), S. 205-206: „Caesareae in Cappadocia ordinatio sancti Basilij episcopi, qui tempore Valentis Imperatoris doctrina \& sapientia insignis, omnibusq. virtutibus ornatus mirabiliter effulsit, \& Ecclesiam adversus Arianos \& Macedonianos mira constantia defendit“. Diese unterscheidet sich massgeblich von derjenigen Textversion in BVR, Q 29, c. 85 r.

900 Mit der am 1. November 1579 erlassenen Bulle Benedictus Dominus Deus führte der Boncompagni-Papst die Basilianer in Italien und Spanien auf einen einzigen Orden von Äbten zurück und setzte als deren Protektor Kardinal Guglielmo Sirleto ein. Diese Entwicklung sollte vor allem dazu führen, Missstände innerhalb dieser Kongregationen beseitigen zu können. Vgl. dann Bull. dipl. rom., VIII, S. 307-313, 310; BVR, L 23, f. 226r-229v. Auf Anregung des von Gregor XIII. einberufenen Collegio dei Greci wurde den griechischen Minderheiten Kalabriens gestattet, die Messe nach byzantinischem Ritus zu feiern. Vgl. diesbez. Peri 1972, S. 300-303; idem 1975, S. 78-81.

901 Hieronymus, Epistula 107 ad Laetam (Nr. 1), in: PL, Bd. 22, Sp. 868. 
Die Frage danach, wie die Kirchenväter in den kurienzeremoniellen Vorschriften zur Gestaltung der Sakramentsverwaltung in einem angemessenen Verhältnis zueinander darzustellen waren, forderte den Oratorianer Cesare Baronio heraus, das Martyrologium Romanum eindeutig getrennt von einer hagiographischen Behandlung der Heiligen und Märtyrer zu bearbeiten. Damit brachte es Baronio zustande, dass der Inhalt des neuen Martyrologium in dem vom Tridentiner Konzil vorgeschriebenen Rahmen liturgischer Bücher eingegliedert werden konnte. Dies bedeutete gleichzeitig, dass das Proprium Sanctorum auch kirchenhistoriographisch erfasst werden konnte, damit die Heiligenlektionen einen rechtmässigen Platz innerhalb der sakramentalen Verwaltungspraxis der Kurie zugewiesen bekamen. Baronio scheint für den Boncompagni-Papst eine besonders vermittlungsfähige Figur in Bezug auf die Überführung des römischen Ritus in die anderen Diözesen Italiens gewesen zu sein. Am 20. Januar 1583 sandte ihn Gregor XIII. nach Neapel, um die dortigen Missstände bei der Messefeier der Theatiner zu beobachten und zu korrigieren. Diese Mission Baronios nach Neapel lässt sich allein aus einem bislang undatierten Briefschreiben an den Vater Camillo rekonstruieren, das Baronio aber erst nach seiner Rückkehr nach Rom verfasste. ${ }^{902}$ Baronios Einwirkung auf die Theatiner in Neapel muss auf der Grundlage seiner Auseinandersetzung mit der Frage, wie im Breviarium Romanum enthaltene Märtyrer- und Heiligenfesttage entsprechend der Sakramentsverwaltung liturgisch zu gestalten waren, stattgefunden haben. Mit Wiederauffindung der frühchristlichen Gräber nach 1578 und deren archäologischer Relevanz für den kurienzeremoniellen Wandel des römischen Stadtraumes in eine Heilslandschaft sollten durch den neuen Martyrologium die Grundlagen eines angemessenen rituellen Vollzugs des Proprium Sanctorum geschaffen werden. Damit begann die Kurie, den Stadtraum an die im Martyrologium Romanum enthaltenen Bestimmungen, die in dem für Reliquienüberführungen gestalteten Kurienzeremoniell zum Vorschein kamen, anzupassen. Dieser Prozess der Anpassung von Stadtraum und römischer Liturgik sollte erst im Nachfolgepontifikat Sixtus' V. Peretti zu Ende geführt werden. Nichtsdestotrotz wurden im Boncompagni-Pontifikat die fundamentalen Bedingungen, die einen solchen Abschluss ermöglichen sollten, festgelegt. Am

902 BVR, Q 46, f. 49v: „Tornai da Napoli l'ultimo di carnevale sano, e salvo, per gratia del Signore. Non vi scrissi da che era mandato, ne a che fare principalmente: perche questo importava la secretezza del fatto. Hora che la cosa è divulgata la potete saper ancor voi: cio è ch'io sono stato mandato da Sua Santità motu proprio, per un negotio segreto, quale non sà persona alcuna; ne mi è lecito palesarlo. Me ne andai, e mena meco Mess. Giov. Paulo nostro [...] et habbiamo fatto questo viaggio felicemente. Siamo stati in Napoli 22 giorni accarezzati dal Arcivescovo, dal Nuntio, et altri Signori in gran maniera. Tornato da Napoli andai a basciar gli piedi a Sua Santità; e dar relatione di quanto da me si era fatto [...].“ Vgl. auch BVR, Q 63, f. 295r: Anno Domini 158320 Januarij Neapolim a S. D. N. missus sum: viginti illic mansi dies apud Clericos Regulares in ecclesia S. Pauli: inde Romam reversus sum 20 Februarij. Calenzio, Vita, S. 193-194 und Pullapilly 1975, S. $43-44$ beachteten dieses Briefschreiben allein im Zusammenhang mit der Gründung der Oratorianerfiliale in Neapel. 
28. Juni 1578 berichtete der in Rom anwesende Botschafter Antonio Tiepolo dem venezianischen Senat über diese wundersame Auffindung des Cimiterio di Santa Presilla:

Da quelli, che cavano una certa terra, per fabricare, che si chiama pozzolana, è stato trovato il Cimiterio di Santa Presilla, luogo smarito sino al tempo dell'indondatione de Gotti per le rovine, che fecero, non pure in quella parte, ma per tutta Roma, et Italia. Et in questo Cimiterio, nel quale s'entra con gran fatica, et vi bisognano le torze, vi si veggono molte sepolture de santi con le loro inscrittioni di diverse lingue. Et l'altr'hieri di ordine di Sua Santità vi fù l'Ill, mo Cardinale Savello, concorrendovi molta gente, per vedere una antichità, che e forsi la maggiore, che habbino, per quello, che appartiene alla santa Religione, li Christiani. ${ }^{903}$

Die frühchristlichen Gräber begann demgemäss schon ab diesem Zeitpunkt eine Anziehungskraft auf die zahlreichen Rombesucher auszuüben und liessen damit den Stadtraum selbst in einem neuen Licht erstrahlen. Die unterirdischen Ruhestätten kehrten die liturgische Andachtspraxis sowohl der römischen Stadtgesellschaft als auch der Kurie, die sich während des anno santo von 1575 noch auf einer vom Kurienzeremoniell eingerichteten Theaterbühne vollzogen hatte, schlagartig in eine innere und verborgene Form der Verehrung um. Diese den coemeteria innewohnende Verborgenheit galt es nun mit Hilfe einer Liturgik, die den kurienzeremoniellen Richtlinien entsprach, wieder an die Oberfläche der städtischen Heilstopographie zu führen. Die im Juni 1580 stattgefundene Reliquienüberführung der Gebeine des heiligen Gregor v. Nazianz konnte diesbezüglich als geeignete Grundlage verwendet werden. Zusätzlich mussten im Zusammenhang mit dem Wandel der Märtyrern und Heiligen dargebotenen römischen Frömmigkeitsverehrung die beiden Apostelfürsten im Zentrum dieser kurienzeremoniellen Gestaltungsprinzipien der römischen Liturgik stehen. Erst dadurch liess sich Rom als Nabel und Haupt des orbi Christianus präsentieren, wie es auch in der Galleria delle Carte Geografiche in einer Romdarstellung mit folgender Überschrift festgehalten wurde: Roma per sacram B. Petri sedem caput orbis effecta (Abb. 47). Während aber der Bildtitulus nur Petrus als Stifter Roms als Zentrum des christlichen Erdkreises bezeichnet, wurde im neuen Martyrologium Romanum auch der Apostelfürst Paulus dazugezählt. Beide Apostel hatten während Neros Kaiserherrschaft das Martyrium erlitten und wurden in Rom begraben. ${ }^{904}$ In Cesare Baronios Annotation zum liturgischen Festtag der beiden Apostelfürsten in der 1586 gedruckten Edition des Martyrologium wird auf die bezüglich dieses Festes vorgeschriebenen kurienze-

903 Zit. n. Herklotz 2012, S. 426.

904 Mart. Rom. (MLCT, 6), S. 222: „Romae natalis sanctorum Apostolorum Petri \& Pauli, qui eodem anno, eodemq. die passi sunt sub Nerone Imperatore: quorum prior in eadem urbe capite ad terram verso cruci affixus, \& in Vaticano iuxta viam triumphalem sepultus, totius orbis veneratione celebratur: alter vero gladio animadversus, \& via Ostiensi sepultus, pari habetur honore“. Das Breviarium pianum von 1568 hatte diesen Festtag als liturgisch universelle Feier anerkannt: Brev. Rom. (MLCT, 3), S. 797-806. 
remoniellen Richtlinien und deren liturgisches officium verwiesen. Das Kurienzeremoniell zum Festtag der beiden Apostelfürsten hatte Rom nämlich erst zu einer „räumlichen Koordinate“ innerhalb des sich auf dem christlichen Erdkreis ausbreitenden Heilsgeschehens erklärt. Dieser Raumparameter gehört zu den bereits erwähnten „hagiographischen Koordinaten“ des neuen Martyrologium Romanum. Die Bedeutung der räumlichen Wahrnehmung Roms, die mit der Märtyrer- und Heiligenverehrung einherging, hat Cesare Baronio im zweiten Band seiner Annales Ecclesiastici, der zwei Jahre nach der Drucklegung des ersten wieder von der Tipografia Vaticana herausgegeben wurde, festgehalten. Den Annales zufolge lässt sich anhand des römischen Stadtraumes ein besonderes Verhältnis zwischen den Gräbern intra muros und solchen, die ausserhalb der Stadtmauern liegen, ablesen. Damit zeigt Baronio in seinen Annales, wie sich eine Kirchengeschichte, welche die Überführung einer frühchristlichen Begräbnisliturgie in den von der Aurelianischen Mauer begrenzten Stadtkreis behandelte, schreiben liess. Eine solche Kirchengeschichte musste vornehmlich die Bedeutung einzelner Märtyrergräber stets in Bezug auf die Gräber der beiden Apostelfürsten Petrus und Paulus demonstrieren. ${ }^{905}$ Die Grundlagen für eine solche kirchenhistorische Rekonstruktion der coemeteria Roms hatte Baronio während seinen Revisionsarbeiten am Martyrologium Romanum ausgearbeitet. Dort werden die Märtyrer- und Heiligengräber nicht als Orte, an denen selbst ein ritueller Vollzug der liturgischen Märtyrer- und Heiligenverehrung stattfindet, behandelt. Die Ruhestätten werden bewusst in ihrem Spannungsverhältnis zur urbanen Konstellation der Kirchen Roms, die als Räume einer solchen liturgischen Verehrung angesehen werden, erläutert. ${ }^{906}$

905 Mit den Gräbern frühchristlicher Heiliger intra muros leitete Baronio den wohl entscheidenden Punkt des zweiten Bandes in Ann. Ecc., II, S. 326-327 ein: „Praeter coemeteria duo Callisti, \& Calepodij, quorum hic mentio est, illud fuit cum primis nobilissimum positum in Vaticano, in quo S. Petri \& aliorum plurimum summorum Pontificum corpora condita sunt: aliud Ostrianum Via Salaria, in quo idem S. Petrus dicitur baptizasse [...] Via Ostiensi in loco ubi nunc est basilica S. Pauli [...] Qualia autem esse solerent eiusmodi coemeteria alia occasione supra meminimus, descripsimusq. Paucis quod inspeximus coemetrium Priscillae positum Via Salaria quale \& esse reperimus nuper coemeterium Callisti. [...] Dum essem Romae puer, \& liberalibus studijs eruditer, solebam cum ceteris eiusdem aetatis \& propositi diebus Dominicis sepulchra Apostolorum \& martyrum circumire [...]“. Baronio hatte die vorhin erwähnten Besuche frühchristlicher Katakomben mit den Klageworten des Propheten David über die falschen Brüder (Ps 55, 16) verglichen: in ibid., S. 327: Descendant in infernum viventes, \& raro desuper lumen admissum horrorem temperet tenebrarum, ut non tam fenestram, quam foramen dimissi luminis putes [...]. Baronio legte hier auch eine Aufzählung von insgesamt 43 Gräbern vor, die weitestgehend derjenigen in Panvinio, De ritu sepelliendi, S. 18-22 entspricht. Hinzu zählte der Oratorianer aber noch diejenigen Ruhestätten, welche die mittelalterlichen Mirabilia Urbis Romae aufführten. Zu dieser Liste der coemeteria aus der Mirabilienliteratur vgl. Valentini/Zucchatti 1940-53, Bd. 3, S. 26-28, 84-85. Hinsichtlich Panvinios Aufzählung vgl. dann Ferretto 1942, S. 93-97.

906 Mart. Rom. (1586), S. 10, n. e: „Erant Romae complura Coemeteria, quarum tantum quadraginta ex tabulis vaticanis descripsi [...] Erant coemeteria omnia, vel areae extra civitatem posita: vi- 
Cesare Baronio konnte damit die von der Kurie seit dem anno santo offen gelassene Frage, wie der Orbis Christianus in Einklang mit dem Verhältnis zwischen coemetria und den Kirchen Roms zu bringen war, angemessen beantworten. Die kurienzeremoniellen Bestimmungen zu den Reliquientranslationen boten sich als eine geeignete Lösung der Frage an, wie der Abstand dieser beiden Grenzorte im Stadtraum liturgisch zu überwinden sei. Die im Zeremoniell solcher translationes formulierten rituellen Vorkehrungen spiegelten sich in den Verkehrsachsen innerhalb der urbanen Stadttopographie. Die Infrastruktur des Stadtraumes wurde als Fläche zur Abbildung des sich in den Heiligen- und Märtyrerreliquien enthaltene Heilsversprechens genutzt. Dadurch wurde ein kulturelles Programm entworfen und realisiert, in welchem die verborgenen coemeteria in die sichtbare Kirchenarchitektur überführt wurden. In seinen adnotationes zu der 1586 erschienenen Fassung des Martyrologium Romanum stellte Baronio nämlich diese translationes als ein deskriptives Instrumentarium der römischen Heiligen- und Märtyrerverehrung dar. Diese spezifisch auf den Stadtraum Roms abgeglichene Verehrungspraxis im Martyrologium berücksichtigte die topographischen Bedingungen der Stadt gemäss einer Sakraltopographie. Eine solche Konfiguration der urbanen Heilslandschaft wurde in dem anlässlich der Reliquienüberführung vom 15. September 1583 gestalteten Kurienzeremoniell erreicht. Die Prozessionsfeier, bei welcher die beiden Heiligen Abundius und Abundantius von SS. Cosma e Damiano in die Kirche des Gesù übertragen wurden, stellte der Zeremonienmeister Francesco Mucanzio in seinem Tagebuch als eine das Orbis Christianum umfassende Überführung dar, die auch Baronio in seinen Anmerkungen zum Festtag der beiden Heiligen im

gentibus etenim Gentilium legibus, ex leg. XII tabularum, nefas erat intra moenia mortuum sepelire“. Vgl. diesbez. neben der begrifflichen Fassung von coemeteria als dormitoria auch die Erwähnung von Reliquienüberführungen in Mart. Rom. (1586), S. 10, n. $e$ : „Vox notissima, Coemeterium, qua Christiani illum locum dicere consueverunt, in quem fidelium defunctorum corpora sepelienda inferuntur; inde deducto vocabulo, quod sicut divina scriptura obitum iustorum, somnum dicere solita est, eadem significatione locum illum ubi sepelientur, Coemeterium, hoc est dormitorium [...] quod est dromio, voluit appellari. Quae etiam loca, modo Concilia sanctorum, de qua voce agemus inferius, modo etiam a natura loci denominatione deducta, Arenaria, Cryptae, Catacumbae seu Catacumbae in veteribus Martyrologiis appellata inveniuntur. [...] Ex Coemeterio Callisti de quo agimus, effosum corpus s. Anterii papae translatum est intra Urbem in ecclesiam S. Silvestri in Campo Martio, ubi in lapidea tabula eiusmodi vetus inscriptio legentur [...]“. Vgl. auch die entsprechende Stelle in Baronio, Ann. Ecc., II, S. 328: „Cessarunt autem fidelium studia in coemeterijs adeundis postquam ea quae ibi fitaerant corpora sanctorum martyrum intra Urbem sunt delata, \& in diversis Ecclesijs honorificentius collocata. Sed \& accidit ut sicut maiorum consuetudine etsi non in ijsdem sepulchris, in eisdem tamen coemeterijs sepeliebantur aliorum quoque corpora Christianorum: translatis iam sub Christianis Imperatoribus sanctorum martyrum reliquijs in Ecclesias intra civitates positas, in eisdem etiam aliorum fidelium corpora coepta sint sepeliri [...]. Eodem quoque consilio sanctus Ambrosius prope sanctos martyres voluit sepeliri: sed de his pluribus Augustinus; atque haec satis. Vacavit sedes post obitum Callisti diebus sex, sicq. vigesimaprima die Octobris substituitur ei Urbanus Romanus, natus patre Pontiano“. 
Martyrologium Romanum erwähnte. ${ }^{907}$ Die Reliquien wurden in einer Krypta unterhalb des Hauptaltars des Gesù gelegt, um sie dadurch in eine besondere Wechselwirkung mit dem liturgischen Mysterium des Namens Jesu und dem Andenken der Beschneidung Christi, denen der Hauptaltar der Jesuitenkirche geweiht war, zu bringen. Im Gegensatz zu der im Juni 1580 stattgefundenen Reliquienübertragung der Gebeine des Heiligen Gregor v. Nazianz wurde die Translation vom 15. September 1583 nicht als Gelegenheit für ein Zeremoniell der Kirchenweihe des Gesù genutzt. Die Kirche sollte nämlich erst am 25. November des darauffolgenden Jahres - am Festtag der Heiligen und Märtyrerin Katherina von Alexandrien - geweiht werden. ${ }^{908}$

907 Mart. Rom., S. 420, n. e: „Temporibus Diocletiani .\&c. eadem verò ex tribus alijs antiquis exemplaribus recognita, emendata, auctaq. nobili historia eorundem sacrorum corporum translationis tertio factae, notationibusq. illustrata modò edidit Romae Collegium Patrum Societati Iesu, in quorum basilicam Farnesiam religiosissima \& magnificentissima pompa ex Diaconia sanctorum Cosmae \& Damiani translata sunt xvij. Octobris, anno Domini 1584. Pontificatus Gregorij Papae xiij. an. duodecimo. [...] condita sunt in cathedrali ecclesia sub primario altari, prout ex veteribus eiusdem ecclesiae monmentis didicimus“. Gemäss den Einträgen im Tagebuch des Zeremonienmeisters Mucanzio hatte sich diese Reliquienüberführung vom 15. September 1583 einerseits an derjenigen Gregors v. Nazianz angelehnt, wobei sie andererseits bewusst als Begräbnisprozession vollzogen wurde. Die Reliquienüberführung nutzte Mucanzio als Gelegenheit, die Jesuitenkirche als opera totius Orbis Gymnasium zu würdigen, in BAV, Chig.L.II.31, f. 869r-871r, hier f. 870r-v: „[...] apud novam fabricam eiusdem Collegij Societatis Jesu apud Arcum Septimianum, quae Auri immensas sumpsu, et mino opera construitur liberalitate, et pietate ss.mi D. N. Greg. XIII ad hoc, ut ibi fiat universale totius Orbis Gymnasium, in quo disciplinae, et bonae Artes, praecipue sacra Theologia ab ipsius Collegij Religionis Confratribus quoviis totius orbis idiomate, et lingua explicentur, atq. interpretarent. Ex quo Deo dante maximum Christianae Religioni fructum, qugumentumq. accessum esse speramus cum ipsius Collegij, et Societati Viri iam per Universum orbem Vortutis eorum radius expanderint, et nulla ut in parte sive orientalis, sive occidentalis plaque Indiam, et novi orbis ipsius mores, doctrina pietas, Religio, et Instituta celebrent. Ingresso in Ecclesiam fecetuo eo fuit [...] ut vere factae Celestis Variae fores, et Paradisi Ianuae viderentur“. Schraven 2014, S. 167 meinte hingegen, dass die Reliquienüberführung auf ein von Carlo Borromeo entwickeltes Modell innerhalb seiner Mailänder Diözese zurückzuführen sei. Vgl. hierzu auch Sannazzaro 1986, S. 299340; Himmelheber 1984, S. 19-21. Ein zentraler Unterschied zwischen der römischen und ambrosianischen Zeremonialkultur im Zusammenhang mit der Reliquienverehrung bestand darin, dass im römischen Kurienzeremoniell Reliquien bewusst als corpora betrachtet wurden. In der ambrosianischen Auslegung Borromeos wurden Reliquien aber stets als trophaeae gewürdigt: Himmelheber 1984, S. 213. Zur Überführung der Reliquien in die Kirche des Gesù vgl. zudem auch Cardulo, Sanctorum Martyrum, S. 37-48, 38-40; Ciappi, Compendio, S. 16.

908 BAV, Chig.L.II.31, f. 935v-938v. Der Zeremonienmeister Mucanzio hielt dabei fest, dass die Einweihung des Gesù gemäss dem pontifikalen Einweihungsritus verlief und neben der Weihe des Hauptaltars auch die Altäre der Kapellen im Langhaus eingeweiht wurden. Hierbei ergab sich eine spezifische Konstellation der Altäre im rechten Langhausarm gegenüber denjenigen im linken: Während erstere Märtyrern geweiht waren, wurden die Altäre der Kapellen des linken Langhausarmes der Trinität, der Geburt Christi sowie schliesslich den beiden Apostelfürsten Petrus und Paulus konsekriert. Damit verfügten die überführten Reliquien in die Krypta unterhalb des Hauptaltars über eine besondere Nähe zu den Apostelfürsten Roms. Am 28. Oktober 1584 weihte der Boncompagni-Papst selber das Collegio Romano ein, wodurch die besondere Wechselwirkung zwischen Aus- 
Das anlässlich der Reliquienüberführung vom 15. September 1583 aufgeführte Kurienzeremoniell hatte damit mit Hilfe der Strategie der Jesuiten gegenüber der Reliquienkultur Roms eine Übertragungsdynamik der verborgenen Märtyrerwelt aus der civitas subterranea in die sichtbare Form der römischen Sakraltopographie geschaffen. Dadurch ergab sich eine spezifisch sakramentale Übereinstimmung der neu aufgefundenen frühristlichen Gräbern mit dem römischen Sakralbautypus. Die Kirchenweihe des Gesù stand am Ende einer sich innerhalb des Jesuitenordens selbst vollzogenen Entwicklung der Kirchenraumarchitektur, in der die Nationalkollegien mit den Kirchengebäuden der Jesuiten zu einer institutionellen Einheit zusammengeführt wurden. Zwei dieser Nationalkollegien Roms - das Collegio Germanico und das Collegio Inglese von San Tommaso di Canterburry - wurden vom Boncompagni-Papst ab 1580 zusätzlich der Leitung des Jesuitenordens anvertraut, nachdem das Collegio Germanico mit dem Collegio Ungarico verbunden wurde. Der damalige Rektor dieses Kollegs, Michele Lauretano, liess die Aussenwand des Ambulatoriums des mit dem Kolleg verbundenen Kirchenbaus von Santo Stefano Rotondo mit einem insgesamt 31 Märtyrerfresken umfassenden Zyklus ausstatten. ${ }^{909}$ Die Forschung hat sich im Zusammenhang mit der Ausmalung des Ambulatoriums bislang ausschliesslich der Frage gewidmet, wie ein solch „blutrünstiger“ und „geschmackloser“ Freskenzyklus überhaupt zu einer „visuellen Ästhetik“ des Jesuitenordens beigetragen haben konnte. Dadurch blieb die Problematik in Bezug auf den Stellenwert, den die Kollegskirchen der Jesuiten im römischen Stadtraum im Zusammenhang mit dem rituellen Vollzug der römischen Liturgik einnahmen, weitgehend unberücksichtigt. ${ }^{910}$

bildungsstätte und Kirchenraum der Jesuiten verstärkt wurde. Vgl. hierzu neben dem avviso in BAV, Urb. lat. 1052, f. 452r auch Kat. Vaticano 1990, S. 170.

909 Bull. dipl. rom., VIII, S. 250-251. Zur Geschichte der beiden Kollegien vgl. Pastor 1893-1933, Bd. 9, S. 175-177; Steinhuber 1906, Bd. 1, S. 155-156; Schmidt 1984. Hinsichtlich der Ausschmückung der weiteren mit dem Collego Germanico-Ungarico assoziierten Kollegskirchen von Santa Saba und Sant' Apollinare vgl. insbes. Ciappi, Compendio, S. 26-27: „[...] havendo Sua Beatitudine di nuovo fatto congregare un Collegio della natione Vnara, le parue per degni rispetti unirlo al Collegio Germanico, \& perche erano molti di numero, concesse loro per habitatione, \& residenza il Palazzo, \& la Chiesa di S. Apollinare, \& anco una buona somma di denari per ristorare esso palazzo, \& chiesa, \& per sostètamento, \& vitto de' collegiati, unì à detto Collegio le Abbatie, le Chiese di Santo Sauo, \& San Stefano Rotondo, le quali furono da i Rettori similmente con la mano adiutrice del Prencipe ristorate, \& quella di San Stefano in particolare (richiedendo il Santo titolare, \& anco la forma della Chiesa fabricata in cerchio) fù fatta ornare tutta di nobili pitture con l'historie più celebri de' santi Martiri di Christo“. Zur Dekorationskampagne in Santo Stefano Rotondo vgl. Haskell 1971, S. 67; Röttgen 1975, S. 89-122; Vannugli 1983, S. 101-116; Nimmo 1985, S. 91-102; Salviucci Insolera 2000, S. 129-137; Monssen 1981, S. 130-137; idem 1982a, S. 10-12; idem 1982b, S. 175-317; idem 1983, S. 11-106; idem 2009, S. 305-366.

910 Für die Beschreibung der Märtyrer-Fresken in Santo Stefano Rotondo als ein Panorama von „horror and butchery“ vgl. neben Dickens, American Notes, S. 415 auch Sade, Oeuvres, VI S. 288-289. 
Während der Freskenzyklus in Santo Stefano Rotondo noch erhalten ist, wurden die Märtyrerszenen in San Apollinare und San Tommaso di Canterbury beim Abbruch der beiden Kirchen im 18. und 19. Jahrhundert zerstört. Glücklicherweise hatte der Kupferstecher Giovanni Battista de' Cavalieri 1584 in seiner gedruckten Stichserie der Ecclesiae anglicanae trophaea die Märtyrer-Fresken aus San Tommaso festgehalten. Auf der Grundlage dieser Stichserie lässt sich die ursprüngliche malerische Ausstattung dieses Kirchengebäudes rekonstruieren. Die Fresken aus San Apollinare wurden zwei Jahre später in die Stichserie Beati Apollinaris martyris primi ravennatum epi res gestae aufgenommen. ${ }^{911}$ Mit Ausnahme des Altarbilds in San Tommaso di Canterbury, für das Georg Gilbert, einer der grössten Förderer des Englischen Kollegs, Durante Alberti beauftragte, wurden die Märtyrerfresken vom Toskaner Niccolò Circignani, der auch die übrigen Kollegskirchen der Jesuiten ausmalte, ausgeführt. Die letzte Szene dieser 36 Fresken zeigte jedoch nicht ein Martyrium, sondern den Boncompagni-Papst vor dem Hauptaltar von San Tommaso kniend. Gregor XIII. bittet Christus darum, die sich um ihn scharenden englischen Kollegspriester bei ihrer Aufgabe, „,in England [für] die Verteidigung des Glaubens“ (in Angliam ad fidei defensionem) zu sorgen, zu bestärken, wie es auch in der Bildunterschrift festgehalten wird (Abb. 48). Aus den jährlich im Jesuitenorden eintreffenden Briefen, welche die Priester in England verfassten, kann festgestellt werden, dass die Märtyrer-Fresken 1583 fertiggestellt worden sind. Bailey schlug dabei die womöglich zutreffendste Chronologie ihrer malerischen Ausführung durch den Toskaner Niccolò Circignani, der im August 1582 nach Fertigstellung der Fresken in Santo Stefano Rotondo mit der Ausstattung von San Tommaso di Canterbury anfing, vor. ${ }^{912}$ Die Themenwahl für das letzte Fresko der Messe Gregors XIII. im Englischen Kolleg musste daher auf der Grundlage der im April 1579 erlassenen Papstbulle Quoniam divinae bonitati stattgefunden haben. Ein Jahr später und am Festtag des hei-

$\mathrm{Zu}$ den bisherigen, kunsthistorischen Forschungsarbeiten hinsichtlich der Auseinandersetzung um den Begriff eines „Jesuitenstils“ vgl. Freedberg 1971, S. 448-449; Buser 1976, S. 433; Paoletti/Radke 1997, S. 429; Wittkower 1982, S. 27; Bailey 2003, S. 122-126, 133-152; idem 1999-2006, S. 39; Kat. Chestnut Hill 1999, S. 151-178; Korrick 1999, S. 176-179; Levy 2004, S. 28-41; Wittkower/Jaffe 1972. Neuere Forschungsansätze, wie dieser Frage nach einem „Jesuitenstil“ entkommen werden kann, finden sich bei Behrmann 2014, S. 103-105; eadem 2015, S. 163-251.

911 Zu San Apollinare vgl. Santini 1937, S. 5; Mancini 1967, S. 8-11. Hinsichtlich der ursprünglichen Kirchenausstattung und -architektur vgl. Ugonio, Historia delle stationi di Roma, c. 285v-286r sowie Bailey 2004, S. 128-133.

912 Ann. Litt. Soc. Ies. Ann. MDLXXXIII, S. 22; Bailey 2003, S. 159; Baglione, Vite, I, S. 118; Ciappi, Compendio, S. 28; Richardson 2005, S. 256-257. Bailey unterteilte die Ausgestaltungskampagne in zwei Abschnitte. Die erste Kampagne umfasste noch nicht die englischen Jesuiten, die im England Elisabeths I. das Martyrium erlitten. Sie wurde nämlich kurz vor dem Oktober 1583 ausgeführt, dem Todestag George Gilberts, dem eigentlichen Auftraggeber der Fresken. Vgl. hierzu das Briefschreiben des damaligen Rektors des Kollegs, Alfonso Agazzari, an den Ordensgeneral Acquaviva vom Juni 1583, zit. in Bailey 2003, S. 324-325. 
ligen Thomas v. Canterbury gewährte der Boncompagni-Papst dem Englischen Kolleg einen Plenarablass. Im Tagebuch des Zeremonienmeisters Francesco Mucanzio findet sich aber kein Eintrag zur der in San Tommaso di Canterbury gefeierten Papstmesse, weshalb die Bezeichnung des letzten Freskos Circignanis als Messe Gregors XIII. irrig zu sein scheint. Dennoch lässt sich die Bildlösung als eine Darstellung eines spezifischen Moments in der sakramentalen Verwaltungspraxis, die der Boncompagni-Papst gegenüber den Kollegienpriestern ausführt, aufrechterhalten. In Baronios scholia zum Festtag des Kollegsheiligen im neuen und 1586 gedruckten Martyrologium Romanum findet sich nämlich die Aufforderung des Boncompagni-Papstes an die Jesuiten, den Glauben in England mit ihrem Leben und Blut zu verteidigen. Dieser Akt der Selbstaufopferung im Zeichen des Glaubens wird bewusst in einer sakramentalen Bedeutung gefasst: Diese Jesuitenmärtyrer reihen sich nämlich mit ihrem vergossenen Blut in eine Nachfolge des Kreuzes- und Messopfers Christi ein, wodurch ihr „Sakrament des Blutes“ folglich als eine aemulatio Dei verstanden werden kann. ${ }^{913}$ Diese Bedeutung des Martyriums wird nicht nur durch die Bildprogrammatik der Zyklen Circignanis in Santo Stefano Rotondo und in San Tommaso di Canterbury vermittelt, sondern floss bereits in die Bildlösung von Durante Albertis Altarbild der Trinität mit den beiden Heiligen Edmund und Thomas v. Canterbury ein, das $1581 \mathrm{im}$ Englischen Kolleg aufgestellt wurde. Der Kupferstecher Cavalieri übernahm Durantes Bildlösung im Frontispiz seiner 1584 gedruckten Ausgabe der Ecclesiae anglicanae trophaea. Während der Bilderzyklus in Santo Stefano Rotondo mit der Szene der Kreuzigung Christi beginnt und die Bildunterschrift - tu vincis in martyrium - den Märtyrertod als sakramentalen Triumph bezeichnet, hatte Alberti in seiner Darstellung der Trinität den traditionellen Bildtypus der pietà mit den zwei in Ehrfurcht vor dem toten Körper Jesu knienden Märtyrern verbunden. Dadurch gelang es Alberti, die zeitgenössischen englischen Jesuitenmärtyrer und ihre Frömmigkeitspraxis stärker als stetige Erneuerung und Wiederholung des Todes Christi am Kreuz zu inszenieren. ${ }^{914}$

913 Mart. Rom. (1586), S. 580-581, n. a: „Videre meruit saeculum nostrum hac ex parte Anglicanos ampliori quamplurimos Thomas, sanctissimos sacerdotes, aliosque nobilissimos viros Anglicanos ampliori (liceat dicere) martyrio coronatos, duplicisq. tituli coronis auctos; cum non solum (ut Thomas) pro ecclesiastica libertate, sed pro fide catholica tuenda. Restituenda, ac conservanda, nobilissimo martyrio occubuerint; ut inter alios, quos nuper S. Societatis Iesu velut agnos innoxios in sacris septis, sanctis eruditionibus ad martyrium, acceptissimas Deo hostias segnavit; quos Romanum, quos Rhemense sacra collegia, quae dixerim celsas turres a facie Aquilonis, et fortissima propugnacula fidei, emiserunt ad triumphos et provexerunt ad coronas. Macte animo, macte virtute, Anglicanora iuventus, que tam illustri militae nomen dedisti, ac sacramento sanguinem spopondisti: aemulor sane vos Dei aemulatione, cum vos martyrii candidatos, ac nobilissimae purpurae martyres designatos ascipio. Compellor et dicere: Moriatur anima mea morte iustorum, et fian novissima mea horum similia“. Vgl. auch den 1582 herausgegebenen Jahresbrief der Jesuiten in Ann. Litt. Soc. Ies. Ann. MDLXXXII, S. 19.

914 Die Bildunterschrift in Circignanis erstem Fresko für Santo Stefano Rotondo bezog sich damit eindeutig auf den Hymnus der liturgischen Commune in Brev. Rom. (MLCT, 3), S. 966. Dies haben 
In Bezug auf die Bedeutung und Lage des Gesù innerhalb der Sakraltopographie Roms dienten die einzelnen Jesuitenkollegien und deren Kirchen dazu, die verborgene civitas subterranea mittels des Kurienzeremoniells in den römischen Sakralbau zu überführen. Die liturgischen Wesenszüge dieser „unterirdischen Stadt“ und deren angemessene sakramentale Verwaltung trat schliesslich durch die Architektur des römischen Kirchenbaus visuell zum Vorschein. Die liturgische Andacht zu Ehren des Märtyrertodes, der als eine stetige Nachfolge des Kreuzes- und Messopfers Christi verstanden wurde, erfuhr in den Jesuitenkollegien eine zeremonielle Erweiterung des sakramentalen Heilsverständnisses des urbanen Raumes. Das Kurienzeremoniell zeichnete sich somit als eine liturgische Werkstatt aus, in die der Oratorianer Cesare Baronio ab der Reliquienüberführung des Kirchenvaters Gregor v. Nazianz eintrat. Mit Hilfe von Baronios Revisionsarbeiten am Martyrologium Romanum konnte die Kurie mit diesem liturgischen Buch die rituelle Vorrangstellung Roms gegenüber den übrigen Bischofsdiözesen Italiens, welche die neuen rituellen Vorschriften zu übernehmen hatten, behaupten. ${ }^{915}$ Diese rituelle Verwen-

bereits Monssen 1981, S. 134 und Noreen 1998, S. 701 erkannt, ohne diesen zum Breviarium hergestellten Bezug konkret einzuordnen, der sich erst aus der Praxis der in Santo Stefano Rotondo praktizierenden Jesuitenpriester während der quaresima der Adventszeit ergab. Vgl. hierzu neben den Einträgen in Michele Lauretanos Diario in Archivio Collegio Germanico-Ungarico di Roma, Hist. 103, f. 49r, 63r auch Ann. Litt. Soc. Ies. Ann. MDLXXXII, S. 12-13: „[...] ac diebus festis antequam Sacrificio missae intersint, in singulis contubernijs privatum veniam invicem petunt eorum, quae offenderint ea hebdomada: voluntarias poenas, \& mortificationes sua ipsi sponte, Adventus praecipue, \& Quadragesimae temporibus suscipiunt: longinquas quoque peregrinationes ad Lauretum, Casinumq. montem pedibus ingrediuntur. [...] uti spiritualibus exercitijs instituantur, ut cum ad omnia Societatis urbana loca mittantur aliqui, satisferi tamen omnibus non possit“. Die Bildunterschrift zu Albertis Altarbild bezieht sich hingegen besonders auf den zentralen Stellenwert des officium der Dreifaltigkeit: „Cum Anglis toto terrarum orbe unicum templum Catholicum relictum sit, idq. Romae S.mi Trinitati Sacrum, cuius in Summa ara haec tabula conspicitur, merito in illo suorum cum priscae, tum huius aetatis martyrum certamina exprimi curarunt: ut alios ad laudes, precesq. se verò ad parem animi constantiam, maiorum et sociorum exemplis, excitarent“. Zit. n. Cavalieri, Ecclesiae anglicanae trophaea in BAV, Stamp.R.I.II.954, c. 2r. Vgl. dann auch Ann. Litt. Soc. Ies. Ann. MDLXXXII, S. 19, wo berichtet wird, dass am Festtag des heiligen Stephanus ein Jesuitenpriester aus dem Englischem Kolleg coram papam predigt. Dies bestätigt auch der Eintrag Mucanzios in seinem Tagebuch in BAV, Chig.L.II.31, f. 827r: „In die s.ti Stephano celebravit missam in Cappella R.mus Cardinalis de Sermoneta in rubeis Papa praesente, et in sede venient, Cardinales fuerunt num. 24 cum Celebrante in Assistentia Papae R.mus Borromeus Presbiter, et Diaconi ijdem [...] sermonem habuit quidam Alumnus Collegij Anglicam gravissimum Papae, et omnib. ob sui elegantiam, et oportunam deplorationem Regni Anglici, et persecutionis Cattoliorum ob nefandam Reginae impietatem. Ad fuit ex nobilibus laycis omn. Bononiae in suo loco Indulgentiae Annor. 15“.

915 Eine solche Abhängigkeit von Rom als Zentrum des Orbis Christianum hatte Baronio in Bezug auf die Bischofsordination des heiligen Zama, des Bischofs von Bologna, durch Papst Dionysius hergestellt, und zwar in der scholia zum 24. Januar, dem Festtag des Bischofs. Vgl. hierzu Mart. Rom. (MLCT, 6), S. 58; Mart. Rom. (1586), S. 47, n. g: „De eodem tabulae Ecclesiae bononiensis. Legi commentarium nondum typis excusum de Ecclesia bononiensis, quo series Episcoporum eius atque ipsorum res gestae narrantur, quem Sigonius vir quidem disertus conscripsit hortatu ampli- 
dung einer bezüglich der Märtyrer- und Heiligenverehrung gestalteten Liturgik im Kurienzeremoniell der translationes hatte Baronio zufolge den frühchristlichen Märtyrergräbern eine neue Sichtbarkeit verliehen. Die wiederaufgefundenen Grablegen stellten die frühchristlichen Märtyrer als Vorbilder im Himmelsreich Gottes dar, indem sich der unterhalb der urbanen Oberfläche gelegene Heilsraum mit der Himmelssphäre, in welche die Märtyrer und Heiligen eingegliedert waren, verband. Der 1586 gedruckten Ausgabe des Martyrologium Romanum stellte Baronio eine Tractatio voran, in welcher der Oratorianer diese Bedeutung der Märtyrer und Heiligen für den gesamten Orbis Christianum festhielt. ${ }^{916}$

Damit unterscheidet sich Cesare Baronios Umgang mit dem Nachlass der Märtyrer und Heiligen deutlich von dem seines Oratorianer-Mitbruders Antonio Gallonio. Gallonio hatte den reichen Korpus an frühchristlichen Märtyrern und Heiligen nur mit einer hagiographischen Aufarbeitung zu erschliessen beabsichtigt, während für Baronio eine angemessene rituelle Formulierung desselben Schatzes im Zentrum stand. Indem Baronio die Märtyrer- und Heiligenverehrung stets in Bezug zur Sakraltopographie Roms als Zentrum des Christianum Orbis betrachtete, gelang es ihm, die Bedürfnisse der Kurie nach einer zeremoniellen Gestaltung der für die Reliquienüberführung gedachten Liturgie zu erfüllen. Nach Baronios zweiter Ausgabe des Martyrologium Romanum 1586 sollte sich Gallonio ebenfalls dieser liturgischen Bedeutung der Märtyrer und Heiligen annehmen. Es bleibt aber immer noch fraglich, wie fähig Gallonio selbst war, solche officia unabhängig von der römisch-kurialen Klientel der Oratorianer-Kongregation verfassen zu können. ${ }^{917}$ Auch wenn der Bon-

ssimi Cardinalis Paleoti archiepiscopi bononiensis“. Baronio stützte sich somit auf die 1584 noch unabgeschlossene De episcopis Bononiensibus von Carlo Sigonio, welche wohl von Kardinal Gabriele Paleottis Rombesuch ein Jahr zuvor inspiriert gewesen sein musste. Während diesem Besuch in der Ewigen Stadt erhielt Paleotti das Pallium des Erzbischofs, wonach auch Bologna zur Erzdiözese erhoben wurde. Mucanzio hielt diese Erhebung Bolognas in seinem Diarium in BAV, Chig.L.II.31, f. 835r-837r fest. Vgl. hierzu auch Prodi 1959/67, Bd. 2, S. 430-434; idem 2005, S. 291-310; McCuaig 1989, S. 90; Bianchi 2008, S. 110-112; Malesevic 2018b, S. 145. Vgl. zudem auch Paleotti, Discorso, S. 419 für Aussagen des Kardinals von Bologna zu den Darstellungsweisen des Martyriums in bildproduktiver Hinsicht.

916 Mart. Rom. (1586), S. X: „Nec est praeterea, quod quis miretur, si in eodem ipso, de quo agimus Romano Martyrologio, clarissimos illos martyres videat praetermissos, quos nostro seculo, ob tuendam, propagandamque catholicam fidem poenas atrocissimas, si qui alij olim martyres, in Anglia potissimum atque in Galijs ab haereticis passos, et in coelum (ut par est cedere) recensitos inter alios martyres aequali scimus triumphi gloria cooptatos; nec illos inveniat recensitos, qui velut tonitrui filij, in similitudinem fulguris coruscantis novo Orbi evangelico lumine illuxerunt, ac fidei casa martyrium subire. Non enim (ut apparet) fuit in praesens Romanae Ecclesia institutum, novum conscribere Martyrologium, sed vetus (ut diximus) ex veteribus exemplaribus restituere“. Vgl. dazu Malesevic 2018b, S. 146-147.

917 Gallonios Sammlung von Lebensbeschreibungen und liturgischen officia von Märtyrern und Heiligen in BVR, H 18, scheint der Oratorianer im Auftrag von Baronio zusammengestellt zu haben. Sie ist nicht vor 1593 zu datieren. Vgl. bspw. die Vita Sancti Ambrosij Gallonios in ibid., f. 27r-99v, 
compagni-Papst Gregor XIII. die weiterführende Verwandlung Roms in einen urbanen Sakralraum nicht mehr erleben konnte, hatte sein Pontifikat die entscheidenden Voraussetzungen bewerkstelligt. Die noch bis zum Todesjahr des Papstes zum Abschluss gebrachten Revisionsarbeiten am Martyrologium Romanum und die bildprogrammatischen Ausstattungen der Kirchenräume, die den nationalen Jesuitenkollegs angebunden waren, verwendete die Kurie im Nachfolgepontifikat Sixtus' V., um die fast in Vergessenheit geratene römische Stationsliturgik entsprechend kurienzeremonieller Richtlinien zu gestalten und zu realisieren. Der Oratorianer Cesare Baronio hatte sich somit noch während der Amtszeit Gregors XIII. zu einer selbständigen und von der Kurie konsultierbaren Figur entwickeln können. Seine Fähigkeit lag darin, dass er rasch die zentralen Probleme der Kurie nicht nur bezüglich einer kirchenhistoriographischen und kontroverstheologischen Bestätigung der Romana Ecclesia, sondern auch hinsichtlich der liturgischen Auseinandersetzungen mit dem römischen Ritus erkannte und entsprechend lösen konnte. Mit dem neuen Martyrologium Romanum schuf Baronio Klarheit darüber, wie das Vermächtnis der Patristik liturgisch in den rituellen Vollzug des römischen Kurienzeremoniells anlässlich von Reliquienüberführung einzugliedern war.

Liturgie, Zeremoniell, Kontroverstheologie und Kirchenhistoriographie traten damit in eine bis zu diesem Zeitpunkt undenkbare Wechselwirkung ein. Es sollte sich als Cesare Baronios Verdienst erweisen, die kurienzeremoniellen Vorschriften zum liturgischen Vollzug des römischen Ritus so zu formulieren, dass sie schwer zu widerlegen waren. Dies brachte ihn im Aldobrandini-Pontifikat Clemens' VIII. jedoch wiederholt in Konflikt mit der spanischen Fraktion des Kardinalskollegiums und kostete ihn letztlich die Wahl zum Papst. Der Oratorianer Baronio scheint aber nicht unglücklich über diesen Ausgang der Papstwahl von 1605 gewesen zu sein, zumal er sein Ziel, im päpstlichen Herrschaftsapparat Fuss zu fassen, bereits während des Boncompagni-Pontifikates Gregors XIII. in Zusammenarbeit mit Guglielmo Sirleto erreicht hatte. Im Nachfolgepontifikat Sixtus' V. Peretti sollte sich Baronio mit seinen Arbeiten sogar gegenüber einem diesem Papst nahestehenden Kreis von Kurienprälaten behaupten können. Die Drucklegung des ersten Bandes seiner Annales Ecclesiastici 1588 bot der Kurie eine unbestreitbare Grundlage, auf welche sie sich während des allmählich beobachtbaren Zusammenbruchs des Kurienzeremoniells im nur fünf Jahre dauernden Peretti-Pontifikat berufen konnte.

welche sich eindeutig auf Baronios eigene Lebensbeschreibung des mailändischen Kirchenvaters stützt. Zur Problematik und der bislang überschätzten Rolle Antonio Gallonios in Bezug auf die Ausarbeitung einer römischen Liturgik vgl. Touber 2014a, S. 55; idem 2014b, S. 85-87; idem 2012, S. 197-229. 